Review Article

\title{
Application of Epoxy-Asphalt Composite in Asphalt Paving Industry: A Review with Emphasis on Physicochemical Properties and Pavement Performances
}

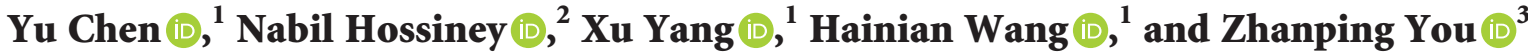 \\ ${ }^{1}$ School of Highway, Chang'an University, Middle Section of NanErhuan Road, Xi'an 710064, China \\ ${ }^{2}$ Department of Civil Engineering, Christ University, Kumbalgodu, Bengaluru 560074, Karnataka, India \\ ${ }^{3}$ Civil and Environmental Engineering, Michigan Technological University, Houghton 49931, MI, USA
}

Correspondence should be addressed to Yu Chen; chenyu1123@chd.edu.cn

Received 8 April 2021; Revised 17 July 2021; Accepted 7 August 2021; Published 23 August 2021

Academic Editor: Davide Palumbo

Copyright $(92021$ Yu Chen et al. This is an open access article distributed under the Creative Commons Attribution License, which permits unrestricted use, distribution, and reproduction in any medium, provided the original work is properly cited.

One of the failure mechanisms associated with asphalt paving layers, especially on steel deck bridges, is large permanent deformation, which adversely affects its long-term performance in service. Thus, epoxy resin was introduced in asphalt paving industry to tackle permanent deformation of asphalt mixtures due to its thermosetting nature. In this review, epoxy resin as a dominant component of the epoxy-asphalt composite system was first considered, followed by a discussion on its curing methods and curing mechanism. Furthermore, the physicochemical property and mechanical performance of epoxy asphalt and epoxy asphalt mixture were thoroughly examined. Crosslink density of epoxy asphalt dictates its viscosity and thus the allowable construction time. Phase separation and dispersion of asphalt particles in the epoxy matrix was observed for epoxy-asphalt composite, and it showed superior elastic behavior and deformation resistance capability when compared with conventional asphalt materials. Furthermore, epoxy asphalt mixture exhibited significantly higher compressive strength, much better rutting resistance, and superior durability and water resistance properties. However, its low-temperature cracking resistance was slightly compromised.

\section{Introduction}

The ER technology was initiated in the early 1900s but was only further explored after the World War II [1]. The first commercial product of epoxy resin (ER), which was a reaction product of epichlorohydrin (ECH) and bisphenol A, was introduced by Devoe and Raynolds in 1947 [2]. Epoxy resin has gained increasing importance due to its extensive range of applications such as paints and coatings, adhesives, electrical insulation, electronics, aerospace industry, industrial tooling and biomedical systems [3], and more recently, in asphalt paving industry [4]. The rapid growth of ER application was mainly caused by their advantages such as

Low cure shrinkage

High adhesive strength
High mechanical properties, particularly strength and stiffness

Good chemical resistance

Low creep

High electrical resistance

As an alternative to conventional asphalt binder, epoxy asphalt (EA) has been initially applied in the pavement industry primarily due to its excellent rutting resistance since crosslinked structures were formed during the curing process. EA, generally a two-component composite system, often include ER as component $\mathrm{A}$, and asphalt, curing agent, diluents, fillers, and toughening agents, as component $\mathrm{B}$ [5-7]. The final composite made of components $\mathrm{A}$ and $\mathrm{B}$ was realized to possess great resistance to fatigue loading, moisture damage, and oxidation aging with the added polymeric structure of epoxy $[5,8,9]$. 
The successful incorporation of ER into asphalt materials requires a clear understanding of ER, including each material component and its curing process since behaviors of epoxy-asphalt composite were mostly dominated by epoxy. Pradhan et al. [10] pointed out that epoxy can be divided into glycidyl epoxy and nonglycidyl epoxy based on the molecular structure and applications. The desired properties of cured epoxy can be well controlled through careful selection of ER, curing agent, modifier, component composition, and curing conditions $[1,11]$. For instance, a pothole patching material was developed from $\mathrm{TAF}^{\circledR}$-epoxy based fast curing EAM to reduce the curing period [12] and brucite was added to produce flame retardant EA for tunnel pavement [13]. For cured epoxy-asphalt composite, phase separation and the dispersion of asphalt particles in ER was often observed [14], while secondary phase separation and phase inversion were observed if asphalt content was increased up to $50 \mathrm{wt} . \%$ and 60 wt.\% [15], respectively. This phase separation characteristics of EA were also confirmed by other physicochemical properties such as two-stage degradation of EA under heating [16] and two-peak glass transition temperature $\left(T_{g}\right)$ [7]. Furthermore, a significantly higher complex modulus of EA [17] and resilient modulus of epoxy asphalt mixture (EAM) [18] than the corresponding conventional asphalt and asphalt mixture, respectively, indicated an enhancement towards deformation resistance. However, due to high brittleness and thus reduced flexibility and toughness, its cracking resistance might be a concern [15], especially in the presence of cracks.

This review mainly examines the physicochemical characteristics and mechanical performance of EA. It can be divided into five main parts: (1) overview of ER and its curing; (2) application of EA in asphalt paving industry; (3) physicochemical properties of EA; (4) rheological and mechanical properties of EA and EAM; and (5) pavement performance of EAM. The overall structure of this review is presented in Figure 1.

\section{Overview of Epoxy Resins and Its Curing}

2.1. Classification of Epoxy Resin. Epoxy monomers have been commonly synthesized from acidic hydroxyl groups and $\mathrm{ECH}$. The ERs generated from such monomers are often referred to as glycidyl-based epoxy. Epoxy monomers have also been converted from aliphatic or cyclic aliphatic alkenes with peracids. Therefore, ERs can be categorized into glycidyl epoxy and nonglycidyl epoxy based on the procedure of their synthesis and the molecular structure [10, 19]. Glycidyl epoxy can be further classified as glycidyl-ether, glycidylester, and glycidyl-amine, as shown in Figure 2. Nonglycidyl epoxy can be further divided into aliphatic epoxy with a linear structure and cyclic aliphatic epoxy with a closed structure [19].

It should be noted that hydroxyl groups can be obtained from phenols (e.g., bisphenol A and novolak), polyols (e.g., 1,4-butanediol), aliphatic diols, or dicarboxylic acids (e.g., hexahydrophthalic acid). Through the reaction between $\mathrm{ECH}$ and bisphenol A, the most frequently used ER, i.e., diglycidyl ether of bisphenol A (DGEBA), can be synthesized
[20]. Meanwhile, the reaction of ECH and novolak (the reaction product of phenol and formaldehyde in the presence of acidic catalyst) leads to polyglycidyl ethers of phenolic novolak resins [3]. In addition, the reaction of dicarboxylic acids with caustic is generally used to produce diglyceride ester type resins, which is normally less viscous compared to bisphenol A epoxy resin. By reacting ECH with the nitrogen atom of an amine instead of a hydroxyl group, glycidyl amine resin can be obtained [10].

2.2. Curing Agents for Epoxy Resin. To overcome the poor mechanical, chemical, and heat resistance performance of uncured ERs, the linear ER can be crosslinked in the presence of curing agents to achieve optimum performance properties. The selection of curing agents depends on the application and processing methods, curing conditions, and the desired properties such as mechanical, chemical, thermal, and environmental limitations and costs. Curing agents are either catalytic or coreactive $[11,21]$. The curing of ER can be completed through epoxy-to-epoxy ring-opening homopolymerization under catalytic curing agents or copolymerization under polyfunctional coreactive curing agents [11].

Catalytic curing agents can be used as initiators for epoxy-to-epoxy ring-opening homopolymerization, or as supplemental curing agent with polyamines or polyamides, or as an accelerator for anhydride-cured systems. Catalytic curing agents are generally inert under ambient temperature and indoor lighting, but they become active by heating or photoirradiation [3]. The commonly used catalytic curing agents include Lewis bases (e.g., tertiary amines), Lewis acids (e.g., boron trifluoride monoethylamine), and photoinitiators [21]. Once under UV irradiation, photoinitiators produce a Lewis acid, which cures the ERs in the traditional way.

On the contrary, coreactive curing agents function as comonomers in the polymerization process. Furthermore, due to its strained three-membered ring structure, the highly reactive ER can react with compounds containing activated hydrogen atoms, for instance, amines (both primary and secondary), phenols, carboxylic acids, thiols, and anhydrides [11]. Among those, primary and secondary amines are the most commonly employed curing agents for epoxy. The general reaction of ER with those compounds is illustrated in Figure 3 . The approximate reactivity of common hardeners in the ascending order is phenol, anhydride, aromatic amine, cycloaliphatic amine, aliphatic amine, and thiol [22]. Based on the curing temperature range, they can also be divided into low-temperature [23], ambient temperature [24, 25], moderate temperature [26], and high temperature [27] curing agents.

A yellow liquid state $\left(60^{\circ} \mathrm{C}\right)$ curing agent, aliphatic diamine, was synthesized in the laboratory by Cong et al. [20] to improve elongation and delay rapid viscosity growth. Jiang et al. [28] synthesized adipamide through esterification and ammonolysis (see Figure 4) to overcome the strong volatilization, high toxicity, and skin irritation of the traditional amine-based curing agents. It was confirmed to have 


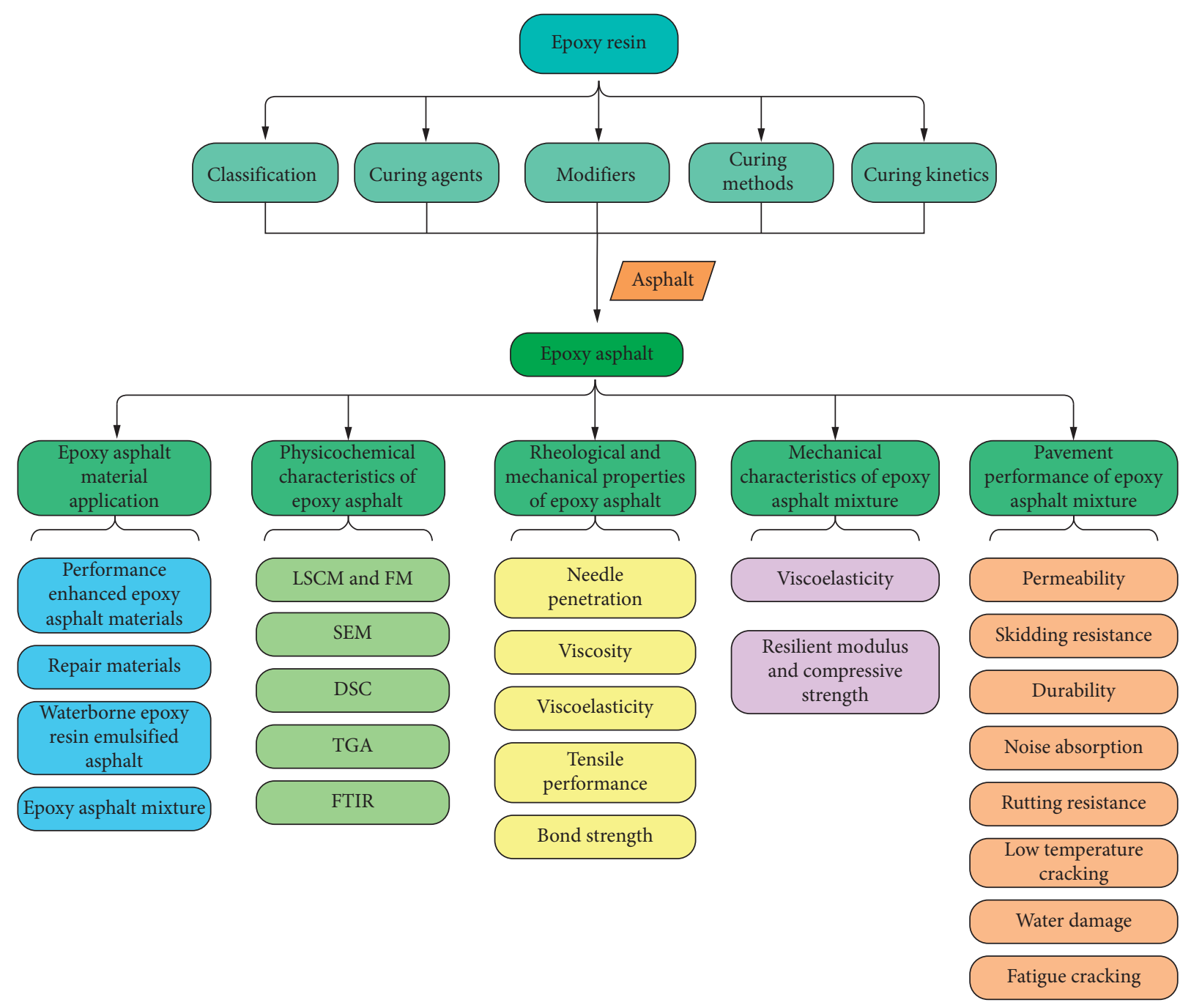

Figure 1: The flow chart of this review paper.

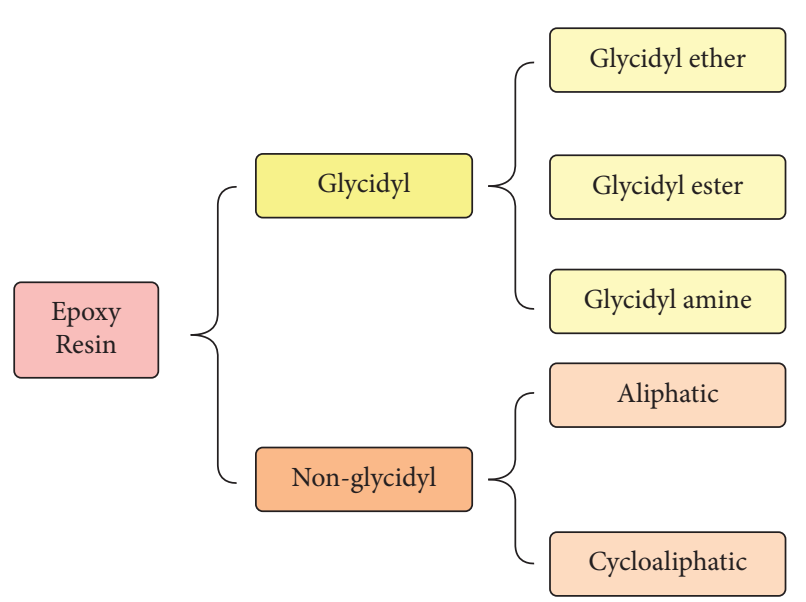

FIgURE 2: Classification of ER [10].

good thermal stability, mechanical performance, and good compatibility with pristine ER. A new flexible curing agent, decanediamide, was prepared from castor oil by esterization with methanol and ammonolysis with ammonia to improve the cracking resistance [29]. A flexible curing agent, polymerized fatty acid (PFA), was also successfully synthesized through catalytic ring-opening polymerization and epoxy fatty acid methyl ester [30].

A bio-based anhydride curing agent was prepared by the addition of maleic anhydride (MAH) and methyl ester of eleostearic acid from tung oil fatty acid [31]. MAH alone was used as the curing agent to cure soybean oil based ER [32], where hydroxyl groups react with anhydride molecules. Compound curing agents, prepared by sebacic acid with methyl-tetrahydrophthalic anhydride (MeTHPA) or sebacic acid with tung oil anhydride (TOA) to create a bimodal microstructure to ensure the low-temperature cracking resistance and rutting resistance [33].

2.3. Modifiers. The properties and behavior of ER can be adjusted with the addition of diluents, fillers, and toughening agents [21]. Diluents can be used to modify the properties of ER, especially lowering the viscosity to improve the handling characteristics. For instance, epoxy propane butyl ether was used as a diluent to lower the viscosity of the gel system [34]. 


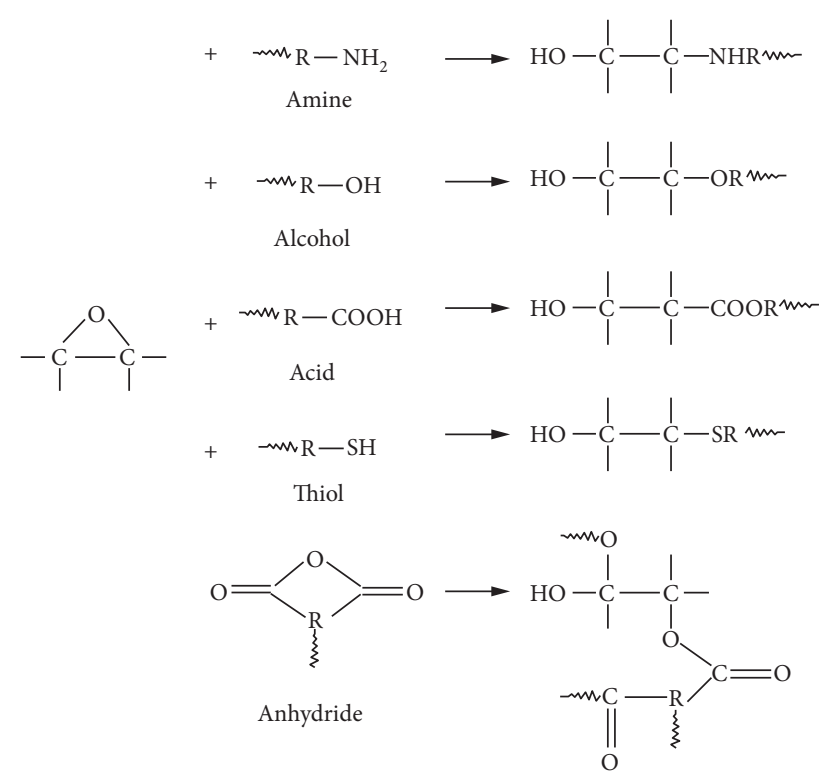

Figure 3: Reaction between epoxy and hardeners [11].

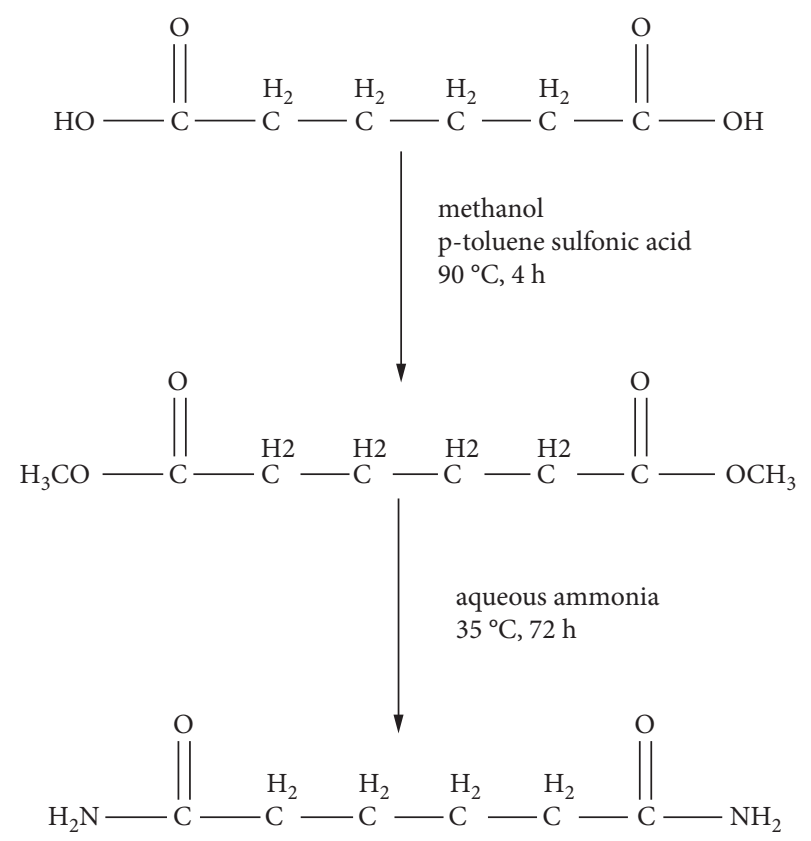

FIgURE 4: Synthetic route of adipamide [28].

Reactive diluents, 1,4-butanediol diglycidyl ether and 1,6hexanediol diglycidyl ether, have been added to DGEBA to reduce the viscosity and improve the phase compatibility and toughness [35]. Diluents are generally prepared by glycidylation of aliphatic alcohols or polyols, which might be monofunctional, difunctional, or with higher functionality. Fillers are mainly employed to reduce the costs of ER while reducing curing shrinkage and coefficient of expansion. Toughening agents and flexibilizers are often used to mitigate the brittleness and low elongation of ER after curing.

To ensure the fire safety and reduce the flammability of its use on tunnel pavement, flame retardants like brucite
[13], the mixture of aluminum trihydroxide (ATH), and zinc borate (ZB) [29], the combination of decabromodiphenyl ethane and antimony trioxide $\left(\mathrm{Sb}_{2} \mathrm{O}_{3}\right)$ [36], brominated styrene-butadiene-styrene triblock copolymer (BrSBS) [37], and reactive polymeric flame retardant (RPFR) [38] are added.

It should be noted that the optimum combination of the fractions of ER, curing agents, and modifiers should be determined for each specific application. For instance, the optimum combination of unsaturated polyester resin modified asphalt was determined to consist of bisphenol A, 3\% of compatibilizer (maleic anhydride), $4 \%$ of curing agent (tertbutyl peroxybenzoate), and $1 \%$ of silence coupling agent [39].

2.4. Curing Methods of Epoxy Resin. Besides epoxy resin and its hardener, the curing method also has a significant effect on the properties of epoxy. The methods for curing ER control the chemical reaction between epoxy groups and curing agents and thus the subsequent properties of epoxy products. Primary curing methods are chemical curing (under room or increased temperature), microwave curing, and radiation curing (electron-beam and ultraviolet curing) [40].

2.4.1. Chemical Curing. The ambient temperature curing of ER can be attained using various curing agents. For instance, modified aromatic amines, alicyclic polyamines, low molecular weight polyamide, and aliphatic polyamines can be employed to activate the curing of ER at ambient temperatures. Epoxides cured at room temperatures often possess low $T_{g}$ values, high flexibility, and great impact resistance $[24,41]$.

2.4.2. Thermal Curing. The curing of ERs at elevated temperature has often been referred to as thermal curing. According to the previous study, the curing process is generally separated into two stages, precuring at low temperature and postcuring at high temperature. It has higher degree of crosslinking and higher $T_{g}$ and thus better performance than those cured at room temperature [42]. Therefore, many researchers have focused on the heating method, including induction heating curing, microwave heating curing, and radiation curing.

(1) Induction Heating Curing. Induction heating technology was first introduced by Garcia [43] in asphalt industry. It refers to adding some metals to the asphalt mixture. When these metals are exposed to high-frequency alternating magnetic field generated by induction coils in the pavement system, they will generate heat through the Joule effect, thus heating the asphalt metals [44-46]. Based on the above technology, Apostolidis et al. [47] employed induction heating system to accelerate the crosslinking of steel fiber modified epoxy-asphalt systems. The electromagnetic induction was confirmed to stimulate the polymerization. However, in practice, this will require a special vehicle equipped with an induction coil passing over the pavement after compaction. 
(2) Microwave Curing. Microwave heating technology is a promising technology. The key of effective heating is that microwave heating is a kind of direct energy conversion within the material while heating $[48,49]$. According to the previous studies, the amount of curing time can be substantially reduced by using microwave curing due to largely concentrated microwave energy [11], and it is very convenient for large-scale commercial application. Microwave curing was reported to uniformly penetrate deep into the specimens [50]. Microwave curing was tried as a candidate for bridge deck repair maintenance, and it was heated up to $200^{\circ} \mathrm{C}$ after $8 \mathrm{~min}$ but with lower level of curing when compared to conventional heating method [51]. Compared to thermal curing, microwave curing can lead to higher mechanical strength [34].

(3) Radiation Curing. Radiation curing or photocuring refers to the curing of ER using electron beam, ultraviolet, or infrared light accompanied by a photoinitiator. The polymerization and crosslinking of ER can also be greatly accelerated under the high-energy electrons. As compared with other curing methods, radiation curing provides a more consistent and controlled process $[52,53]$.

2.5. Curing Kinetics. By using finite element modeling, the degree of conversion/curing (see equation (1)) under induction heating was found to increase with lower activation energy and higher reaction rate [47]. This curing model was simplified and expressed as the function of time for the predefined temperature and activated energy [54]. A chemorheological model (see equation (2)) was introduced based on equation (1) to describe the polymerization process of ER [55]. This model was incorporated in COMSOL Multiphysics to evaluate the viscosity evolution during the curing process as an indicator of reaction progress. It was found that lower levels of activation energy can enhance the curing process and its viscosity:

$$
\frac{\partial \alpha}{\partial t}=k_{0} \exp \left(-\frac{E_{a}}{R T}\right) \cdot(1-\alpha)^{n},
$$

where $\alpha=$ conversion rate; $k_{0}=$ pre-exponential kinetic factor (i.e., reaction rate); $E_{a}=$ activation energy; $R=$ universal gas constant; $T=$ temperature; and $n=$ reaction order of polymerization.

$$
\eta^{*}(T, \alpha)=\eta_{g}^{*} \cdot \exp \left[-\frac{C_{1}\left(T-T_{g}(\alpha)\right)}{C_{2}+T-T_{g}(\alpha)}\right] \cdot\left(\frac{\alpha_{g}}{\alpha_{g}-\alpha}\right)^{\eta_{r}},
$$

where $\eta^{*}(T, \alpha)=$ complex viscosity at temperature $T$ and curing degree $\alpha ; \alpha_{g}$ = the extent of reaction at the gelation point; $T_{g}(\alpha)=$ glass transition temperature of uncured material; $\eta_{g}^{*}=$ complex viscosity at glass transition temperature; $C_{1}$ and $C_{2}=$ material-dependent and temperatureindependent constants from WLF equation, respectively; and $\eta_{r}=$ material-dependent constant.

Based on the calculation of activation energy, the introduction of asphalt to the cold-mixed ER system was reported to have a negative effect on the curing reaction [56], while the effect on the curing reaction of hot-mixed was reported to be negligible [16]. However, Li et al. [30] reported that the curing system has a lower activation energy than the pure epoxy curing system if the epoxy-asphalt composite system was properly optimized. In this regard, the activation energy calculated from Kissinger model (see equation (3)) and Flynn-Wall-Ozawa model (see equation (3)) was found to be in close agreement based on dynamic kinetic analysis [16]:

$$
\left\{\begin{array}{l}
\frac{d\left[\ln \left(\beta / T_{p}^{2}\right)\right]}{d\left(1 / T_{p}\right)}=-\frac{E_{\alpha}}{R}, \\
\log \beta=A-0.457 \frac{E_{\alpha}}{R T_{p}},
\end{array}\right.
$$

where $T_{p}=$ peak exothermal temperature of differential scanning calorimetry (DSC) curve; $\beta=$ heating rate; $E_{\alpha}=$ activation energy; and $R=$ universal gas constant.

The complete curing time of hydrogenated bisphenol A epoxy resin (AL-3040) was found to increase with the increase in flexibilizer (polypropylene glycol diglycidyl ether) content because the large molecular weight and long molecular chain of the flexibilizer can reduce the crosslink density of AL-3040 [57]. In addition, the degree of polymerization network is higher when higher modification level is applied since the lower amount of the binder is available to restrict the network formation. The reaction between the oxirane group $\left(\mathrm{C}_{2} \mathrm{H}_{4} \mathrm{O}\right)$ and the carbonyl acid group $(\mathrm{RCOOH})$ was assumed to be responsible for the crosslinking and the generation of ester $\left(\mathrm{RCOOR}^{\prime}\right)$ and ether (ROR') compounds [58].

Radial distribution function results (see Figure 5) from molecular dynamics simulation indicated that epoxy moved closer to aromatics and saturates than asphaltenes during the curing process. However, the covalent binding formed during the curing process was the strongest between epoxy and asphaltenes based on the first principle [59]. Furthermore, based on fluorescence microscopic analysis, it was observed that particles of specific sizes $(45 \mu \mathrm{m}$ and $130 \mu \mathrm{m})$ were mainly formed in the epoxy-asphalt composite system, after it was chemically gelled [17], which was often referred to as a bimodal network [60].

\section{Epoxy Asphalt Materials}

Based on its usage, EA has been mainly used as binders to produce EAM and also as layer bonding materials, like tack coat [61-63] or prime coat [64]. As compared with conventional tack coat, superior bond strength has been reported.

Besides conventional EA, EA was also successfully prepared with tung oil maleic tribasic acid as the curing agent [30], partially depolymerized lignin (PDL) as ER and tung oil fatty acid-derived curing agent [31], epoxidized soybean oil (ESO) as ER and MAH as the curing agent [32], and waste cooking oil-based epoxy resin (WCO-EP) and 


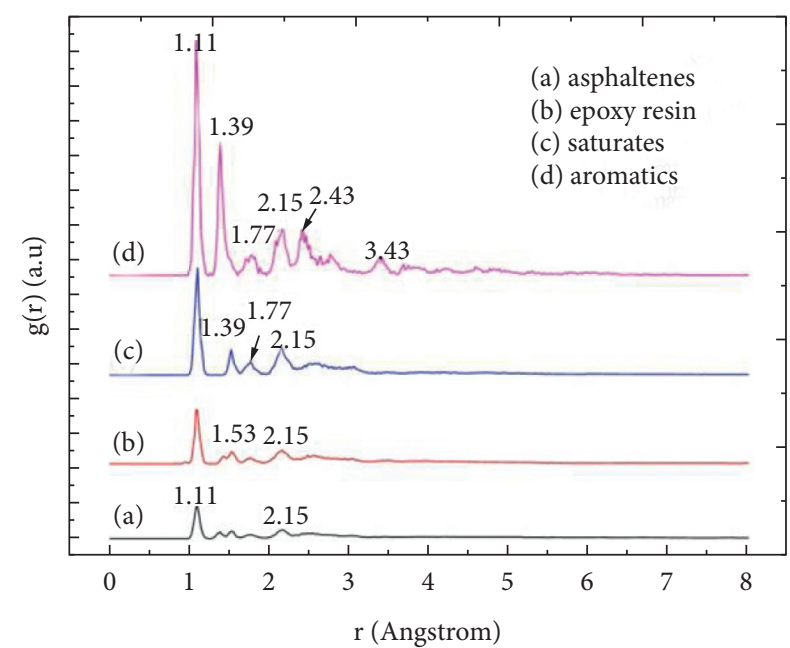

FIGURE 5: Radial distribution function curve of each component in epoxy bitumen [59].

kraft lignin-based polycarboxylic acid (KL-COOH) as curing agents [65]. When nadic methyl anhydride (NMA) was added as the cocuring agent for processability adjustment, WCO-EP cured with low KL-COOH/NMA molar ratio $(0: 1$ and $1: 1)$ exhibited one glass transition and good thermal stability than that with high KL-COOH/NMA ratio (2:1 and $5: 1)$ [65], indicating the homogeneous phase structure at low molar ratio and inhomogeneous crosslinked network at high molar ratio.

\subsection{Performance Enhanced Epoxy Asphalt Materials}

3.1.1. Construction Temperature and Construction Time. Despite many advantages of epoxy, its properties need to be adjusted for its application in asphalt paving industry. The main issues encountered during the construction of EAM include short construction time, high construction temperature, and low workability [66], which can eventually affect EA pavement performances. Foamed epoxy asphalt (FEA) $[27,67]$ was proposed to solve those difficulties since it can reduce the mixing temperature and improve the mixture workability. FEA can also increase the adhesion between asphalt and aggregates since epoxy asphalt was foamed to thin membranes.

It was also very attractive to reduce the construction temperature of EAM since EA was normally cured at high temperature $\left(>170^{\circ} \mathrm{C}\right)$ [27]. Cold-mixed $[5,56,68]$ and warm-mixed $[14,69,70]$ EA technologies have been attempted to save energies and protect the environment and construction staff. Compared to hot-mixed epoxy asphalt (HMEA) and warm-mixed epoxy asphalt (WMEA), coldmixed epoxy asphalt (CEA) can be treated as a green material for paving [68]. In addition, CEA was successfully used to replace cold tar bearing emulsion on runways [5], which was toxic and not allowed anymore. The compatibility between epoxy and asphalt binder within CEA was successfully improved by incorporating ESO [71, 72] since both ER and ESO contain epoxy groups.
To reduce the curing period after the compaction of EAM on pavement, a polyetheramine with long chains and polar ether groups was introduced as the curing agents [73], which can optimize the curing conditions down to $1 \mathrm{~h}$ at $160^{\circ} \mathrm{C}$ and $3 \mathrm{~d}$ at $60^{\circ} \mathrm{C}$. To accelerate the curing process of EA, an accelerant of 2,4,6-tris(dimethylaminomethyl) phenol can also be successfully capsulated within macroporous resin [74], which has the encapsulation efficiency of over $50 \%$ and facilitates the use of EA as the material for the long-term asphalt pavement.

3.1.2. Compatibility and Mechanical Properties. The polar ER and nonpolar asphalt will cause the compatibility problems for epoxy-asphalt system $[14,75]$. To improve the certain drawbacks of EA, polymers (both elastomers and plastomers) have been added to EA. For instance, ethylene vinyl acetate copolymer (EVA) was added to increase the compatibility between epoxy and asphalt [14]. The improvement of compatibility between ER and asphalt was attempted by modifying the asphalt with $\mathrm{MAH}$ and it can mitigate the asphalt bleeding from the epoxy-asphalt composite system [76]. EA cured by PFA was also reported to have excellent compatibility [30].

A new shape memory ER was synthesized by AL-3040, curing agent, isophorone diamine, and flexibilizer, and polypropylene glycol diglycidyl ether (JH-230), and the deformation recovery performance of the asphalt mixture prepared with this new ER was indeed improved [77]. Kang et al. [78] successfully prepared a bimodal anhydrides-cured rubber like EA through diglycidyl ether of bisphenol A (E51), MeHHPA, MAH, and adipic acid, which has good flexibility and thus has the potential to prolong the pavement service life. Styrene-butadiene-styrene (SBS) was employed to improve the fracture toughness/ductility of EA $[15,79,80]$. It is interesting to note that the addition of SBS was reported to have little effect on the composition ratio of ER and curing agents [79]. Crumb rubber was also reported to increase the ductility of EA [81]. Due to its highly branched structures, hyperbranched polyester (HBP) was a strong candidate modifier for toughening EA. However, high viscosity of ER was often observed during the curing process due to the high reactivity between hydroxyl end groups of HBP and ER. Xu et al. [82] modified the hydroxyl groups of HBP with acetyl chloride to reduce this reactivity, and it was also modified with stearic acid chloride to improve the compatibility of EA (see Figure 6).

3.2. Repair Materials. For regular pavements, many repair materials and field repair procedures have been developed. For epoxy asphalt pavement on steel deck bridges, a finegrained EAM consisting of fast-curing EA, limestone filler, and basalt aggregates [12] and epoxy-based crack-sealing materials [83] were developed for pothole patching and crack sealing, respectively. An epoxy repair material with 10 asphalt per hundred resin (phr) as a modifier was also introduced for crack-sealing of concrete structures [84]. A blend of room temperature curable epoxy and liquid sulfur polymer was successfully fabricated by Kwon et al. [25] for 


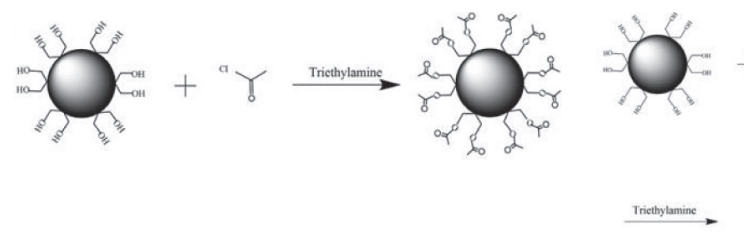

(a)

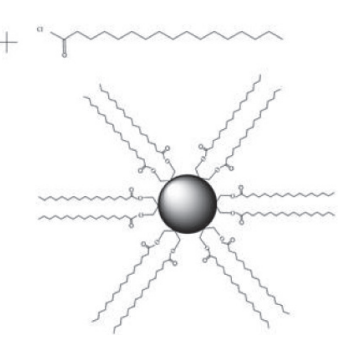

(b)

Figure 6: Synthesis of H102 with terminated acetyl end groups $\left(\mathrm{H} 102-\mathrm{C}_{2}\right)(\mathrm{a})$ and $\mathrm{H} 102$ with terminated fatty alkyl end groups (H102- $\left.\mathrm{C}_{18}\right)$ (b) [82].

pothole patching application. Cold patching material was also prepared by using waterborne epoxy resin emulsified asphalt (WEA) [85].

3.3. Waterborne Epoxy Resin (WER) Emulsified Asphalt. WER, or water-based ER, can be prepared by surfactants or attaching hydrophilic polar groups to it, where water is used as a carrying medium rather than solvent [86]. WER has also been used as fog seal when modified with nano- $\mathrm{TiO}_{2}$ to degrade vehicle exhaust [87], microsurfacing to improve the performance and durability [88], tack coat to mitigate pavement shoving at bridge deck [89], performance enhanced tack coat when blended with styrene-butadiene rubber (SBR) [63], prime coat for cement treated base (CTB [64]), a high-performance cold binder for cold recycling or cold-mix paving due to its superior adhesion, strength, and fatigue life [90], and cold patch materials [91].

EA has been used as a strong waterproof bonding layer for orthotropic steel bridge decks, and attapulgite (ATT) was successfully added to increase its mechanical performances [92]. Silane coupling agent surface-treated rubber particles (ARP) were added to EA to increase the durability of tack coat for orthotropic steel bridge in seasonal frozen areas [61].

3.4. Epoxy Asphalt Mixture. To increase the durability, especially due to raveling of open-grade friction course (OGFC)/porous asphalt, ER was proposed to modify the open-graded mixture due to its increased stiffness and strength after curing $[8,93-95]$. It is interesting to note that mixtures with $4.75 \mathrm{~mm}$ nominal maximum aggregate size (NMAS) [93, 95] have increased resistance to raveling and mixtures with $9.5 \mathrm{~mm}$ NMAS [95] have increased performance of surface friction at a high slip speed. With the intention of increasing skidding resistance, the volume design method (V-S method) [96] based EAM with a skeleton-dense structure was designed for steel bridge deck [97]; a design approach was proposed for the epoxy-modified binder suitable for the antiskid asphalt surface layer [98]; a high friction treatment prepared with epoxy and aggregate was successfully implemented in Virginia to provide strong skidding resistance [99]; an epoxy-modified binder was successfully used to replace the tar-containing binder for the ultra-thin surface layer on asphalt runways, which was determined to be toxic due to its high polycyclic aromatic hydrocarbon content [100]. An epoxy resin-based ultra-thin antiskid surface layer (UTASS) with $2.36 \mathrm{~mm}-3 \mathrm{~mm}$ basalt aggregates was developed for steel bridge deck to enhance the skidding resistance of epoxy asphalt pavement [101].

To reduce or eliminate problems related to chip seal, like chip loss, flushing, and cracking, the performance of epoxymodified asphalt chip seal was comprehensively investigated by Bagshaw et al. [102]. To ensure safety and prolong service life of railway bridges, EAM was used as the waterproof protective layer to mitigate water damage to bridge deck [103]. One of the challenges for EA is the low elongation at low temperatures and thus high cracking potentials due to its high stiffness. Glass [104] and mineral [105] fibers have been introduced to EA for their reinforcing and toughening effects. EAM prepared with ceramsite-based lightweight aggregates was applied on bridge deck to reduce its deadweight [106]. As an approach to consume waste glasses, glass aggregates processed from sheet glasses were blended with EAM and good performance was obtained for up to $50 \%$ glass aggregates [107].

\section{Physicochemical Characteristics of Epoxy Asphalt}

The physicochemical characteristics of epoxy asphalt are very critical for the understanding of macroscale properties of epoxy asphalt binder, including rheological and mechanical performances. In this section, microscopic and spectroscopic properties and thermal analytical and gravimetric properties are studied.

4.1. Laser Scanning Confocal Microscope (LSCM) and Fluorescence Microscopy (FM). LSCM has been widely used to observe the morphology of EA since ER part will strongly fluoresce under blue light (488 nm), which can reveal the size and distribution of the epoxy part in the epoxy-asphalt composite system [16]. For the epoxy-asphalt system, asphalt is dispersed in the continuous ER phase [14]. The evolution of the phase-separated microstructure for EA during curing process is illustrated in Figure 7. Polydispersity index results indicated poor asphalt dispersion at the beginning followed by constant dispersion [108]. For EA, 

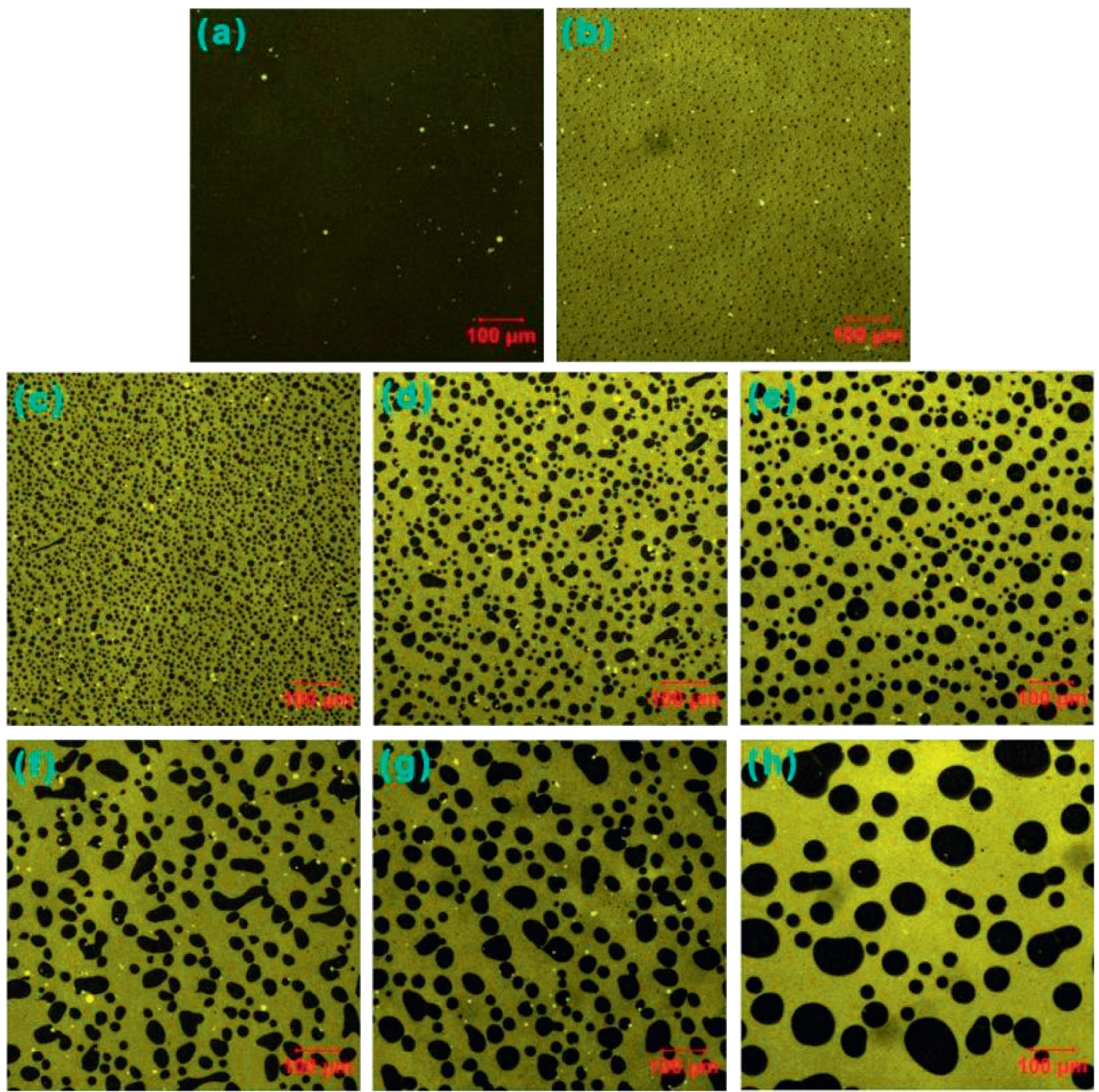

Figure 7: LSCM images of EA during curing at $150^{\circ} \mathrm{C}$ : $0 \mathrm{~min}(\mathrm{a}), 3 \mathrm{~min}(\mathrm{~b}), 5 \mathrm{~min}(\mathrm{c}), 10 \mathrm{~min}(\mathrm{~d}), 15 \mathrm{~min}(\mathrm{e}), 20 \mathrm{~min}(\mathrm{f}), 30 \mathrm{~min}(\mathrm{~g})$, and $60 \mathrm{~min}(\mathrm{~h})$ [108].

phase separation was often attributed to nucleation and growth mechanism [109]. Liu et al. [14] pointed out that this phase separation can only be observed after the curing reaction started since the epoxy-asphalt composite system was homogeneous at the beginning of curing reaction. The phase separation phenomenon was also observed for the polymermodified EA system, like EVA-modified EA [14], SBSmodified EA [15, 80], crumb rubber-modified EA [69], and BrSBS-modified EA [37]. As a matter of fact, double phase separation $[15,110]$, i.e., phase separations occurred between epoxy and SBS-modified asphalt (SBA) and between SBS and asphalt, was reported for epoxy SBS-modified asphalt (ESA), as shown in Figure 8. Double-phase separation was also observed in RPFR-modified EA, i.e., spherical brominated epoxy oligomer particles disperse in the asphalt phase, which acts as the dispersed phase of the modified EA [38]. Secondary phase separation, dispersed asphalt containing some small yellow epoxy-rich particle, was observed in the EA system with high asphalt concentration (e.g., 50 wt.\%) [15]. If asphalt concentration increases up to $60 \mathrm{wt} . \%$, inversion phase separation will occur where epoxy is dispersed in the continuous asphalt phase. Phase inversion was also observed when 6\% WCO was added, and interestingly, secondary phase separation in the dispersed epoxy phase, i.e., asphalt particles dispersed in epoxy phase, was also observed at this WCO concentration [70]. However, no phase inversion was observed between BrSBS and asphalt with over 6 wt.\% BrSBS [37]. For epoxy asphalt rubber 

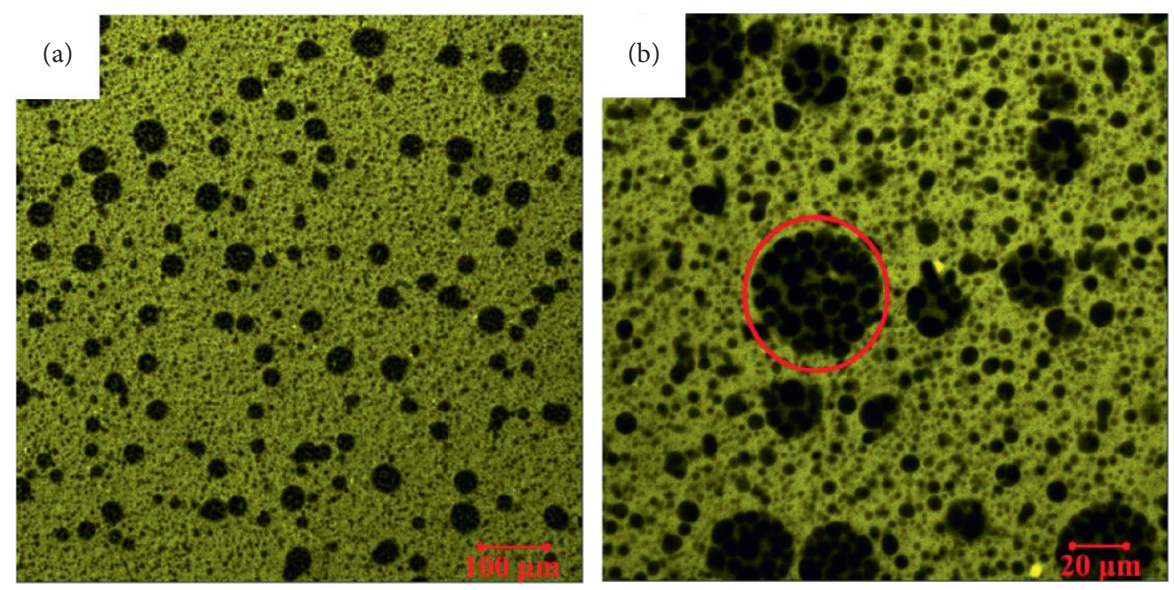

Figure 8: LSCM images of cured ESA: (a) $\times 100$ and (b) $\times 400$ [15].

(EAR) with Sasobit, a double-phase separation microstructure was observed, i.e., phase separation between rubber and ER, and phase separation between rubber and asphalt [69]. In the polymer-modified epoxy system, this phase separation was often attributed to the spinodal decomposition mechanism [111].

Meanwhile, smaller EVA-asphalt particles and homogeneous distribution for low EVA concentration and larger EVA-asphalt particles and inhomogeneous distribution for high EVA concentration were observed [14]. As compared with SBA in the ESA system, base asphalt in the epoxyasphalt composite system showed better dispersion and compatibility characteristics [68]. Asphalt binders, in the form of spherical particles in the epoxy-asphalt composite system, will act as stress concentrators and cause localized plastic shielding, which often lead to increase in toughness as compared with the pure epoxy system $[7,16]$. As a matter of fact, the size of spherical asphalt particles will increase with the increase of asphalt concentration (see Figure 9) [7], which indicates lower compatibility between asphalt and epoxy. As compared with ESA, EA has larger asphalt particles and wider distribution of asphalt domains [110].

FM has also been employed to study the morphology of EA. A similar phenomenon has been observed as in LSCM; for instance, ER was shown to be the continuous phase and asphalt was the dispersion phase when low concentration of asphalt was used $[51,56,112]$. Inversion phase separation (see Figure 10) was also observed for CEA with ER to asphalt ratio as $1: 1.5$, epoxy-modified bitumen with more than 70 wt.\% asphalt [79], and epoxy-modified bitumen with more than 75 wt.\% asphalt [113]. Double phase separation, yellow islandshaped ER distributed in black asphalt while black rubber particle spot distributed in ER, was observed as well [59].

No crosslinked structure was observed at the initial curing stage [112], which can explain the poor mechanical performance of uncured EA [20]. As the curing progresses, crosslinking of ER is activated while asphalt aggregates into larger particles. Larger dispersed asphalt particles were observed in microwave cured EA than those in conventional heating cured EA [51]. Asphalt particle size was reduced with the increase of ESO concentration in blends of CEA and
ESO [71, 72], as shown in Figure 11, which indicated improved compatibility between asphalt and epoxy. Compatibility of CEA can be further improved by incorporating ESO-modified nanosilica and it increased with increased ESO/nanosilica content [38]. The particle size of the asphalt phase was also reduced with the increase of ESO-modified nanosilica content. The addition of WCO was reported to reduce the particle size of the dispersion phase due to the decrease in stiff asphaltene component [70].

For foamed asphalt, the water content has a significant effect on the morphology of EA with small particles of ER uniformly dispersed in asphalt for less than 3 wt.\% water but the disappearance of epoxy phase for $3 \mathrm{wt} . \%$ water or more [27]. For WEA, a continuous crosslinked structure of ER can be observed if more than $20 \%$ of WER was applied [89]. Additionally, FM has been used to confirm that appropriate amount of $\mathrm{H} 102-\mathrm{C}_{2}$ or $\mathrm{H} 102-\mathrm{C}_{18}$ can effectively improve the compatibility of EA [82].

4.2. Scanning Electron Microscope (SEM). SEM has been often employed to observe the morphology of the fracture surface of EA, generated by the brittle fracture in liquid nitrogen [29, 30, 33]. A typical SEM image of ER and EA is presented in Figure 12. Phase separation was again observed with cured ER as the composite matrix and asphalt as the dispersed phase [30, 33, 51, 84, 92] (see Figure 12). In the cured epoxy-asphalt composite system, asphalt was more evenly distributed with the increase of the PFA content, which can enhance the compatibility between asphalt and ER with PFA as a flexible curing agent [30]. On the other hand, a large number of globular cavities were dispersed in the MeTHPA-cured ER phase, which indicated the incompatibility between asphalt- and MeTHPA-cured ER. Liu et al. [14] proposed to extract asphalt phase from EA first and then observe the holes left in the epoxy phase on SEM images.

Compared to single curing agent (sebacic acid), compound curing agents (sebacic acid with MeTHPA or sebacic with TOA) will cause uneven distribution of asphalt phase (2-5 $\mu \mathrm{m}$ and $20-50 \mu \mathrm{m}$ in size) but it still remain in the 

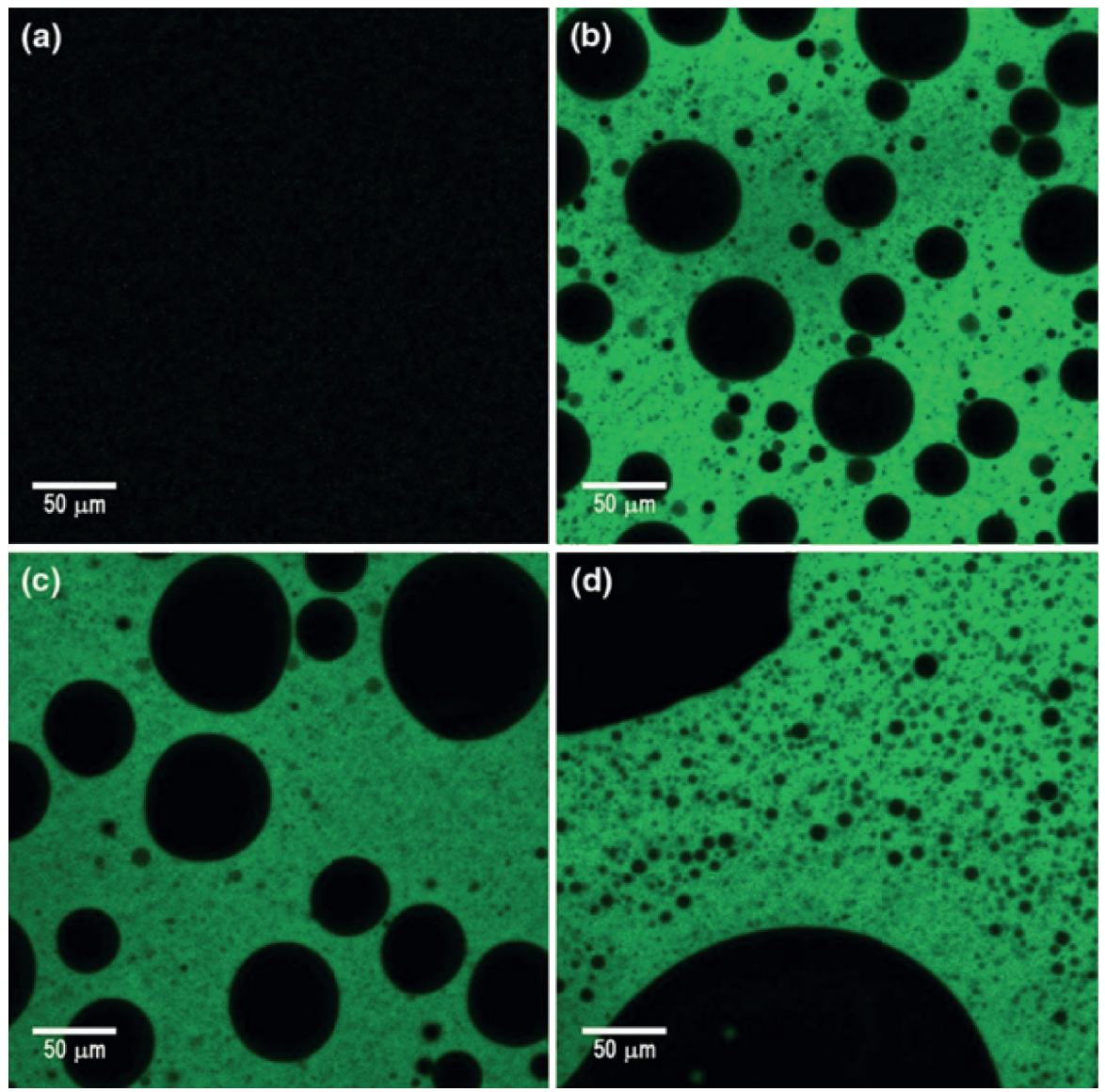

FIGURE 9: LSCM images in the reflection mode for cured neat epoxy (a), HMEAs: HMEA45 (b), HMEA50 (c), and HMEA55 (d) [7]. HMEA = hot-mixed epoxy asphalt; 45, 50, 55 = asphalt content by weight of HMEA binders.
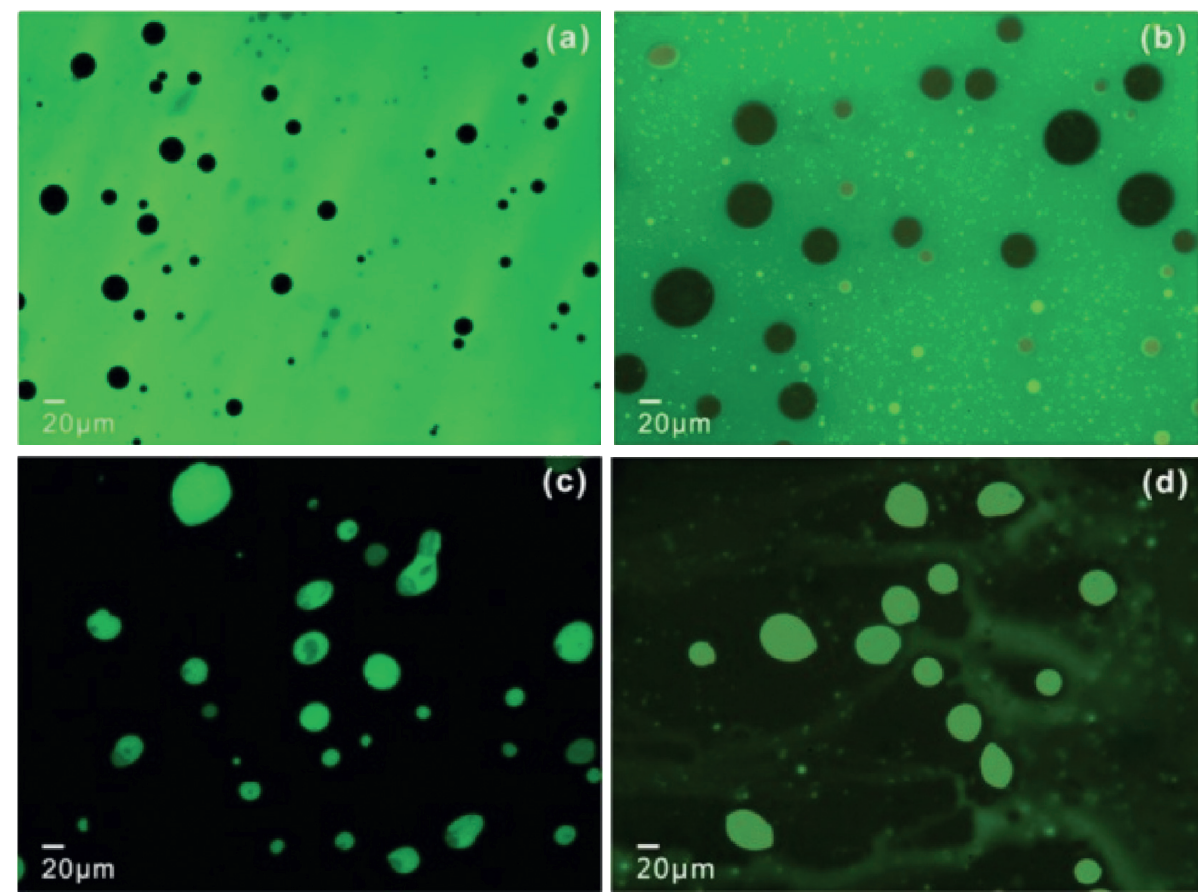

Figure 10: FM images of (a) CEA-0.4 blend, (b) cured CEA-0.4, (c) CEA-1.5 blend, and (d) cured CEA-1.5 [56]. Note: CEA = cold-mixed epoxy asphalt; $0.4,1.5=$ ratio of epoxy resin to asphalt $=1: 0.4$ and $1: 1.5$, respectively. 

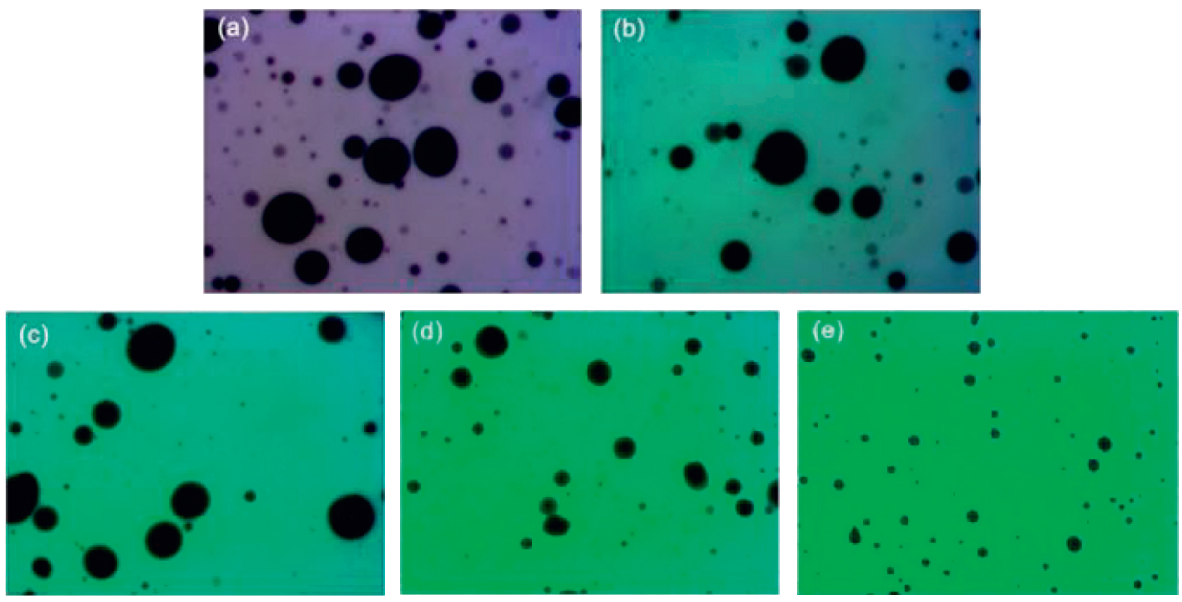

Figure 11: FM of (a) CEA blend, (b) CEA-ESO10 blend, (c) CEA-ESO20 blend, (d) CEA-ESO30 blend, and (e) CEA-ESO40 blend [71].
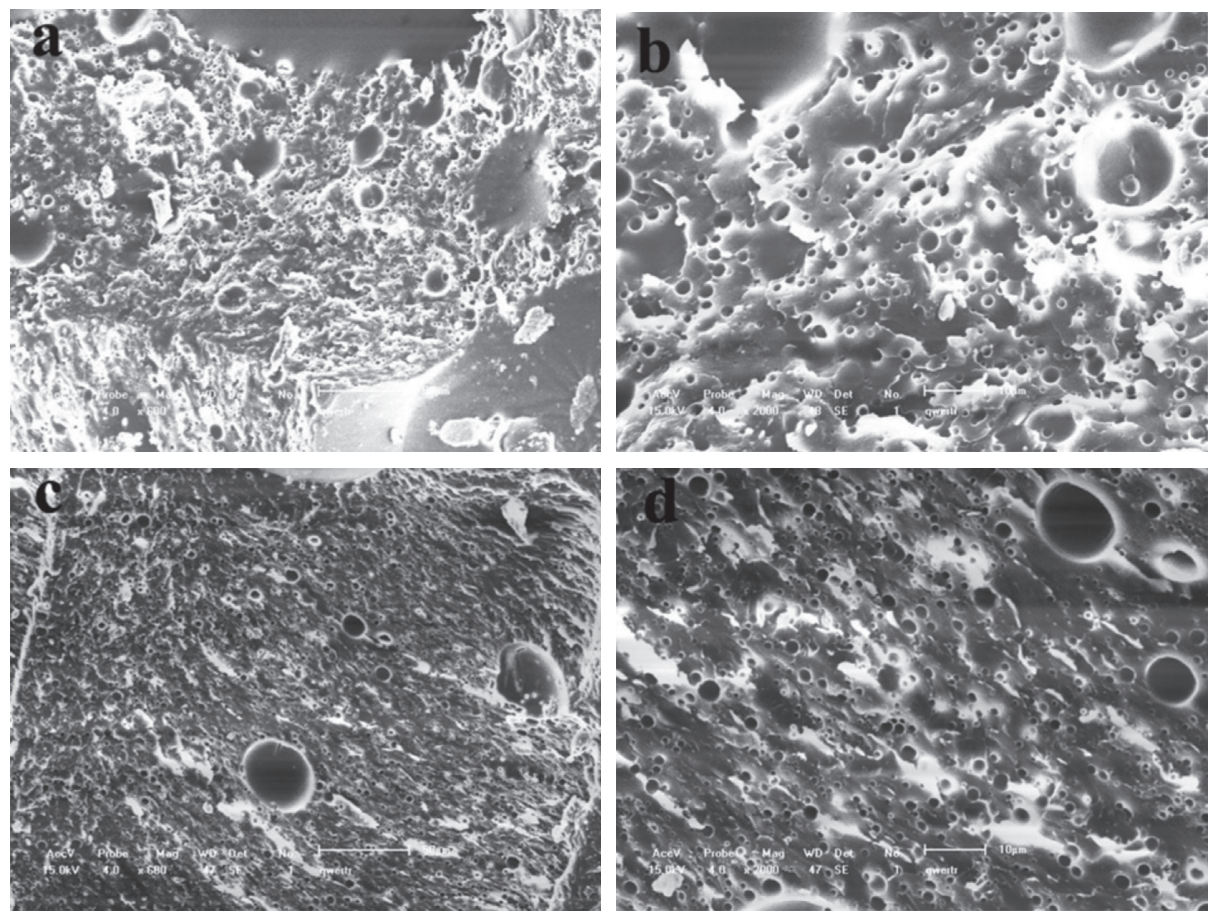

Figure 12: SEM micrographs of ER (a, b) and EA (c, d). (a, c) 600× and (b, d) 2000× [84].

island-shaped two-phase structure [33]. In contrast to heatcured epoxy, asphalt was more uniformly distributed in the microwave-cured epoxy-asphalt composite system and a better compatibility system can be obtained [51]. In addition, cured ER was in a squeezed state due to the high energy induced by microwave and thus fast crosslinking of ER.

CEA with a flame retardant, ATH, has more rough fracture surfaces than CEA with a compound flame retardant, ATH/ZB [29]. The larger quantities of rough fracture surfaces in ATH were reflected in its increased tensile strength as compared with those modified with ATH/ZB. The addition of asphalt into epoxy repair materials can create a "sea island structure" in the epoxy matrix and asphalt can act as a stress concentrator under external loading, which can dissipate energy through large deformation in the asphalt [84].
4.3. Differential Scanning Calorimetry. DSC is a thermoanalytical technique which measures the dependency between the temperature change and the corresponding flow of heat introduced to a specimen. High heat absorption demonstrates large amount materials experiencing phase change during the heating process. Typical DSC curves for EA can be seen in Figure 13, where EA undergoes phase change during the sudden alternation section [68]. The peak of DSC derivative signal is often taken as $T_{g}$, which has been measured for shape memory hydrogenated epoxy resin (SMHER) [77], ESA [68], rubber-like thermosetting epoxy asphalt composite (REAC) [6], brucite-modified EA [13], decabromodiphenyl ethane (DBDPE)/ $/ \mathrm{Sb}_{2} \mathrm{O}_{3}$-modified EA [36], ATH/ZB-retarded CEA [29], PDL-based EA [31], and RPFR-modified EA [38]. 


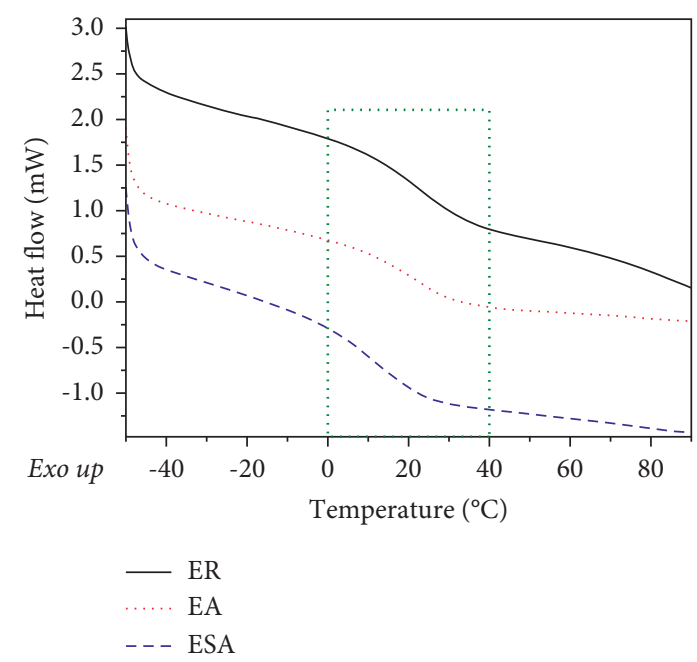

(a)

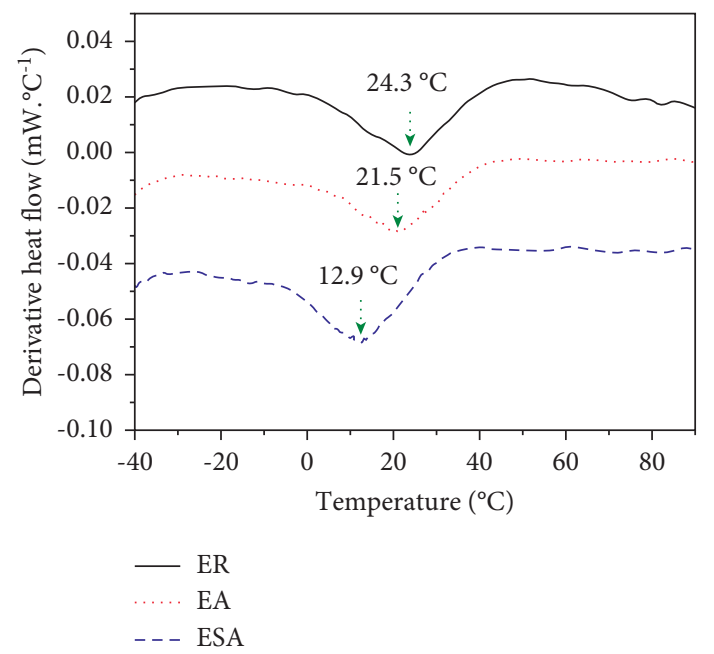

(b)

FIgURE 13: Nonisothermal DSC curves (a) and derivative of DSC curves of ER, EA, and ESA samples (b) [68]. Note: ER=epoxy resin; EA = epoxy asphalt; ESA = epoxy asphalt with SBS.

$T_{g}$ was noted to increase as the curing reaction progresses, with faster crosslinking in neat epoxy polymer than in EA and it indicated that the asphalt binder prohibits the chemical curing process and the interaction between epoxy and asphaltene was limited $[58,114]$. It should be noted that $T_{g}$ has been reported to correlate mainly to nonpolar maltene and the polar asphaltene-epoxy chain reaction might lead to increased mobility of nonpolar maltene and thus decreased $T_{g}$ [115]. Therefore, it seems logical to assume that contact opportunities between unreacted epoxy polymers were reduced by asphalt binder.

When compared with pure ER, lower $T_{g}$ values were reported for CEA [56, 68] and CEA with SBS [68], which was probably due to the lower crosslink density after addition of asphalt into ER and soft segments of SBS. Meanwhile, the $T_{g}$ value was reported to increase with the increase in the maleated asphalt content [6], which will increase the crosslink density. Good compatibility between ER and asphalt was concluded based on the findings that addition of up to 55\% asphalt did not change the $T_{g}$ value for HMEA [7]. No significant effect of asphalt addition on the $T_{g}$ value of EA was also confirmed by Yin et al. [16]. As a matter of fact, typical $T_{g}$ values for asphalt are between $-40^{\circ} \mathrm{C}$ and $0^{\circ} \mathrm{C}$ [68], whereas typical $T_{g}$ values for EA are between $-8^{\circ} \mathrm{C}$ and $50^{\circ} \mathrm{C}$ [58].

$T_{g}$ for SM-HER was found to decrease with the increase in flexibilizer, JH-230 [77], which may be attributed to the lower crosslink density by increasing JH-230 content and thus increased segment mobility. Flame retardants, like brucite [13] and $\mathrm{DBDPE} / \mathrm{Sb}_{2} \mathrm{O}_{3}$ [36], have no significant effect on $T_{g}$ values of EA. It is interesting to note that the flame retardant ATH/ZB slightly increased $T_{g}$ value for CEA [29]. Actually, effects of particle incorporation on $T_{g}$ values depend on two competing factors, i.e., rigid phase reinforcement and epoxy network disruption [29, 36]. ESO, a compatibilizer and plasticizer, can improve the molecular chain mobility of EA and thus reduce $T_{g}$ value [71].
The optimum content of SBR was determined to be $3.0 \%-3.5 \%$ for ER based on the peak value and peak width on DSC curves [63], which manifests the materials stability. Wider exothermic peak for PDL epoxy than commercial epoxy DER332 indicated more complicated chemical structure and more active epoxy groups for PDL than those for DER332 [31]. It is worth noting that microwave-cured EA exhibited smaller area than conventional hot-cured EA under the DSC curve and thus lower degree of polymerization for microwave curing [51], which was probably due to the rapidly formed rigid chain network in microwave-cured EA and it mitigated the further reaction of unreacted groups.

4.4. Thermogravimetric Analysis (TGA). TGA is a method to evaluate material thermal stability by measuring the weight changes over time as a function of temperature. There are generally two stages involved in the TGA curves for EA [14-16, 29, 36, 80], including minor volatilization of light components of asphalt (i.e., saturates and polar aromatics) and degrading of uncured epoxy from $200^{\circ} \mathrm{C}$ to $350^{\circ} \mathrm{C}$, and major decomposition of large asphalt molecules and epoxy network from $350^{\circ} \mathrm{C}$ to $500^{\circ} \mathrm{C}$, as illustrated in Figure 14 . Three stages have also been reported if water loss is included [92]. It should be noted that the characteristics of the TGA curve for EA are a combined effect of neat ER and asphalt. For pure ER, its two stages include minor degradation of unreacted epoxy or impurities apart from cured ER at around $325^{\circ} \mathrm{C}$ and major degradation of epoxy network at above $400^{\circ} \mathrm{C}[116,117]$. One-stage decomposition of ER has also been reported [16]. For asphalt, its TGA curve can also be separated into two stages: breaking of weak chemical bonds and generation of small gaseous molecules from $250^{\circ} \mathrm{C}$ to $400^{\circ} \mathrm{C}$ in the first stage and later decomposition of large molecules into smaller molecules from $400^{\circ} \mathrm{C}$ to $550^{\circ} \mathrm{C}$ $[16,36,81,118,119]$ (see Figure 14). If modifiers like 


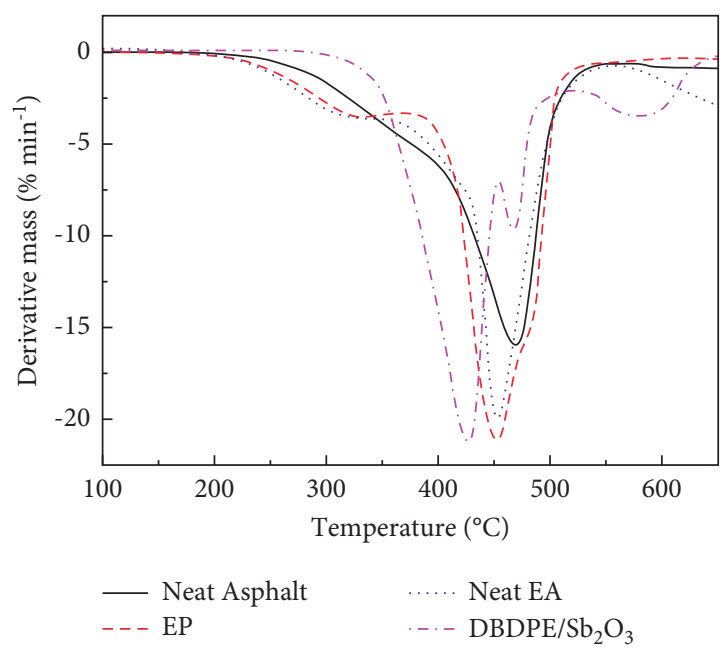

FIgUre 14: First derivative of the TGA curve [36].

DBDPE $/ \mathrm{Sb}_{2} \mathrm{O}_{3}$ [36] and brucite [13] are added, a third stage often appeared (see also Figure 14).

When compared with neat ER, EA $[15,68,120]$, ESA $[15,68]$, and EAR [120] showed superior thermal stability, as presented in Table 1. However, with the increase in the asphalt content in EA, its thermal stability was reduced $[16,121]$. Also, reverse trends on the effect of asphalt content on thermal stability for EA [15, 81], ESA [15], and EAR [81] was reported. Addition of modifiers such as DBDPE/ $\mathrm{Sb}_{2} \mathrm{O}_{3}$ [36], brucite [13], ATH/ZB [29], EVA [14], SBS [15, 80], and ATT $[92,122]$ increased the thermal stability of EA based on evaluation of parameters like initial decomposition temperature (IDT), $T_{\max }$, and char at $550^{\circ} \mathrm{C}, 600^{\circ} \mathrm{C}$, or $700^{\circ} \mathrm{C}$. On the other hand, the addition of crumb rubber [81] and Sasobit [123] was reported to reduce the thermal stability of EA.

TGA has also been used to evaluate the thermal stability of flame retardants, synthetic brucite and natural brucite [13]. Natural brucite contains much more impurities than synthetic brucite since natural brucite has 5 decomposition stages as compared with only one main decomposition stage for synthetic brucite. The decomposition of crumb rubber also involves two stages, including degradation of natural rubber and degradation of SBR [120]. As an alternative to commercial ERs such as bisphenol A, PDL-based ER was found to have comparable thermal stability [31]. IDT for EA, defined as the temperature with $5 \%$ weight loss, was determined to be above $250^{\circ} \mathrm{C}[13,14,29,36,37]$, which was absolutely over the EA mixing temperature.

4.5. Fourier Transform Infrared (FTIR). FTIR spectroscopy is an analytical technique used to determine the presence of certain functional groups in a molecule based on the absorption peaks in infrared spectrum. A typical FTIR curve for EA is shown in Figure 15. Conversion rate $(\alpha)$ for the epoxy group can be calculated based on equation (4). Absorption peak on the FTIR curve at $906 \mathrm{~cm}^{-1}[59,79,124]$, $908 \mathrm{~cm}^{-1}[31], \quad 910 \mathrm{~cm}^{-1}[27,84, \quad 89], \quad 917 \mathrm{~cm}^{-1}$ $[8,58,90,112]$, and $918 \mathrm{~cm}^{-1}$ [56] has generally been
TABLE 1: Thermal stability analysis of ER, EA, and neat asphalt [15].

\begin{tabular}{lcccc}
\hline Sample & IDT $\left({ }^{\circ} \mathrm{C}\right)$ & $T_{\max }^{1}\left({ }^{\circ} \mathrm{C}\right)$ & $T_{\max }^{2}\left({ }^{\circ} \mathrm{C}\right)$ & Residue at $600^{\circ} \mathrm{C}($ wt.\%) \\
\hline ER & 286.3 & 308.6 & 398.0 & 0.8 \\
EA40 & 288.4 & 397.1 & 463.1 & 7.6 \\
EA50 & 292.7 & 401.3 & 466.2 & 8.9 \\
EA60 & 298.7 & 402.2 & 469.2 & 10.6 \\
NA & 341.6 & 352.6 & 473.1 & 19.9 \\
\hline
\end{tabular}

Note: $\mathrm{ER}=$ epoxy resin; $\mathrm{EA}=$ epoxy asphalt; $\mathrm{NA}=$ neat asphalt.

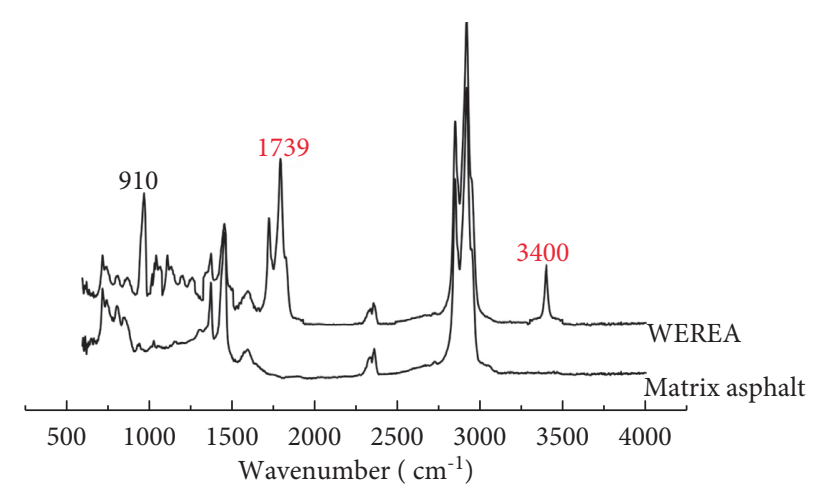

Figure 15: FTIR spectrum for WEA and asphalt [89].

attributed to oxirane ring. The disappearance of the absorption peak for the epoxy group indicated the complete curing of ER [8, 84, 90, 112]. For WEA, the hydroxyl groups at $3400 \mathrm{~cm}^{-1}$ indicated cohesion, hydrophilicity, and storage stability [89]. The disappearance of the peak at around $1700 \mathrm{~cm}^{-1}$ indicated the reaction between ER and carboxylic acid within asphalt besides its reaction with curing agents [79].

$$
\alpha=1-\frac{\left(A_{\text {epoxy }} / A_{\text {ref }}\right)_{t}}{\left(A_{\text {epoxy }} / A_{\text {ref }}\right)_{0}},
$$

where $\alpha=$ conversion rate; $A_{\text {epoxy }}=$ absorption peak area for epoxy group; $A_{\text {ref }}=$ absorption peak area for reference group; and 0 and $t=$ reaction time 0 and reaction time $t$;

Esterification and etherification were assumed to take place at the beginning of curing process based on the observation of increase of carbonyl ether and ester and decrease of carbonyl acid [58, 112]. More specifically, the curing process involves two stages [112]: (a) generation of carbonyl ester and hydroxyl groups after reaction between carboxyl acid and epoxy and (b) generation of carbonyl ether after further reaction between hydroxyl and epoxy groups (see Figure 16). Sulfoxide compound contents were showed to be the most effective parameter for the evaluation of oxidative-controlled curing for EA [58]. In addition, a period of rapid decrease of carbonyl and sulfoxide compounds under isothermal oxidation conditioning indicated epoxy curing, whereas a period of constant increase of both compounds after curing indicated oxidative aging [125].

It has been observed that the curing efficiency was reduced with the increase of ER content based on the ratio of absorption peak area between the epoxy functional group 


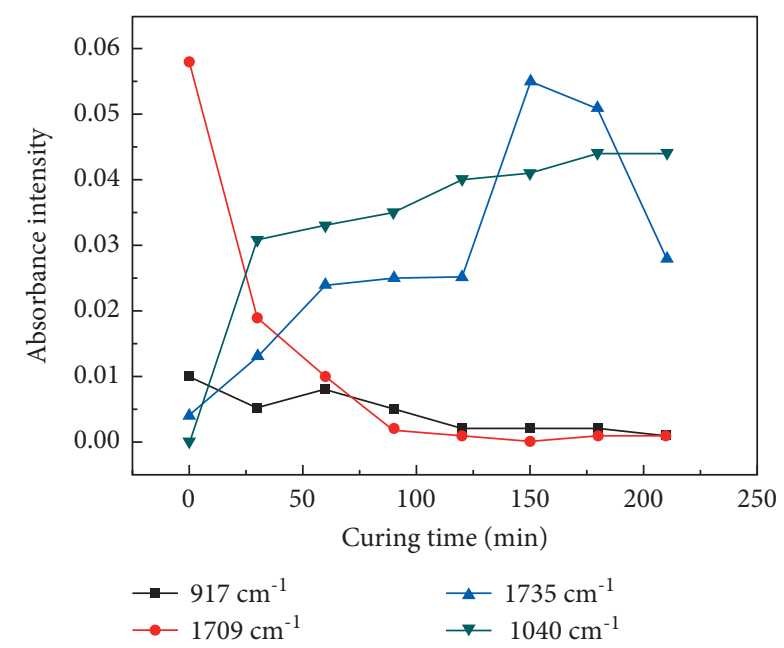

FIgURE 16: Evolution of epoxy group $\left(917 \mathrm{~cm}^{-1}\right)$, carbonyl acid $\left(1709 \mathrm{~cm}^{-1}\right)$, carbonyl ester $\left(1735 \mathrm{~cm}^{-1}\right)$, and carbonyl ether $\left(1040 \mathrm{~cm}^{-1}\right)$ [112].

and the reference functional group [59]. The curing degree was also reduced with the increase of asphalt content for CEA based on the peak positions of the O-H bond [56]. Conversion rate was found to increase linearly with time in the initial curing phase [124], and the curing reaction slows down afterwards $[20,124]$. For FEA, it can be concluded that the higher water content leads to higher degree of reaction between epoxy and curing agent since the absorption peak area for the epoxy group was reduced with the increase of the foaming water content [27].

FTIR has also been used to confirm the successful synthesis of ER from PDL [31], flexible epoxy curing agent from PFA [30], waterborne curing agent from bisphenol-A type ER, triethylenetetramine, and glycidyl tertiary carboxylic ester [90], and modification of hydroxyl end groups of second-generation aliphatic hyperbranched polyester with 12-end hydroxyl groups (H102) into alkyl groups [82].

\section{Rheological and Mechanical Characteristics of Epoxy Asphalt}

As the most crucial component of the epoxy asphalt mixture, rheological and mechanical properties of epoxy asphalt are reviewed in this section to give some insight into the performances of epoxy asphalt concrete.

5.1. Needle Penetration. Penetration test, one of the oldest tests on asphalt binders, measures the depth to which a standard needle penetrates the asphalt sample under specified standard conditions. Compared with EA with sebacic alone, compound curing agents like sebacic acid with MeTHPA or sebacic acid with TOA were reported to reduce the needle penetration from $31.8 \mathrm{dmm}$ to $10.1 \mathrm{dmm}$ and $16.0 \mathrm{dmm}$ at $25^{\circ} \mathrm{C}$ [33], respectively. This reduction in penetration depth was attributed to the shorter molecular chain of MeTHPA and TOA and thus high crosslink density and rigid network as compared with the long linear chain of sebacic acid. For WEA, less than $2 \%$ dosage of resin has no significant effect on the penetration since no three-dimensional crosslinked skeleton was formed [63]. When WEA was used as the prime coat on cement treated base, the penetration depth needs to be greater than 78 at $110^{\circ} \mathrm{C}$ [64]. Similar to the effects of WER on viscosity, increasing the WER content will also reduce the penetration depth of EA [91].

The processability of liquid state sulfur polymer (LSP) modified EA was evaluated based on American Society for Testing and Materials (ASTM) C 1611. It was found that 50 wt.\% of epoxy will produce a mixture with $12 \mathrm{~cm}$ flow value [25], which was the boundary for workability.

5.2. Viscosity. As a thermosetting material, the viscosity of EA will increase with the progression of curing reaction due to the increment of the molecular weight for ER $[7,14,37,69,79,80,104,122,124]$, which is totally different from conventional asphalt as a thermoplastic material. This indicates that the degree of curing reaction, mixing time, and mixing temperature should be carefully controlled to ensure the operation time. Due to the higher curing rate at higher temperatures, EA showed higher viscosity at higher curing temperature $[32,124]$. It has been generally agreed that the optimum viscosity of EA has to be between $2 \mathrm{~Pa} \cdot \mathrm{s}$ and $3 \mathrm{~Pa} \cdot \mathrm{s}$ when it comes to the pavement compaction $[20,36,79,122]$. Viscosity ranging from $100 \mathrm{~Pa} \cdot s$ to $200 \mathrm{~Pa} \cdot \mathrm{s} \cdot$ for epoxy asphalt mastic was recommended for compaction of warm-mixed EAM based on the compactability analysis [126]. Therefore, pot life or working life, defined as the length of time for viscosity of EA to increase up to $3 \mathrm{~Pa} \cdot \mathrm{s}[56,68]$, has been widely used in the EA pavement construction practices since the viscosity of EA has a significant effect on its workability [79]. For instance, pot life has been determined to be around 35 min for CEA with SBS [68], 55 min for EA [17] and ATTmodified EA [122], 55 min for CEA with $40 \%$ asphalt [56], 58-64 min for Sasobit-modified EAR [69], around 65-69 min for EA with DBDPE and $\mathrm{Sb}_{2} \mathrm{O}_{3}$ as flame retardants [36], $102 \mathrm{~min}$ for CEA asphalt with $20 \mathrm{wt} \%$ flame retardant $\mathrm{ATH} / \mathrm{ZB}$ [29], and increased from $40 \mathrm{~min}$ to 66 min when $30 \%$ ESO was added to CEA [71]. It should be noted that EAM can be divided into cold-mix, warm-mix, and hot-mix based on its mix temperatures and hot-mix EAM can have pot-life as long as $200 \mathrm{~min}$ even at $145^{\circ} \mathrm{C}$ [20]. On the other hand, warm-mix and cold-mix have considerably shorter allowable construction time [56, 68, 69]. The short pot life of ESA might be attributed to the poor compatibility between SBA and ER [68]. A shorter allowable construction time was also observed with the decreasing rubber particle size for EAR due to increased specific area [61]. For EAM to be paved on bridge deck, the time duration for the viscosity to reach $1000 \mathrm{mPa} \cdot \mathrm{s}$ was recommended to be no less than $55 \mathrm{~min}$ at $120^{\circ} \mathrm{C}[4,14]$. When $2 \%-6 \%$ WCO was added to WMEA, the allowable construction time was increased to $52 \sim 58 \mathrm{~min}$ [70]. In addition, allowable construction time was determined following evolutions of both viscosity of EA and Marshall stability of EAM (see Figure 17), which were described by Arrhenius model [127]. 


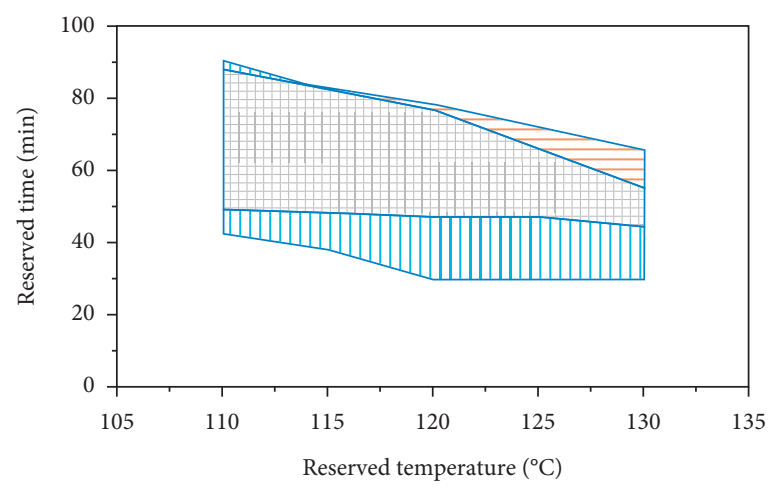

Permissible resercved time range satisfying the requirements of both viscosity limits and Marshall indices. Reserved time range based on the viscosity-time curve of EAB.

Reserved time range determined by the Marshall test on EAM.

FIGURE 17: Reserved time based on evolution of both viscosity and Marshall stability [127]. Note: $\mathrm{EAB}=$ epoxy asphalt binder; $\mathrm{EAM}=$ epoxy asphalt mixture.

It indicated that high mechanical strength and long reserved time for EAM should be well balanced and curing temperature also has a significant effect.

It is interesting to note that the addition of ATT slightly reduced the viscosity of $\mathrm{EA}$, which is attributed to its thixotropic behavior under rotational shearing [122] or hindrance effect of ATT on molecular movement [92]. RPFR was also observed to reduce the viscosity of EA due to its hindrance effect on chemical curing [38]. This is contrary to the general observation that the viscosity of EA will increase with the addition of modifiers like brucite [13] and $\mathrm{ATH} / \mathrm{ZB}$ [29] as flame retardants, industrial SBS [15], styrenic polymers [80], crumb rubber [69, 81], EVA [14], glass fiber [104], mineral fiber [105], silane coupling agent for EAR [61], and BrSBS [37]. Viscosity of EA modified with epoxidized SBS was found to increase with epoxidation degree [128], which was due to the reaction between epoxide groups of reactive epoxidized SBS and curing agents. Warm-mix additive, like Sasobit, can reduce the viscosity of EA since Sasobit has a long-chain aliphatic hydrocarbon [123] and thus much lower viscosity than rubberized asphalt at liquid state [69].

Viscosity of EA was reported to increase with increasing asphalt content in the initial curing stage due to the high viscosity of asphalt [7, 81, 113], as illustrated in Figure 18. It should be noted that asphalt content was also reported to have negligible effect on the curing reaction in the initial stage [15]. However, as the curing reaction progresses, the viscosity of EA decreases with increasing asphalt content $[7,15,32,56,79,81,113]$, which indicates that asphalt binder can delay the curing reaction of EA in the later stage by diluting ER and curing agents [56]. On the other hand, viscosity of EA was reported to decrease with increasing penetration grade in the initial curing stage and it was lower than that of pure ER [129]. Afterwards, viscosity of EA

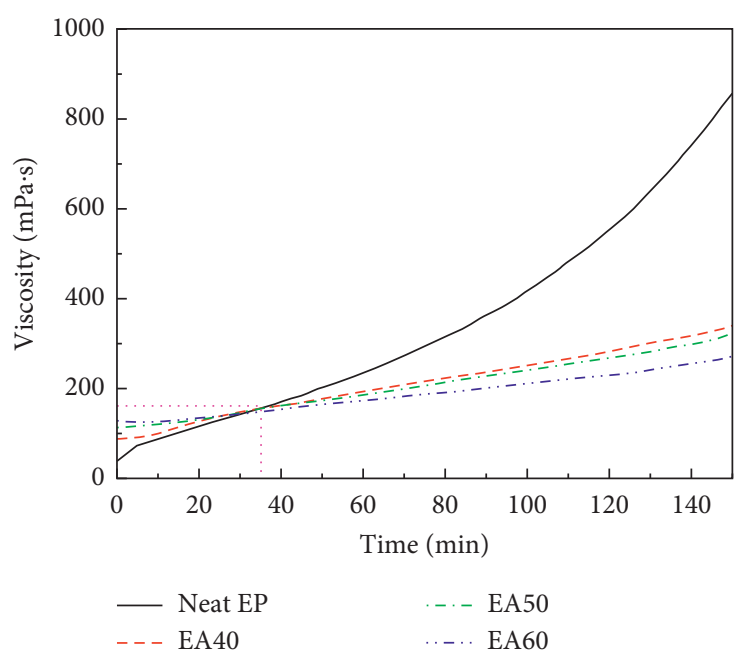

FIGURE 18: Rotational viscosity versus time for neat EP and EA [81]. Note: EP = epoxy resin; EA = epoxy resin; 40, 50, and $60=$ asphalt content.

increased with the increasing penetration grade and it was higher than that of pure ER.

For EA, the chemical composition characteristics, including oil content, polymer content, and crosslink density, have a significant effect on its viscosity [4]. EA with higher crosslinking density and polymer content has a higher viscosity. It is well known that the viscosity of polymermodified asphalt depends on the polymer solubility, which in turn relies on its molecular weight [130]. The ranking order of ESA agrees well with the molecular weight of SBS with different styrene to butadiene ratios as modifier [80]. $\mathrm{Xu}$ et al. [82] also reported that by modifying the hydroxyl end groups of HBP to inert alkyl end groups, the viscosity of EA can be greatly reduced due to the low molecular entanglement level within the hyperbranched structure.

Increase of WER will obviously increase the viscosity of EA $[63,91]$. FEA has considerably lower viscosity than nonfoamed EA, since the foaming process can promote the expansion ratio of the system [27]. Carreau model [131] instead of extrapolating frequency sweep test was employed to determine the zero shear viscosity for EA, and it was again found that the higher foaming water content will lead to lower zero shear viscosity at $60^{\circ} \mathrm{C}$, which demonstrated the compromised rutting resistance at higher foaming water content.

Viscosity-Temperature Susceptibility (VTS) index as defined in equation (5) was proposed to evaluate the temperature susceptibility of EA. It was found that temperature susceptibility of EA increases with the increase of curing time [20]:

$$
\mathrm{VTS}=\frac{\log \log V_{T 2}-\log \log V_{T 1}}{\log T_{2}-\log T_{1}},
$$

where $T=$ the absolute temperature $(\mathrm{K})$ and $V_{T}=$ viscosity (mPa s). 


\subsection{Viscoelasticity}

5.3.1. Static Viscoelasticity. Relaxation tests were conducted using the direct tension test $[5,100]$, and the dynamic shear rheometer (DSR) [98] test to evaluate the stress release behavior of EA. Relaxation percentage (see equation (6)) was employed to estimate the stress relaxation potentials. Relaxation percentage was found to be $55.46 \%$ [98] and $23.1 \%$ [5] even at $-10^{\circ} \mathrm{C}$ and more than $70 \%$ at $0^{\circ} \mathrm{C}$ [100]. It should be pointed out that aging can reduce the relaxation capability of EA at low temperatures [98] and thus low temperature cracking resistance will be compromised:

$$
R=\left(\frac{1-F_{\text {remain }}}{F_{\text {applied }}}\right) \times 100,
$$

where $R=$ relaxation percentage $(\%) ; F_{\text {remain }}=$ retained force after relaxation at a certain time $(\mathrm{N})$; and $F_{\text {applied }}=$ maximum applied force $(\mathrm{N})$.

Tensile-recovery shape memory test was performed on dumbbell-shaped samples prepared with SM-HER [77]. It was found that recovery time increased with the increase in the flexibilizer JH-230 content, since crosslink density was decreased and thus less strain energy was stored, which was reflected in the decreased storage modulus.

The strong elastic behavior of EA was further confirmed by its extremely low creep compliance as compared with neat asphalt and SBA (see Figure 19).

\subsubsection{Dynamic Viscoelasticity}

(1) Oscillatory Shear Using Dynamic Shear Rheometer. Higher complex modulus $\left(G^{*}\right)$ and lower phase angle $(\delta)$ for EA than that of neat asphalt was observed $[5,17,59,89,90,100,132]$ as illustrated in Figure 20, which indicated that ER can significantly increase the elastic behavior of asphalt. Meanwhile, higher rutting factor for cured EA [31, 32, 59] and lower fatigue factor [32] than that of neat asphalt was also observed. Bioepoxy based on waste cooking oil and lignin showed comparable high-temperature performance enhancement as commercial DGEBA based on rutting factor analysis [65]. It is worth noting that storage modulus $\left(G^{\prime}\right)$ for CEA was much higher than that of neat asphalt due to macromolecular asphaltene and resin in the neat asphalt [56]. Asphalt binder became less temperature sensitive after the addition of ER since a decreased slope for complex modulus-temperature curve was observed [132]. The temperature sensitivity of FEA was improved at higher water content attributed to more effective curing reaction [27]. $G^{*}$ for oven-aged EA was higher than that for weatherometer-aged EA, which was higher than that for unaged EA [98]. One possible explanation might be that large molecules were disintegrated into smaller molecules under weatherometer aging, which will lead to less interlock in binders and thus lower stiffness than oven-aged binders.

As contrary to the continuous increase of phase angle as temperature was increased [90] or shear loading frequency was reduced $[5,100]$, there was a peak value of phase angle for EA during the temperature or frequency sweep process.

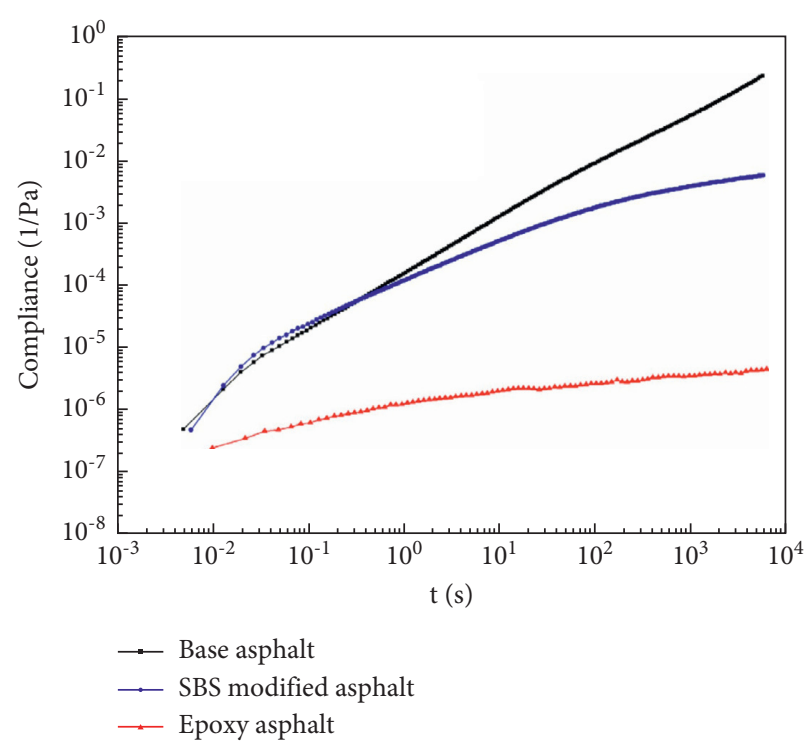

Figure 19: Creep behavior of binders at $40^{\circ} \mathrm{C}$ and $100 \mathrm{~Pa}$ [17].

At low temperature or high-frequency end, asphalt binder played a dominant role on its viscoelastic characteristics. However, at high temperature or low-frequency end, the viscoelastic behavior of EA mainly depends on the epoxy network structure [90]. Sulfoxide formation during the curing process was found to correlate well with the increased complex modulus $G^{*}$ and phase angle [58], as shown in Figure 21.

The value of $G^{*}$ for PDL epoxy increased continuously with ER content, and it has comparable $G^{*}$ value as DER332 EA [31]. EA with 5\% of accelerator has significantly higher $G^{*}$ than that with $2 \%$ of accelerator [102]. Mixing temperature has little effect on $G^{*}$ up to 5 hours after which higher mixing temperature yields higher $G^{*}$ [102]. For FEA, $G^{\prime}$ and $G^{\prime \prime}$ were lower than that of nonfoamed EA, which also decrease with the increase of water content [27].

(2) Oscillatory Tension Using Dynamic Mechanical Analysis (DMA). Dynamic mechanical properties of EA, including storage modulus $\left(E^{\prime}\right)$, loss modulus $\left(E^{\prime \prime}\right)$, loss tangent $(\tan \delta)$, and $T_{g}$, can be effectively determined by DMA. A typical DMA versus temperature curve is presented in Figure 22. $T_{g}$ was often defined as the temperature range where the material changes from a glassy state to a soft but not melted state. The temperature corresponding to a maximum value of $\tan \delta$ on $\tan \delta$-temperature curve from DMA was commonly identified as $T_{g}$ for EA. It should be noted that there are two peaks for $\tan \delta$ : one at low temperature range (identified as $\beta$ transition temperature, $T_{\beta}$ ) and one at higher temperature (identified as $T_{g}$ ) $[17,70]$. This two-peak glass transition indicated that phase separation existed in the $\mathrm{EA}[7,16,30,71,72,80,113]$, as exhibited by the broad peak at $-22^{\circ} \mathrm{C}$ for asphalt-rich phase, and a larger peak at $28^{\circ} \mathrm{C}$ for epoxy-rich phase (see also Figure 22). This two-peak glass transition phenomenon was consistent with the "bimodal network" assumption for cured EA [60]. With the increase in the content of 


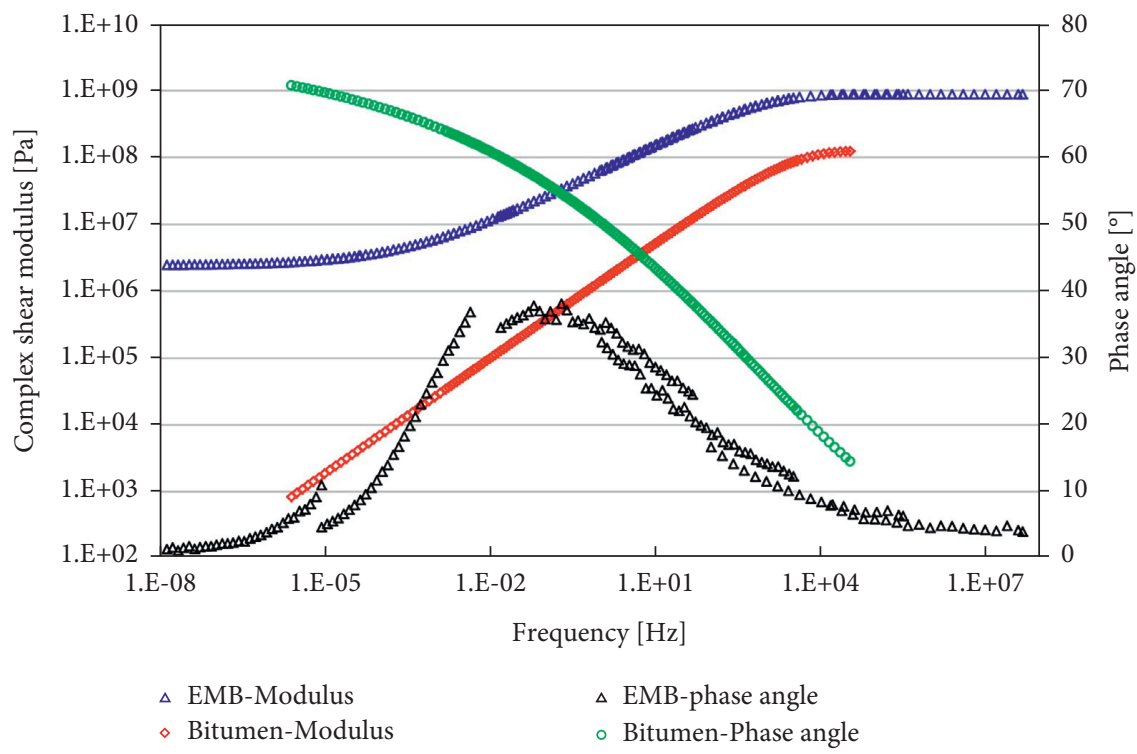

Figure 20: Complex modulus and phase angle for binders [100]. Note: EMB = epoxy-modified bitumen.

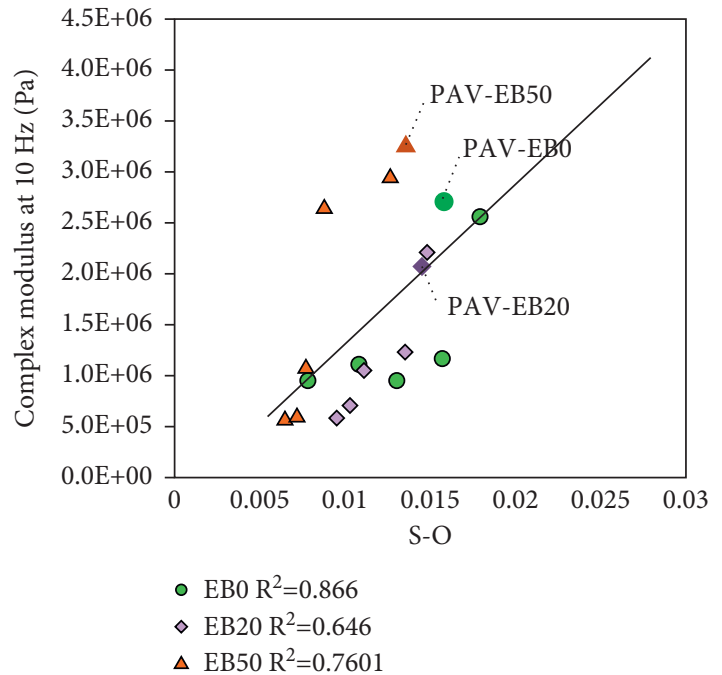

(a)

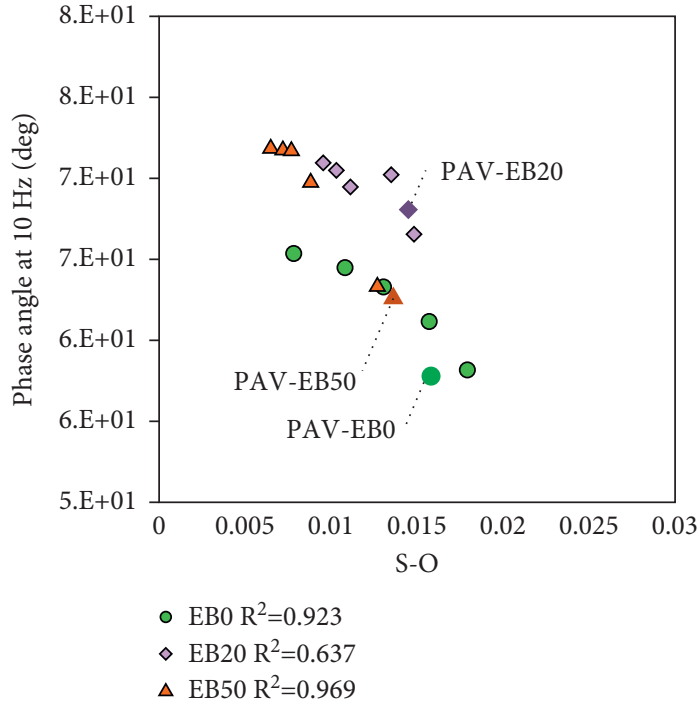

(b)

Figure 21: Relationship between sulfoxide compounds and complex modulus (a) and phase angle (b) during oxidative controlled curing [58].

the flexible curing agent PFA, wider and lower peaks were observed, which indicated that flexible long-chain structure of PFA can enhance the chain mobility of cured EA [30]. Higher $\tan \delta$ for EA and ESA than that of ER was observed in the glassy region, which indicated better energy dissipation capability for EA and ESA [68]. It should be pointed out that, for EA with high mass fraction of asphalt ( $>65 \mathrm{wt} \%$ ), a single $\tan \delta$ peak was observed [113], which indicates good compatibility between epoxy and asphalt. For CEA-ESO30 [71] and CEA-ESO20 [72] system, one $T_{g}$ value for EA was also observed, indicating excellent compatibility between asphalt and ER after addition of ESO.
As compared with ER, $T_{g}$ was significantly reduced for EA, especially at high asphalt content [113]. However, very limited effect of asphalt content on $T_{g}$ for EA was also reported $[7,16]$ (see Table 2). The addition of Sasobit into EAR slightly reduced $T_{g}$ value, which might be attributed to the reduction of crosslink density within epoxy [69]. Higher content of Sasobit within WMEA can also lead to lower $T_{g}$ values [123]. For EA modified with polyethylene glycol, higher molecular weight can reduce its $T_{g}$ values [133]. Meanwhile, addition of SBS increased $T_{g}$ as compared with neat EA [80]. As compared with unmodified EA, $T_{g}$ was reduced with the addition of reinforced nanofiller ATT [122]. The substantial increase in $T_{g}$ was observed for 


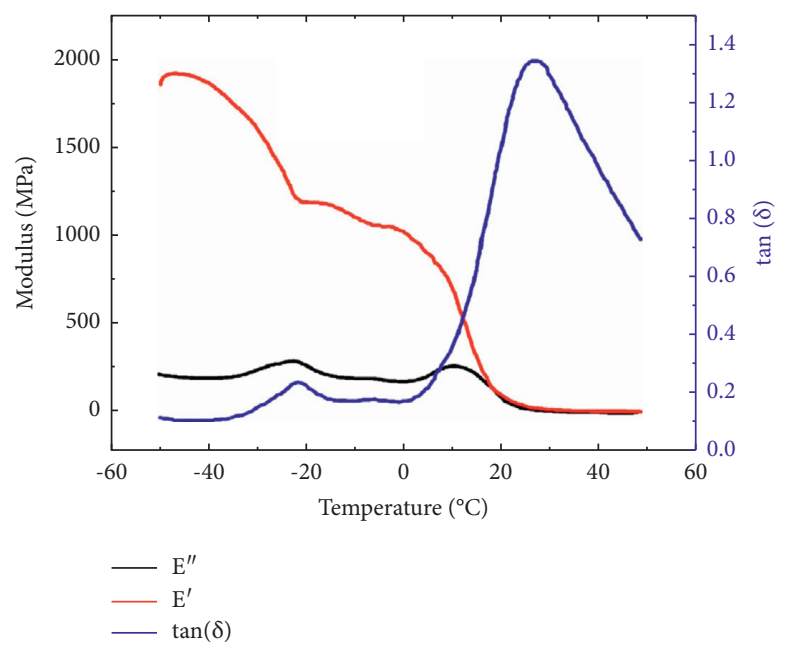

Figure 22: DMA properties versus temperature for EA [17].

TABLE 2: $T_{g}$ and damping properties of the neat EP and HMEA [7].

\begin{tabular}{lcccccc}
\hline Sample & DSC $T_{g}\left({ }^{\circ} \mathrm{C}\right)$ & $T_{g}\left({ }^{\circ} \mathrm{C}\right)$ & $T_{\beta}\left({ }^{\circ} \mathrm{C}\right)$ & $(\tan \delta)_{\max }$ & $\begin{array}{c}\mathrm{DMA} \\
(\tan \delta)_{R T}\end{array}$ & $(\Delta \mathrm{T})$ at $\tan \delta>0.3$ \\
\hline EP & & 27.4 & - & 0.99 & 0.95 & $41.1(9.8 \sim 50.9)$ \\
HMEA45 & 11.3 & 27.6 & -10.6 & 1.09 & 0.99 & $74.1(-1.6 \sim 72.5)$ \\
HMEA50 & 13.1 & 31.2 & -11.3 & 1.16 & 1.03 & $85.3(1.8 \sim 87.1)$ \\
HMEA55 & 13.2 & 29.9 & -11.4 & 1.18 & 1.08 & 84.0 \\
\hline
\end{tabular}

Note: $\mathrm{EP}=$ epoxy resin; HMEA = hot-mixed epoxy asphalt.

compound curing agents (MeTHPA with sebacic acid or TOA with sebacic) cured EA compared with sebacic acid cured EA [33], which was attributed to the formation of small crosslinked grids and high rigidity of the ER network. Both $T_{g}$ and $T_{\beta}$ were reduced with the presence of WCO [70], indicating improved low-temperature cracking resistance for WMEA. The modifier BrSBS can significantly increase the $T_{g}$ value [37], which was ascribed to nucleophilic substitution reaction between BrSBS and amine groups of curing agents and thus interpenetrating polymer network was created.

The values of $T_{g}$ obtained from DMA were consistent with those from DSC analysis [77]. As compared with $T_{g}$ from DSC, around $15^{\circ} \mathrm{C}$ [7] to $20^{\circ} \mathrm{C}$ [16] increase was reported for $T_{g}$ determined from DMA (see Table 2).

$E^{\prime}$ was found to decrease with the increase of PFA content for EA, indicating the increase of flexible long-chain structure proportion in the cured EA system [30]. ESOmodified CEA exhibited lower $E^{\prime}$ than unmodified CEA due to the flexible long chains of ESO [72]. $E^{\prime}$ of Sasobitmodified EAR was higher than that of unmodified EAR other than the glass transition range [69], which was due to the wax crystallization of Sasobit $[134,135]$. Lower $E^{\prime}$ value for CEA with SBS than that of EA and ER in the glassy to rubbery transition region was reported [68], which was probably due to the plasticizing effect of SBS. On the other hand, stronger asphalt-polymer intermolecular interaction often leads to higher $E^{\prime}$ of ESA as compared with that of neat asphalt if it was prepared through conventional hot mixing [80].

The damping properties of EA correlated well with noise and vibration reduction capability, which have often been characterized by $\tan \delta$ at room temperature $\left((\tan \delta)_{\mathrm{RT}}\right)$ $[7,69]$ or maximum $\tan \delta\left((\tan \delta)_{\max }\right)[7,16,72,129]$, temperature range $(\Delta T)$ for effective damping $(\tan \delta>0.3)$, and the area under $\tan \delta$ versus temperature curve $(T A)$ $[7,16,72,129]$ (see Table 2). Large values of $(\tan \delta)_{R T}$, $(\tan \delta)_{\max }, T A$, and $\Delta T$ indicate better damping properties for EA [69]. Addition of Sasobit to EAR can improve the damping properties, which was associated with the better dispersion of asphalt rubber in the epoxy matrix [69]. With the increase in the asphalt content, superior damping properties were reported due to improved flexibility of EA $[7,16]$. For EA, damping properties were also found to increase with increasing asphalt penetration grade [129]. As compared with styrenic polymer-modified EA, neat EA showed superior damping properties [80]. However, better damping was reported for EAR with the WMA additive Sasobit [69], WMEA with less than 4\% WCO [70], and EA with SBS [110]. Better damping properties were reported for the compound curing agent MeTHPA with sebacic acid than those of the compound curing agent TOA with sebacic acid and sebacic acid alone [33]. Damping properties of EAM have also been determined by using the impact resonance test, which was verified through a comparison between theoretical and tested natural frequency [136]. Damping 
parameters were found to be largely dependent on testing temperature.

Crosslink density $\left(v_{e}\right)$ of cured ER can be defined using equation (7). Higher $v_{e}$ for PDL-epoxy than DER332 significantly contributed to its much higher $T_{g}$ than that of DER 332 resin [31]. The $v_{e}$ value significantly increased after the addition of styrenic polymers into EA [80], which was caused by the physical interaction between SBS and virgin binder and thus higher viscosity and lower mobility of SBA within the epoxy phase:

$$
v_{e}=\frac{E}{3 R T}
$$

where $E=$ elastic modulus of cured epoxy in the rubbery state; $R=$ gas constant; and $T=$ absolute temperature.

(3) Creep and Recovery. To further understand the delayed elasticity and recovery behavior of EA, creep and recovery tests were performed under $1 \mathrm{~s}$ loading and $9 \mathrm{~s}$ rest for 100 cycles [17], which can better characterize the rutting performance of binders than the rutting factor [137]. As can be seen in Figure 23, EA showed excellent elastic behavior and rutting resistance than neat asphalt and SBA.

The recoverable part from multiple stress creep recovery tests was increased while the nonrecoverable part was decreased with the increase of waterborne epoxy concentration, which indicated that the elastic performance of asphalt can be strengthened by the epoxy network [90]. This confirmed the strong rutting resistance of EA over conventional asphalt. EA with $15 \%$ of WCO-EP $(\mathrm{KL}-\mathrm{COOH} / \mathrm{NMA}=1 / 1)$ showed the highest percentage recovery and lowest $\mathrm{J}_{\mathrm{nr}}$ [65], which was comparable with commercial epoxy.

Linear amplitude sweep tests performed on WEA residue demonstrated the fatigue life improvement effects of ER as compared with the conventional binder [90], as shown in Table 3. Results from DSR time sweep tests confirmed the superior fatigue performance of EA over the conventional binder [58]. As compared with SBA, EA also showed significantly better fatigue resistance, since complex modulus of EA was still much higher than $50 \%$ after 60,000 loading cycles, while SBA was in the flow state under high shear frequency and shear stress [17].

5.3.3. Viscoelastic Behavior. The linear viscoelastic range for REAC under dynamic shear loading was determined to be $0.1 \%$ shear strain [78]. To characterize the viscoelastic behavior of flowable asphalt binders, generalized Maxwell model has often been used with quite a number of mechanical elements [138]. To reduce the number of elements in the Maxwell model, fractional 2S2P1D model (see equation (8)) was generally used. It should be noted that this 2S2P1D model can be obtained by attaching a linear dashpot in line to the two fractional dashpots and spring in the Huet-Sayegh model (see Figure 24). As a matter of fact, the fractional 2S2P1D model will degrade into Huet-Sayegh model for weak-crossing anhydrides cured EA binder [139], which is equal to combining the linear dashpot into the two fractional dashpots under high asphalt binder content:

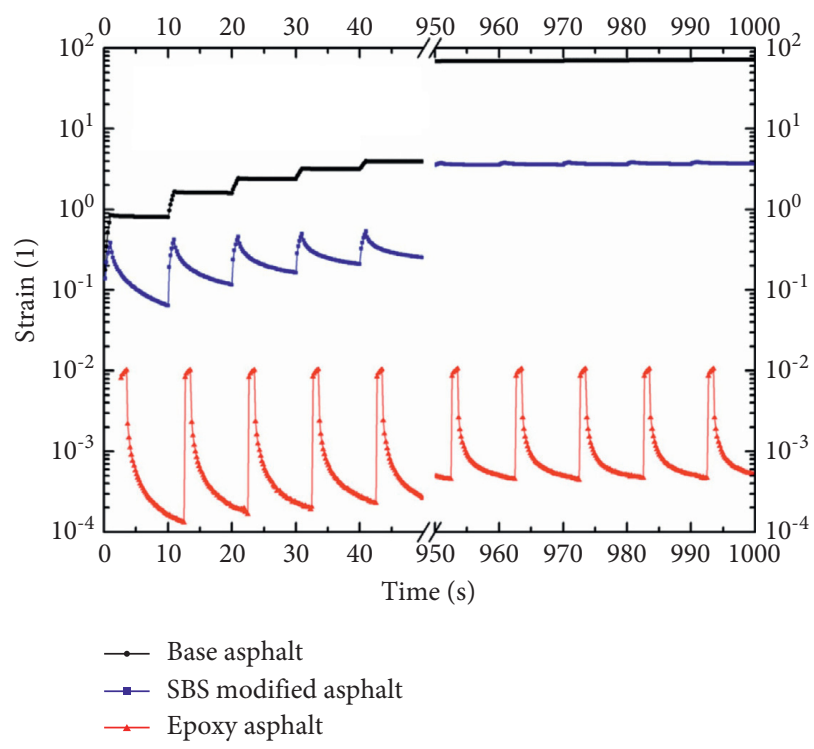

FIgURE 23: Creep and recovery behavior for binders at $60^{\circ} \mathrm{C}$ and $300 \mathrm{~Pa}$ [17].

Table 3: Fatigue life based on linear amplitude tests [90].

\begin{tabular}{lccc}
\hline Binder type & $2.5 \% N_{\mathrm{f}}$ & $5 \% N_{\mathrm{f}}$ & Fatigue model \\
\hline WEA-0 & 6516 & 676 & $1.303 \times 10^{5}\left(\gamma_{\max }\right)^{-3.269}$ \\
WEA-1 & 7162 & 766 & $1.374 \times 10^{5}\left(\gamma_{\max }\right)^{-3.244}$ \\
WEA-3 & 14067 & 836 & $5.875 \times 10^{5}\left(\gamma_{\max }\right)^{-4.073}$ \\
WEA-5 & 59717 & 1231 & $1.011 \times 10^{7}\left(\gamma_{\max }\right)^{-5.601}$ \\
\hline
\end{tabular}

Note: $N_{\mathrm{f}}=$ fatigue life; WEA-1, -3 , and $-5=$ percentages of total weight of epoxy and waterborne curing agent by weight of raw asphalt binder $=1 \%$, $3 \%$, and $5 \% ; \gamma_{\max }=$ applied strain level.

$$
G^{*}(\omega)=G_{0}+\frac{G_{g}-G_{0}}{1+\alpha(i \omega \tau)^{-k}+(i \omega \tau)^{-h}+(i \omega \beta \tau)^{-1}},
$$

where $G^{*}(\omega)=$ complex modulus; $G_{0}=$ static modulus; and $G_{g}=$ glass modulus.

To understand the correlation between the viscoelastic properties (e.g., complex modulus) of EA and its crosslinking characteristics (e.g., degree of polymerization), a kinetic viscoelasticity model (see equation (9)) was proposed to confirm the onset of mechanical response [140]. It was found that the degree of conversion has a significant effect on the viscoelastic behavior, which will eventually affect the stress build-up in the EA:

$$
G(t, T, x)=G_{\infty}+\sum_{i=1}^{n} G_{i} \exp \left(-\frac{t}{a_{T, x} \tau_{i}}\right),
$$

where $G(t, T, x)=$ complex modulus at time $t$, temperature $T$, and degree of conversion $x ; G_{\infty}=$ equilibrium complex modulus; $G_{i}=$ complex modulus for $i$-th element; $\tau_{i}=$ relaxation time; and $a_{T}, a_{x}=$ temperature shift factor and conversion shift factor.

Strongly distorted ellipse of Lissajous curves for EA indicated its nonlinear characteristics especially between $25^{\circ} \mathrm{C}$ and $45^{\circ} \mathrm{C}$ [141], as shown in Figure 25. Besides strain 


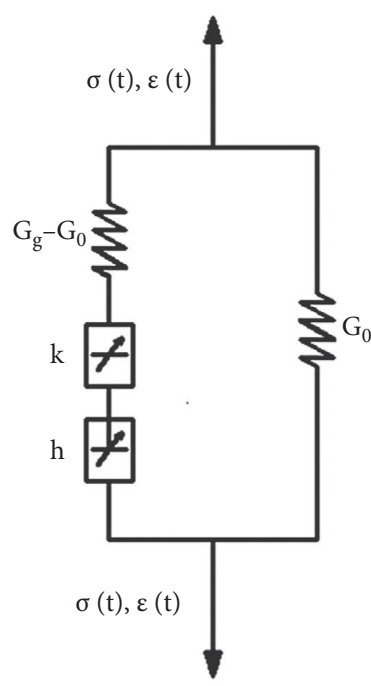

(a)

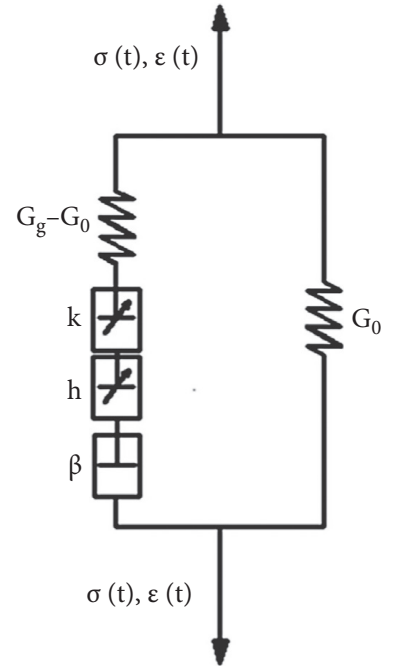

(b)

FIgURE 24: Huet-Sayegh model (a) and 2S2P1D model (b) [139].

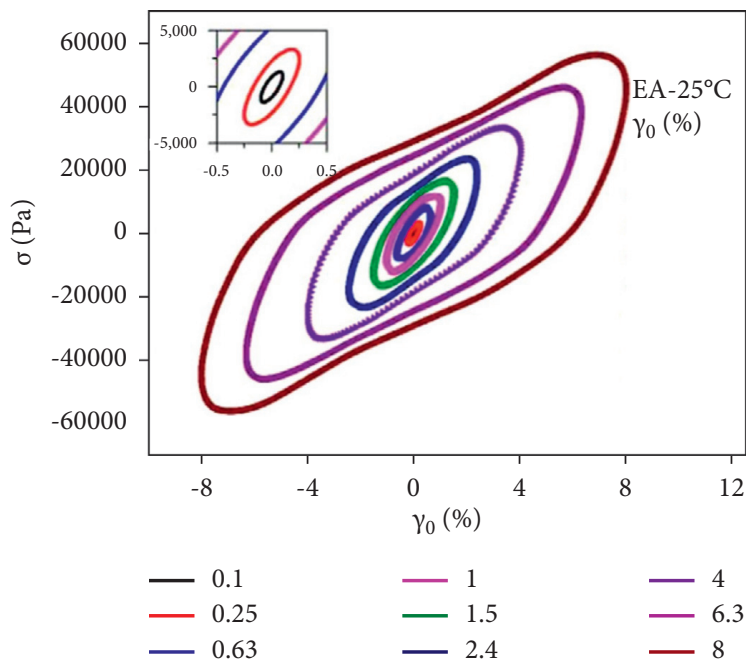

(a)

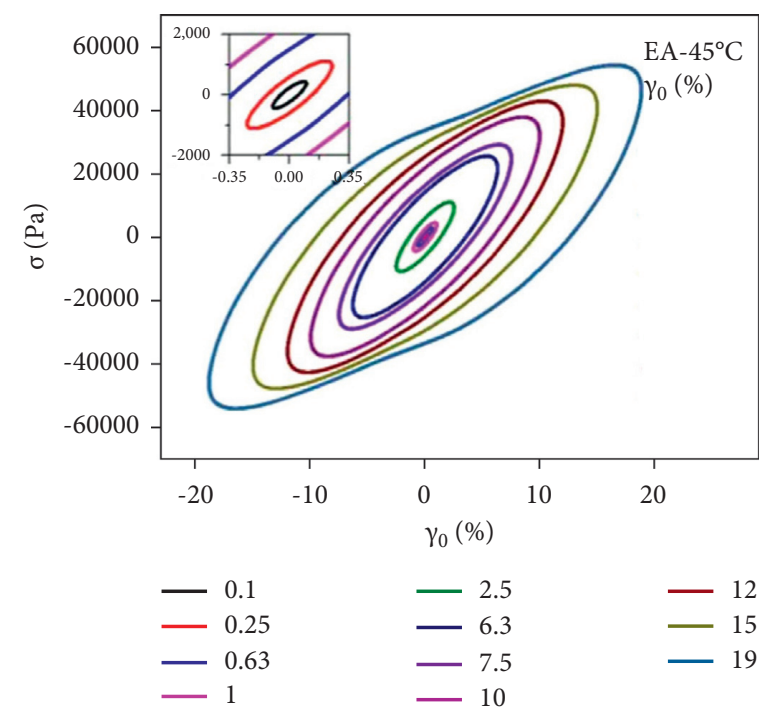

(b)

FIGURE 25: Lissajous curves for EA at angular frequency $\omega=6.3 \mathrm{rad} / \mathrm{s}$ for $25^{\circ} \mathrm{C}$ (a) and $45^{\circ} \mathrm{C}$ (b) [141].

amplitude, it can be seen that temperature has a significant effect on nonlinearity of EA. For instance, intracycle yielding and strain stiffening were observed under the strain amplitude of $2.4 \%$ at $25^{\circ} \mathrm{C}$, whereas these nonlinear responses were only observed under strain amplitude higher than $12 \%$ at $45^{\circ} \mathrm{C}$.

5.4. Tensile Performance. As compared with neat asphalt, EA was reported to have higher tensile strength $[58,79]$, which increased with the increase of epoxy content, especially when the ER content was more than $30 \%$ [79]. The elongation, a ductility measurement, was significantly reduced with the increase of the ER content [79]. The failure strain of $30 \%$ for EA indicated that it can be used for antiskid surfaces under heavy loading [100]. On the other hand, the tensile strength of EA was decreased as compared with ER, whereas the elongation was increased $[7,15,16,56,68,81]$, as shown in Figure 26. Tensile strength will be significantly reduced if phase inversion occurred at high asphalt content [15]. The tensile strength was increased, and the elongation was decreased while the asphalt content was reduced $[16,73,81,113]$ (see also Figure 26) or curing time was increased in EA $[5,20,113,124]$. With the increase of penetration grade, tensile strength and elongation for EA were both increased [129] and this increase might be attributed to better dispersion of asphalt particles within the epoxy matrix for softer binder. A peak tensile strength value of epoxy repair materials was obtained when $10 \mathrm{phr}$ asphalt was added to ER [84]. Higher level of plasticization from 


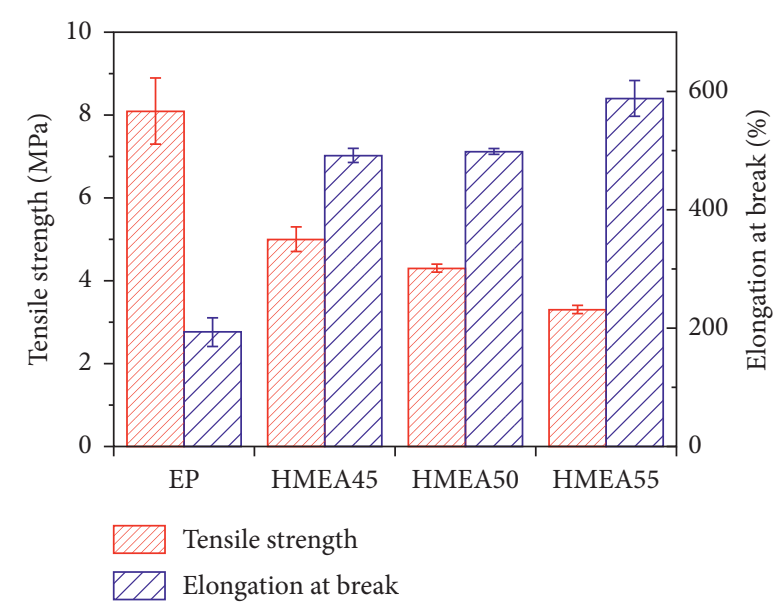

FIgURE 26: Tensile strength and elongation at break for ER and HMEA [7]. Note: ER= epoxy resin; HMEA = hot-mixed epoxy asphalt; 45, 50, and $55=$ asphalt content by weight of HMEA binders.

saturated oil and lower level of crosslinking was proved to exhibit better flexibility [4]. With the increase of curing agent PFA content, tensile strength was observed to increase while elongation was observed to decrease [30], which indicated that the cured EA has higher flexibility. As compared with conventional heat-cured EA, both slightly lower [51] and slightly higher [34] tensile strength have been reported for microwave-cured EA.

For REAC, the high tensile strength and elongation was due to the formation of the interpenetrating biomodal network, which consisted of short-chain maleated asphalt and long-chain dicarboxylic acid $[6,78]$. Stress-strain behavior of REAC can be described with Mooney-Rivlin model (see equation (10)), which was often plotted as $\sigma_{\text {eng }} /\left(\lambda-1 / \lambda^{2}\right)$ against $1 / \lambda$ :

$$
\frac{\sigma_{\text {eng }}}{\left(\lambda-1 / \lambda^{2}\right)}=\frac{2 C_{1}+2 C_{2}}{\lambda}
$$

where $\sigma_{\text {eng }}=$ nominal tensile stress; $\lambda=$ ratio of deformed length over initial length; and $C_{1}, C_{2}=$ adjustable parameters.

ATT $[92,122]$ has showed to improve the tensile performance of EA due to the reinforcement effect from well dispersion of ATT and strong interfacial interaction between ATT and EA matrix. The elongation at break was also increased after addition of ATT into EA [122], which was also attributed to the reinforcement effect provided by well dispersion of ATT within EA. However, tensile strength and elongation will be compromised if high concentration of ATT is added, which will act as flaws or defects due to its agglomeration [142].

The compound curing agent MeTHPA with sebacic acid or TOA with sebacic acid was confirmed to significantly increase the tensile strength of EA, and MeTHPA is more effective than TOA [33]. Addition of low contents of EVA (in the mass fraction of $0.95 \mathrm{wt} . \%$ to $1.90 \mathrm{wt} . \%$ ) into EA can increase its tensile strength and elongation [14], which was attributed to the well distribution of EVA particles in EVAmodified EA, as confirmed in LSCM images and the improved compatibility [143]. It should be noted that the flexible and tough nature of EVA probably contributed to the increased elongation of EA [144]. As compared with neat EA, the tensile strength increased for hot-mixed ESA $[15,80]$ and it was reduced for CEA with SBS [68]. However, both positive $[15,68]$ and negative $[80]$ effect of SBS on elongation was reported. With the decrease of rubber particle size, the tensile strength of EAR was reduced while its elongation was increased [61]. The elongation improvement effect of crumb rubber on EA was attributed to its flexibility [81]. ARPmodified EA showed higher tensile strength and shorter elongation due to increased crosslink density and thus more brittle behavior [61]. For flame retardants, negligible effects on tensile strength were reported for $\mathrm{DBDPE} / \mathrm{Sb}_{2} \mathrm{O}_{3}$ [36] and natural brucite [13]. However, slight increase in tensile strength was reported for synthetic brucite [13], which was probably due to large interface contact area and uniform dispersion of brucites in EA. Furthermore, significant increase in tensile strength of ATH/ZB was also reported [29]. Shorter elongation was also reported for all three flame retardants. However, BrSBS modified EA was reported to have lower tensile strength and elongation due to its brittleness [37]. The introduction of both glass fiber [104] and mineral fiber [105] can increase the tensile strength and elongation due to the formation of three-dimensional network.

The introduction of $\mathrm{H} 102-\mathrm{C}_{2}$ or $\mathrm{H} 102-\mathrm{C}_{18}$ can significantly increase the elongation of EA, while the tensile strength was reduced [82]. It should be noted that $\mathrm{H} 102-\mathrm{C}_{18}$ can provide more toughening effect than $\mathrm{H} 102-\mathrm{C}_{2}$, since $\mathrm{H} 102-\mathrm{C}_{2}$ has only inert short-chain end groups from reactivity elimination, while its toughening effect comes from hyperbranched structures. Meanwhile, only long-chain end groups were terminated for $\mathrm{H}_{102}-\mathrm{C}_{18}$ and flexible end groups remained. Decreased tensile strength and increased elongation at breaking reflect the improved compatibility between EA for CEA after the addition of ESO [71, 72]. Similar observation was also made for WMEA after the addition of WSO [70]. Both tensile strength and elongation at break for CEA modified with ESO/nanosilica was improved as the compatibility between asphalt and ER improved [38].

The fatigue cracking resistance for EA was reported to be better than neat asphalt [58]. Fracture energy of REAC showed to be 8 times that of epoxy-unmaleated asphalt composite [6]. Toughness, defined as the area under stressstrain curve, was also employed to evaluate the cracking resistance of EA. As compared with ER, the addition of asphalt and SBS increases the toughness value if no phase inversion occurred at high asphalt content [15]. This toughness enhancement was probably caused by the soft segment structure [121] and ductility [15] of asphalt binder. EA exhibited significantly lower fracture energy density than conventional asphalt based on the binder fracture energy test according to American Association of State Highway and Transportation Officials (AASHTO) TP 127-17 [145], as presented in Figure 27. Slightly lower toughness value was 


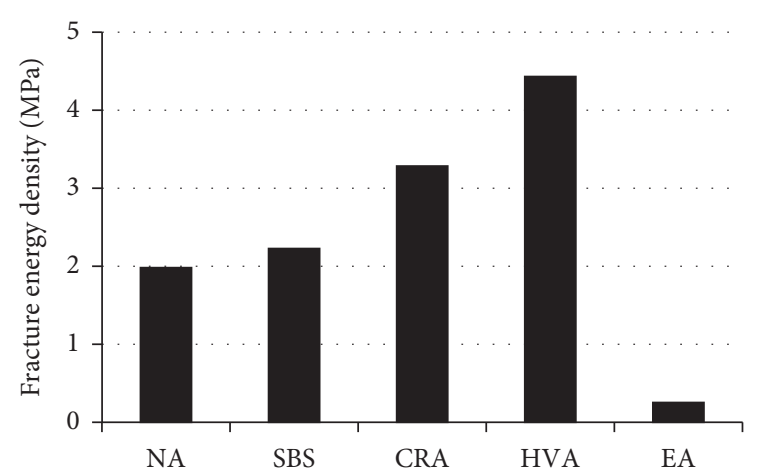

FIGURe 27: Fracture energy density for PAV-aged binders [145]. Note: $\mathrm{NA}=$ neat asphalt; $\mathrm{SBS}=\mathrm{SBS}$-modified asphalt; $\mathrm{CRA}=-$ crumb rubber modified asphalt; $\mathrm{HVA}=$ high viscosity asphalt; $\mathrm{EA}=$ epoxy asphalt.

also reported for EA after the addition of SBS [80]. Low content of Sasobit (<3 wt.\%) can increase the toughness of warm-mixed EAR [69] and WMEA [123]. This different effect of SBS on cracking resistance of EA was probably due to the dispersion of SBS within the EA. The lower tensile strength for EA after addition of crumb rubber was again attributed to the poor distribution of continuous phaseseparated structure of asphalt rubber within the epoxy matrix [81]. With the addition of core-shell rubber, $29 \%$ increment in tensile strength, $60 \%$ increase in elongation at break, and double toughness were reported for EA [108]. As compared with conventional EA, its elongation was increased by $198 \%$ while toughness was increased by $65 \%$ for EA with 2 wt.\% SBS at 31\% epoxidation degree [128].

5.5. Bond Strength. Adhesive strength on steel plates was evaluated using pull-out testing, and ER exhibited significantly higher adhesion strength than EA [56]. The descending order for pull-off strength of three tack coats between steel bridge deck and EAM was determined, which was ARP-modified EA, EAR, and EA [61]. Cohesive energy was measured by separating two steel blocks glued by EA, and it was found that proprietary accelerator modified EA has a significantly higher cohesive energy than base asphalt or asphalt binder diluted EA [102], which indicated excellent adhesion to sealing chips. Adhesion strength between the antiskid layer and the underlying structural layer was determined with a Pull test, and the failure occurred below the interface in the underlying asphalt mixture (see Figure 28), which indicated the superior adhesion performance of EA used for the antiskid layer [98]. Leutner shear test again confirmed the higher shear strength between EA-based antiskid surface and underlying mixture than that between tar-containing binder based antiskid surface and underlying mixture [100], and also higher shear strength for EA than conventional tack coat [62]. EA with higher crosslink density and polymer content was proved to have higher adhesion strength on the steel substrate, EAM substrate, and cement mortar substrate with steel tab [4]. Lower Cantabro loss of WEA-based

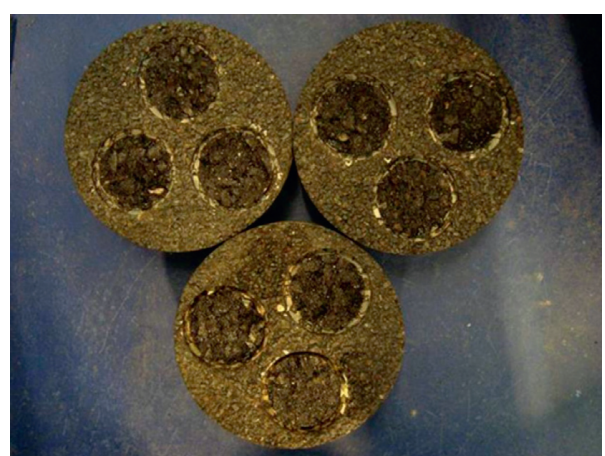

FIgURe 28: Failure in underlying asphalt mixture during the Pull test [98].

microsurfacing mixture than that of SBR-based mixture confirmed the better adhesive performance of ER [88].

The steel-concrete interface shear test indicated that EA has superior shear strength than polymer modified asphalt as a tack coat materials [146]. EA with higher concentration of ATT exhibited higher adhesive strength based on the singlelap shear test [92].

Waterborne epoxy resin as the interlayer material showed to have higher adhesion strength and direct shear strength than matrix asphalt and 4\% SBA emulsion by pullout test and direct shear test [89], respectively. Curing agents that can improve the compatibility of the epoxy system were proved to have higher adhesion strength and direct shear strength. Before curing was completed, the adhesive bond strength increased with curing time [90]. As compared with the common prime coat, water-soluble ER again showed to have much higher adhesive strength and shear strength [64], and the failure surfaces of which can be seen in Figure 29. The embedded surface mixture in EAbased prime coat indicated superior bonding strength than the common prime coat. $\mathrm{Nano}^{-\mathrm{TiO}_{2}}$ (up to $3 \%$ ) can improve the adhesive shear strength of WER [87], which can potentially increase the service life of fog seal. Maximum adhesive shear strength was obtained with $3 \%$ water-based resin content by using the $45^{\circ}$ oblique shear test [63]. Besides the higher strength than polyurethane and SBA, ER also exhibited longer shear fatigue life [147]. The addition of rubber into EA was confirmed to enhance the bond strength in terms of increased interface shear fracture energy [61].

\section{Mechanical Characteristics of Epoxy Asphalt Mixture}

6.1. Viscoelasticity. A static compressive creep test was conducted on cylindrical specimens with $100 \mathrm{kPa}$ loading and significantly lower creep deformation was observed for EAM than that of the conventional asphalt mixture [148], which was also reduced with the increase of the ER content. To accurately describe creep behavior of EAM from $-10^{\circ} \mathrm{C}$ to $60^{\circ} \mathrm{C}$, a modified second-order extensive Kelvin model (see Figure 30 and equation (11)) was employed to include the delayed viscoelastic deformation at the two ends of the temperature range [149], which was further verified with experimental creep data on beam specimens. 


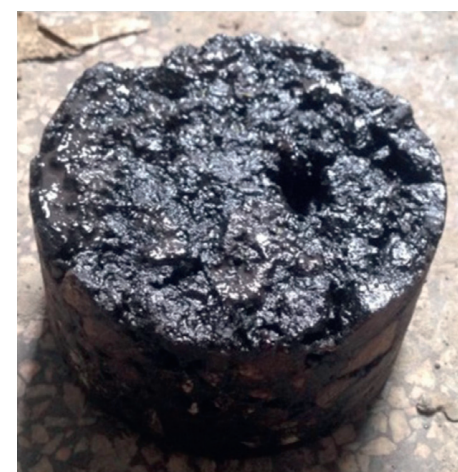

(a)

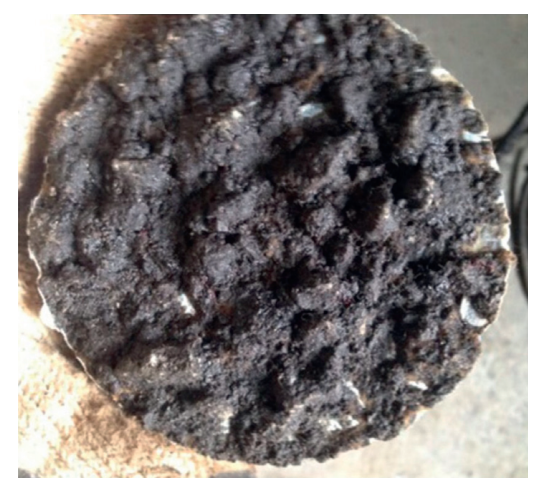

(b)

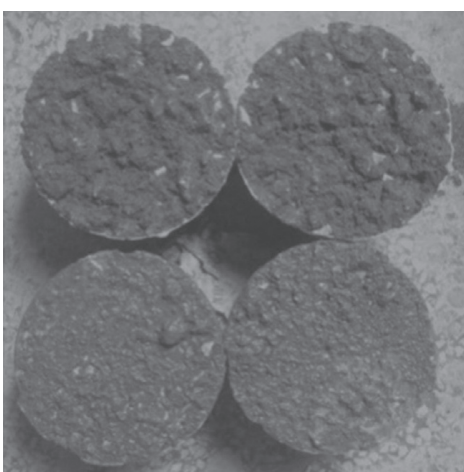

(c)

Figure 29: Interlaminar shear failure surface for EA-based prime coat (a, b) and common prime coat (c) [64].

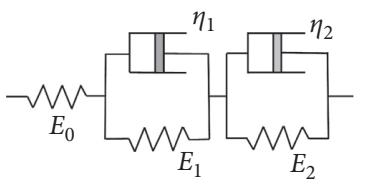

FIgURE 30: Modified second-order extensive Kelvin model [149].

$$
\frac{\varepsilon(t)}{\sigma_{0}}=\frac{1}{E_{0}}+\sum_{i=1}^{n} \frac{1}{E_{i}}\left(1-e^{-\left(E_{i} / \eta_{i}\right) \cdot t}\right),
$$

where $\varepsilon(t) / \sigma_{0}=$ creep compliance; $E_{0}=$ instantaneous modulus; $E_{i}=$ stiffness of spring in the $i$ th Kelvin unit; $\eta_{i}=$ dashpot viscosity; and $n=$ number of Kelvin units and order of extensive Kelvin model.

For cylindrical EAM samples, the linear viscoelastic limit was determined to be $150 \times 10^{-6}$ strain under various temperatures and frequencies [150]. Huet-Sayegh rheological model (see equation (12)) was successfully used to characterize the linear viscoelastic behavior for EAM $[150,151]$ :

$$
E^{*}(\omega \tau)=E_{e}+\frac{E_{g}-E_{e}}{1+\delta_{E}\left(i \omega \tau_{E}\right)^{-k_{E}}+\left(i \omega \tau_{E}\right)^{-h_{E}}},
$$

where $\omega=2 \pi f=$ angular frequency; $\tau_{E}=$ characteristic time; $E_{g}=$ glass modulus; $E_{e}=$ equilibrium modulus; and $\delta_{E}, k_{E}$, and $h_{E}=$ dimensionless model parameters.

For cylindrical EAM specimens under cyclic loading, it exhibits elastic-plastic behavior in the first few cycles with dominant elastic behavior thereafter [152]. With the increase in confining pressure, the dissipated energy can be reduced from $25 \%$ for unconfined specimens to less than $15 \%$ for confined specimens. With the increase of dynamic modulus difference between EA patching materials and existing asphalt materials, larger tensile and shear stresses will be induced at the patching interface based on numerical analysis of composite beams [12], which indicates shorter service life of patching materials. Deformation recovery test was also conducted on rectangular specimens under three-point bending test to confirm the superior deformation recovery performance of asphalt mixture with SM-HER as compared with the conventional asphalt mixture [77], which can mitigate the accumulation of plastic deformation.

6.2. Resilient Modulus and Compressive Strength. Indirect tension modulus was evaluated under the testing condition of $0.04 \mathrm{~s}$ loading and $3.0 \mathrm{~s}$ rest and modulus of open-graded EAM was found to increase with the increase of oxidation time $[8,18]$, which might be attributed to both continued curing and oxidation. Open-graded EAM also exhibited significant higher indirect tension modulus than that of mixtures with base binder and SBA [18], see Figure 31. Open-graded EAM also showed faster increase rate of indirect tension modulus than base asphalt and SBA.

Compressive strength of EAM was observed to be only $10 \mathrm{MPa}$ less than C50 cement concrete [103]. However, it was significantly higher than stone matrix asphalt (SMA) and conventional dense-graded asphalt mixture. Compressive strength of EAM repair materials was found to increase as asphalt content increased up to $10 \mathrm{phr}$ [84], which was probably attributed to elevated cohesion and formation of the microphased structure in EAM materials $[6,124]$. However, a part of the ER network will be disrupted once the asphalt content was over $10 \mathrm{phr}$ and compressive strength will be reduced. It is interesting to note that the compressive strength will increase with more freeze-thaw cycles due to better energy absorption capability of asphalt phase within the EA system. Microwave curing can slightly increase the compressive strength of EAM as compared with conventional thermal curing due to its more evenly cured gel system under microwave curing [34]. When it comes to effects of curing time, rapid increase in compressive strength was observed in the first 3 days and growth rate of compressive strength was observed to increase with increasing binder-aggregate ratio in the first 3 days [153].

\section{Pavement Performances of Epoxy Asphalt Mixture}

How the properties of epoxy asphalt can be translated to the properties of epoxy asphalt mixture in the field still needs to be checked by evaluation on the pavement performances of epoxy asphalt mixtures, which are reviewed in this section. 


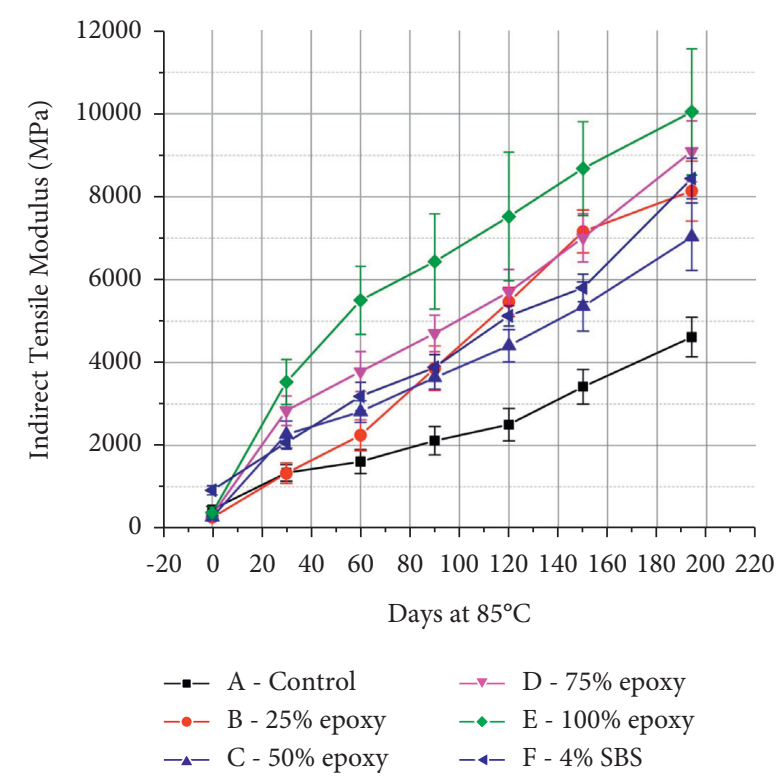

FIGURE 31: Resilient modulus for open-graded mixture with neat asphalt, SBA, and EA [18].

7.1. Permeability. For open-graded asphalt mixture prepared with EA, its permeability was slightly compromised as compared with the conventional asphalt binder [94, 154]. Under a laminar flow condition, there exists a linear relationship between permeability and air void for porous EAM [93]. In addition, the permeability of porous asphalt mixtures with smaller aggregate sizes was slightly reduced if air void content was kept constant. Glass fiber [104] or mineral fiber [105], which was often added for toughness enhancement and draindown prevention, showed negligible effect on the permeability of EAM. The impermeability of the underlying pavement layer can be significantly improved after WER was used as either prime coat [64] or fog seal modified with nano- $\mathrm{TiO}_{2}$ [87], which can prevent water from penetrating down into the pavement. Impermeability of the tack coat layer has been evaluated by using the water tightness test, and no seepage was observed for EAR, ARPmodified EAR, and EA under pressure up to $300 \mathrm{kPa}$ [61].

7.2. Skidding Resistance. British pendulum number (BPN) from British pendulum tester and mean texture depth (MTD) from the sand patch method have been widely used to evaluate the friction performance of asphalt mixture, which reflects the friction at low and high vehicle speeds, respectively. MTD of epoxy resin-based UTASS was found to be almost 10 times that of composite structures with an EAM surfacing structure [101]. Small particle porous epoxy asphalt (SPPEA) was found to have superior friction than SMA and dense-graded mixture, but inferior friction than open-graded mixture based on both BPN and MTD data [93], as shown in Table 4. BPN was also observed to further deteriorate under repeated traffic loading and higher vehicle loading $[93,155]$. For EAM with glass aggregates, mixtures with etched glass were found to have significantly lower BPN friction value than that of mixtures with unetched glass due
TABLE 4: BPN from British pendulum tester and MTD from sand patch test [93].

\begin{tabular}{lccc}
\hline Mixtures & Air-void content (vol. \%) & BPN & MTD $(\mathrm{mm})$ \\
\hline SPPEA & 20 & 76.0 & 1.58 \\
SMA-5 & 3 & 72.3 & 1.21 \\
OGFC-13 & 20 & 78.8 & 1.77 \\
AC-13 & 3 & 62.0 & 0.42 \\
\hline
\end{tabular}

to the horizontal position of etched glass in mixture [107]. The $\mathrm{BPN}$ value of nano- $\mathrm{TiO}_{2}$ modified EAM was compromised and it was attributed to decreased fluidity of WER, leading to more macrotexture covered and thus lower BPN value [87]. Open-graded mixture with EA had lower BPN value than that of open-graded mixture with conventional PG 64-16 [94], which was consistent with friction coefficient results from dynamic friction tester at low slip speeds $[94,154]$. But at high slip speeds, contrary friction coefficient results were obtained, probably attributed to the high stiffness of open-graded mixture with EA, which will thus dissipate more energies from spinning rubber blocks and thus higher friction coefficient. EAM designed based on the $\mathrm{V}-\mathrm{S}$ method showed to have better friction resistance than that of SMA and dense-graded mixture with same NMAS [97].

Glass fiber [104] or mineral fiber [105] was reported to have negligible improvement on MTD of EAM. Antiskid surface with MTD as high as $1.93 \mathrm{~mm}$ was designed by Xiao et al. [98, 100], but it needs further long-term field validation. Microsurfacing prepared with WEA was determined to have almost the same friction in terms of both BPN and MTD as that prepared with SBR [88]. Mass loss during accelerated loading test was determined for prime coat applied on CTB and WEA as prime coat was found to have significantly lower mass loss than that of the common prime coat [64], which indicated better abrasion resistance to construction vehicles for EA due to strong penetrating ability. A GA-BP neural network model was successfully developed for the prediction of long-term skidding resistance of EAM, which was reduced with the increase of binder content and aggregate gradation shape parameter [155].

7.3. Durability. After long-term freeze-thaw conditioning, degraded rheological and mechanical performances were observed for EAR with and without ARP modification [61], including increased creep stiffness, decreased m-value, decreased tensile strength, and shorter elongation, as shown in Table 5.

As compared with asphalt mixture prepared with conventional binder and SBA, open-graded mixture prepared with EA showed significantly less Cantabro mass loss even after 7 days aging at $60^{\circ} \mathrm{C}$ [94], 194 days aging at $85^{\circ} \mathrm{C}$ [18], and 909 hours oxidation conditioning [8], which indicated superior durability for EAM. Longer fatigue life again confirmed superior durability of open-graded mixture over base asphalt and SBA mixture after long-term aging, even if it is diluted [18]. Lower wet track abrasion loss values also validated the stronger durability of WEA-prepared 
TABle 5: Properties of EA, EAR, and EAAR before and after long-term F-T cycles [61].

\begin{tabular}{lcccccc}
\hline \multirow{2}{*}{ Properties } & \multirow{2}{*}{ Temperature } & EA & EAR & EAAR & EA & After 18 F-T cycles \\
& & 247.6 & 225.1 & 230.4 & 319.4 & 270.1 \\
Creep stiffness, $\mathrm{MPa}$ & $-12^{\circ} \mathrm{C}$ & 0.333 & 0.387 & 0.371 & 0.213 & 0.292 \\
$m$-value & $-12^{\circ} \mathrm{C}$ & 6.13 & 6.79 & 6.98 & 4.48 & 5.69 \\
Tensile strength, $\mathrm{MPa}$ & $23^{\circ} \mathrm{C}$ & 257 & Bes & 332 & 131 & 266.3 \\
Fracture elongation, $\%$ & $23^{\circ} \mathrm{C}$ & 236 & 5.85 \\
\hline
\end{tabular}

Note: $\mathrm{EA}=$ epoxy asphalt; $\mathrm{EAR}=$ epoxy asphalt rubber; $\mathrm{EAAR}=\mathrm{ARP}$-modified EAR; F-T =freeze-thaw.

microsurface over SBR-modified asphalt [88], which was also consistent with Cantabro mass loss results.

Raveling resistance of EAM can be determined by Cantabro tests and it was found that $9 \%$ glass fiber [104] or mineral fiber [105] can reduce the Cantabro weight loss by $29 \%$, which indicated a strong bond between aggregate and EA with the addition of glass fiber or mineral fiber. Weight loss for cold-patching mixture prepared with WEA was reduced by $66 \%$ as compared with the conventional emulsified asphalt mixture [85], indicating improved raveling resistance. To evaluate the strength of CTB with prime coat consisting of WEA, the uniaxial penetration test was conducted on cylindrical specimens and a peak value of penetration strength was found with the increase of penetration depth [64].

7.4. Noise Absorption. Sound absorption coefficient test results, measured according to ASTM E 1050, indicated that EA can enhance the noise reduction performance of asphalt mixture $[94,154]$. In addition, open-graded gradation and large nominal maximum size will benefit noise absorption attributed to their pore structure.

\subsection{Rutting Resistance}

7.5.1. Marshall Stability. Marshall stability for cold patch EAM was improved as compared with conventional cold patch mixture [91]. As compared with epoxy resin concrete, around 1/3 reduction of Marshall stability was observed for EAM with $45 \%$ asphalt [7]. With the increase of asphalt content, the Marshall stability was slightly increased and the flow value was slightly reduced, see Table 6 . As compared with commercial net asphalt mixture, mixture of sand, EA, and LSP exhibited twice Marshall stability value [25]. Only 2.45\% drop of Marshall stability was observed for EAM with 50\% glass aggregates as compared with those without glass aggregates, whereas $34.33 \%$ drop was observed for SBA mixture [107]. EAM with snow-melting agents exhibited slightly better Marshall stability than those without snow-melting agents [156]. Bio-based EAM also exhibited better rutting resistance than the conventional asphalt mixture based on the increased Marshall stability value [32]. EAM with higher crosslink density, higher polymer content, and lower oil content possess higher Marshall stability [4]. However, EAM modified by polyethylene glycol with high molecular weight exhibited significantly compromised Marshall stability [133].
7.5.2. Dynamic Stability. The progression of rutting depth versus wheel passes was obtained from wheel tracking tests for a mixture of sand, EA, and LSP [25], and an optimum mixture composition was determined (see Figure 32). Dynamic stability of EAM was reported to be 6.3 to 9.5 times and 2.5 to 3.8 times of neat asphalt mixture and SBA mixture [7], respectively. With the increase of ER content, dynamic stability and maximum deflection for EAM exhibited higher and lower values [91, 148], respectively.

Addition of the snow-melting agent slightly increased the dynamic stability of EAM [156]. Meanwhile, addition of glass fiber [104] or mineral fiber [105] exhibited negligible improvement on both rutting depth and dynamic stability for EAM.

The dynamic stability of EAM was slightly reduced by $3.18 \%$ with up to $50 \%$ glass aggregates, but it was reduced by $40.87 \%$ with only $16 \%$ glass aggregates for asphalt mixture with SBS modification [107]. SPPEA mixture showed considerably lower dynamic stability than OGFC-13, which has larger aggregate size and thus better interlocking skeleton structure [93]. However, dynamic stability EAM was slightly increased with the increase of lightweight aggregate percentage [106]. EAM prepared using the V-S design method showed slightly higher dynamic stability than conventional EAM but significantly higher dynamic stability than SMA due to its skeleton structure [97] and the thermosetting nature of EA [97, 103]. Cold patch EAM showed significantly low dynamic stability and high rutting depth than the conventional asphalt mixture, and it was probably attributed to the existence of residual diluents and thus low binder viscosity [91]. The descending order of dynamic stability for double-layered bridge deck surfacing is EA-EA, EA-SMA, Gussasphalt-EA, and Gussasphalt-SMA [157], which again confirmed the strong rutting resistance of EA.

Repeated simple shear test at constant height was also employed to evaluate the rutting resistance of open-graded EAM, and it exhibited considerably better resistance to permanent shear deformation than the conventional opengraded mixture despite its lower initial shear modulus [94]. This was consistent with the rutting depth progression curves from Hamburg wheel tracking tests. In addition, pavement lateral deformation and pavement vertical deformation results confirmed the superior rutting resistance of microsurfacing mixture with WEA over SBR-modified mixture [88], especially the shearing deformation resistance due to crosslinking in the EA system. Consistent rutting resistance from Marshall stability and dynamic stability were confirmed $[7,25,91,107,156]$. 


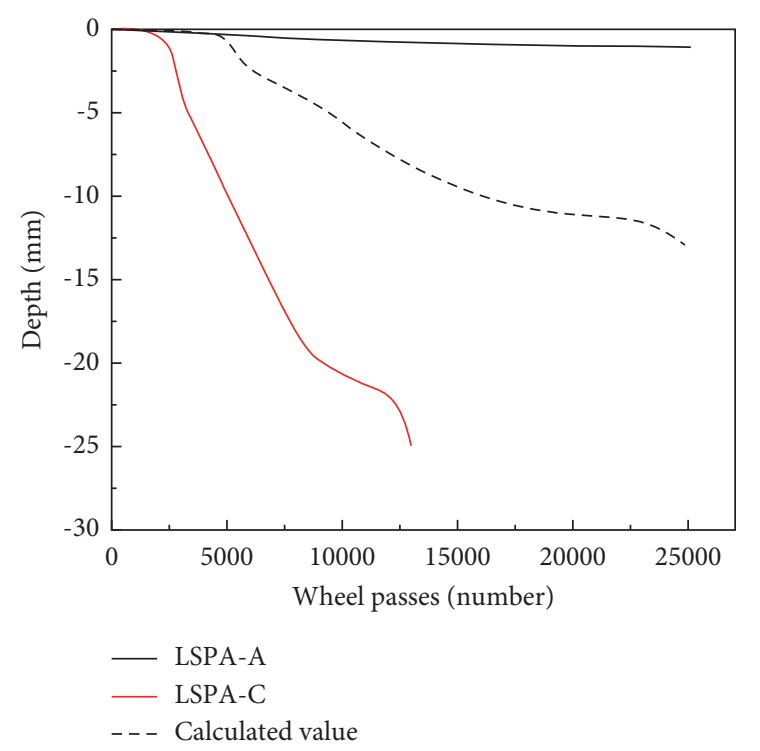

FIGURE 32: Depth profile for EAM [25]. Note: LSPA = blend of EA, LSP, and sand; calculated value $=$ average depth of LSPA A and C.

TABLE 6: Marshall of epoxy resin concrete and epoxy asphalt concrete [7].

\begin{tabular}{lcc}
\hline Sample & Marshall stability $(\mathrm{kN})$ & Flow value $(0.1 \mathrm{~mm})$ \\
\hline EPC & $>90$ & NA \\
EAC45 & 63.1 & 53.3 \\
EAC50 & 64.1 & 49.5 \\
EAC55 & 64.4 & 44.6 \\
\hline
\end{tabular}

Note: $\mathrm{EPC}=$ epoxy resin concrete; $\mathrm{EAC}=$ epoxy asphalt concrete; EAC45, 50 , and $55=$ asphalt content $45 \%, 50 \%$, and $55 \%$.

7.6. Low-Temperature Cracking. Three-point flexural beam at $-10^{\circ} \mathrm{C}$ was often conducted to determine flexural strength, flexural strain, and flexural stiffness for low-temperature cracking resistance evaluation $[93,107]$. SPPEA and small particle porous asphalt with common polymer modified asphalt has comparable cracking performance since ER has almost no effect on the already brittle asphalt binder [93]. Low-temperature cracking resistance of EAM with up to $50 \%$ glass aggregates was only slightly compromised in terms of reduced flexural strength and flexural strain [107]. Addition of ATT slightly increased the flexural strength, flexural strain, and bending strain energy density (see Table 7), indicating better flexibility at low temperature [122]. The V-S method based EAM showed slightly higher flexural strength but considerably lower flexural strain than conventional EAM [97]. Glass fiber [104] or mineral fiber [105] can significantly improve low-temperature cracking resistance of EAM based on increased flexural strength, flexural strain, and flexural stiffness, and optimum content was determined to be $9 \%$. EAM prepared with polyethylene glycol was also reported to have improved low-temperature cracking resistance and toughness by introducing long molecular chains within the crosslinked network for EA [133]. After 30 freeze-thaw cycles $\left(18 \mathrm{~h}\right.$ freezing at $-5^{\circ} \mathrm{C}$ and $6 \mathrm{~h}$ soaking in $4^{\circ} \mathrm{C}$ water), flexural stiffness from three-point bending tests
TABLE 7: Three-point bending results of EAM and EAM with ATT [122].

\begin{tabular}{lccc}
\hline ATT (wt.\% of EAM) & $\sigma_{c}(\mathrm{MPa})$ & $\varepsilon_{c}(\mu \varepsilon)$ & $G_{f}^{c}\left(\mathrm{~J} / \mathrm{m}^{3}\right)$ \\
\hline 0 & 29.2 & $\varepsilon_{c} 2159$ & 2508 \\
0.5 & 31.7 & 2348 & 3020 \\
1 & 31.6 & 2027 & 2586 \\
3 & 31.1 & 2314 & 2779 \\
5 & 29.5 & 2383 & 2741 \\
\hline
\end{tabular}

Note: $\sigma_{c}=$ critical stress; $\varepsilon_{c}=$ critical strain.

at $-14^{\circ} \mathrm{C}$ was reduced by $60.3 \%$ [158], which is a significant damage to EAM. Double-layered bridge deck surfacing, Gussasphalt-EA, exhibited superior low-temperature cracking resistance than other SMA, Gussasphalt, EA combinations (see Figure 33), due to the high strain energy density of Gussasphalt, followed by EA and SMA [157].

A bilinear cohesive-softening model was incorporated into three-dimensional discrete element model to investigate the fracture behavior of quasi-brittle materials, like EAM [159]. The cracking process was successfully characterized, and it was in good agreement with digital image correlation results. Single-edge notched EAM composite beam was assumed to be composed of linear elastic materials, and the effects of freeze-thaw on fracture toughness were numerically determined [158]. It is interesting to note that fracture toughness was decreasing in the first 15 freeze-thaw cycles and fracture toughness was increasing in the following 15 freeze-thaw cycles, which was probably due to stress absorption of bonding layer.

Addition of WCO-EP and KL-COOH/NMA slightly reduced the low-temperature cracking resistance of asphalt binder based on slightly increased stiffness, reduced $\mathrm{m}$-value, and increased cracking temperature from bending beam rheometer tests [65].

7.7. Water Damage. To investigate the moisture damage resistance of EAM, the contact angle of EA was determined by using the sessile drop method, which was further used to determine the surface free energy. It was found that the contact angle between EA and water was higher than $90^{\circ}$ [145], indicating its hydrophobic nature; the contact angle was found to increase with the increase of ER content and curing time $[112,113]$. In addition, the surface energy was also found to increase with the increase of ER content $[113,160]$ and curing time up to $120 \mathrm{~min}$ [112].

Tensile strength ratio (TSR) based on either ASTM D4867 [104-107] or AASHTO T283 [93, 94] was widely used to evaluate moisture resistance of asphalt mixture. Superior moisture resistance for EAM than conventional asphalt mixture has generally been reported [91, 94, 148], probably due to the strong adhesion between EA and aggregates [151]. For mixtures with limestone aggregates, the enhanced moisture resistance was attributed to the increased adhesion between bitumen and aggregates while it was attributed to improved adhesion between aggregates and bitumen as well as the increased wetting of bitumen on aggregates surfaces for mixtures with siliceous aggregates [160]. Moisture 


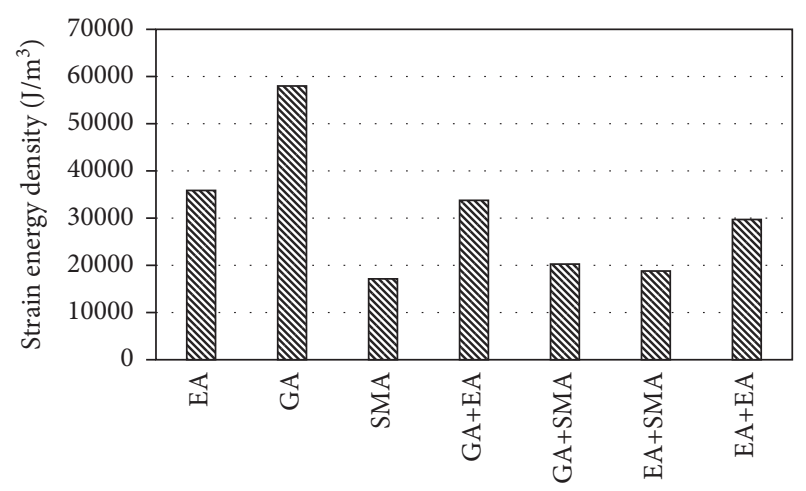

FIGURE 33: Strain energy density of asphalt mixtures [157]. Note: $\mathrm{EA}=$ epoxy asphalt; GA = Gussasphalt.

resistance was also reported to increase with the increase of ER content [91]. SPPEA exhibited around 10\% increase of TSR than small particle porous asphalt with common polymer modifier [93]. The V-S method based EAM presented inferior moisture resistance than conventional EAM [97], which was probably attributed to the voids and cracks in V-S type mixture. The addition of $12 \%$ glass fiber [104] and mineral fiber [105] can increase TSR value to $98.0 \%$, indicating great moisture resistance. For EAM with up to $70 \%$ lightweight aggregates, it still has the TSR value close to $90 \%$ [106], which was above the $80 \%$ TSR requirement. Snow-melting agent slightly improved the moisture resistance of EAM [156]. The TSR value for EAM with up to $50 \%$ glass aggregates was still higher than $80 \%$, whereas the TSR value for SBA mixture dropped below $80 \%$ with even only $16 \%$ glass aggregates [107]. The decrease in TSR for polyethylene glycol modified EAM was due to its inability to accommodate volume expansion caused by water freezing [133], which was hard and brittle at low temperatures.

Weight loss before and after freeze-thaw cycles was also employed to evaluate the moisture resistance of epoxy repair materials, and weight loss decreased with the increase of asphalt content and freeze-thaw cycles [84]. The reduced weight loss was probably attributed to the water repellent nature of asphalt and enhanced crosslink density and network structure from freeze-thaw cycles. In addition, the Vialit adhesion plate test was employed to evaluate waterinduced stripping of aggregates for chip seals and EA showed excellent adhesion to chip sealing surfaces [102]. In addition, boiling water tests based on ASTM D3625 was used to visually inspect the moisture resistance between WEA emulsion and aggregates (see Figure 34), which indicated good adhesion and confirmed its feasibility as a potential high-performance cold binder [90].

7.8. Fatigue Cracking. Superior fatigue resistance of EAM over conventional asphalt mixture $[62,148,161]$ and highstrength asphalt concrete [162] was reported, especially at high ER content $[18,62]$, which was probably attributed to the brittle failure nature of EAM. This brittle failure behavior can be illustrated by the fact that no cracking was observed during the first $7 \times 10^{6}$ loading cycles while it was completely broken in another $1 \times 10^{6}$ loading cycles [162]. It presented a higher fatigue cracking resistance at higher temperature $[161,163]$ or lower loading level $[97,157,161,164]$. Considerable fatigue life reduction was also observed after moisture damage was induced in the EAM [161]. Addition of glass fiber [104] or mineral fiber [105] can greatly enhance the fatigue resistance of EAM.

To evaluate the fatigue cracking performance of a finegraded EAM patching pavement material, three types of composite beams (see Figure 35) were tested [12]. The excellent fatigue cracking performance of fine-graded EAM patching pavement material was reflected in the longer fatigue life of beam II than beam I, whereas a significantly lower fatigue life of beam III was probably caused by the stress concentration at the vertical patching interface. Double-layered bridge deck surfacing, Gussasphalt-EA, and EA-EA showed excellent fatigue cracking resistance as compared with Gussasphalt-SMA or EA-SMA due to the low fatigue cracking resistance of SMA [157]. EAM based on the $\mathrm{V}-\mathrm{S}$ design method exhibited inferior fatigue resistance than conventional EAM [97], probably due to its skeleton structure and thus lower asphalt content.

The bending strain energy density of EAM decreased with the increase of asphalt content, which was significantly lower than that of epoxy resin concrete [7]. Fracture energy of EAM decreased after the addition of lightweight aggregates, and epoxy asphalt mastic was the main bearing structure of EAM [165].

Flexural beam fatigue tests on composite beams (gritblasted steel plate and EAM) indicated that mixtures with stiffer binder had lower deflection and thus better fatigue resistance [4]. It has also been reported that oxidized and stiffer binder often leads to lower fatigue resistance due to loss of lower molecular weight and volatile components [166]. It should be noted that this contradiction might be attributed to different aging conditions and applied loading levels. Both open-graded EAM and dense-graded EAM exhibited excellent reflective cracking resistance than conventional open-graded mixture based on Texas overlay tester [94].

As compared with the yield point of Weibull plot, $50 \%$ stiffness ratio point, and complete sample failure point, the peak phase angle point was determined to be a better criterion for fatigue life determination for EAM based on fourpoint fatigue bending tests [161].

Digital image correlation was employed to observe the crack initiation, crack propagation, and unstable fracture in three-point bending beam [167], which was verified by numerical analysis (see Figure 36). Crack tip opening displacement was found to be a reliable parameter to describe the cracking process, and crack can propagate through most of aggregates at $-10^{\circ} \mathrm{C}$.

To overcome the discontinuous element intersecting problems during cracking process modeling in classical finite element method, the extended finite element method was employed to investigate the cracking behavior of EAM $[163,164]$. Strain response from extended finite element analysis at different locations of steel plate and EAM composite beam was verified with optical fiber sensing 

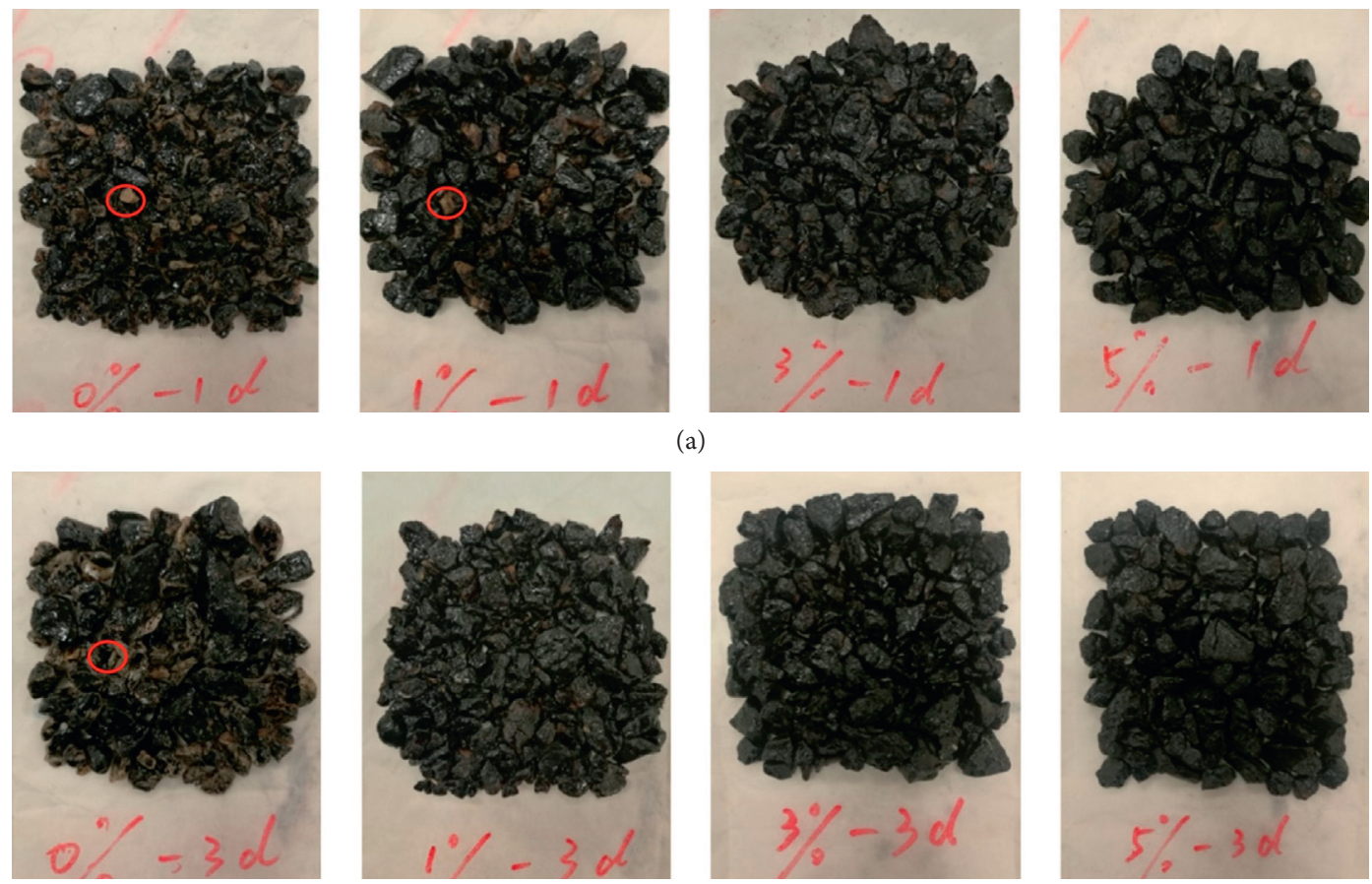

(b)

FIGURE 34: EAM after 10 min boiling (red circles = stripped aggregates) [90]: (a) 1-day bitumen emulsion mixture (from left to right: WEA0, WEA-1, WEA-3, and WEA-5); (b) 3-day bitumen emulsion mixture (from left to right: WEA-0, WEA-1, WEA-3, and WEA-5). Note: WEA-1, -3, -5 = weight of epoxy and waterborne curing agents.
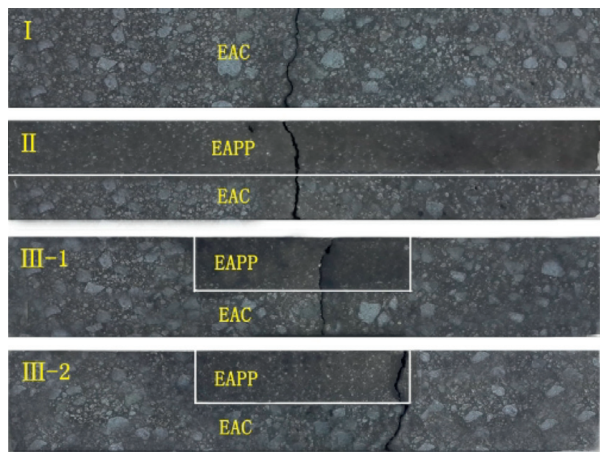

FIGURE 35: Fatigue failure forms of composite beams [12]. Note: EAC = epoxy asphalt concrete; EAPP = fine-graded epoxy asphalt pavement patching material.

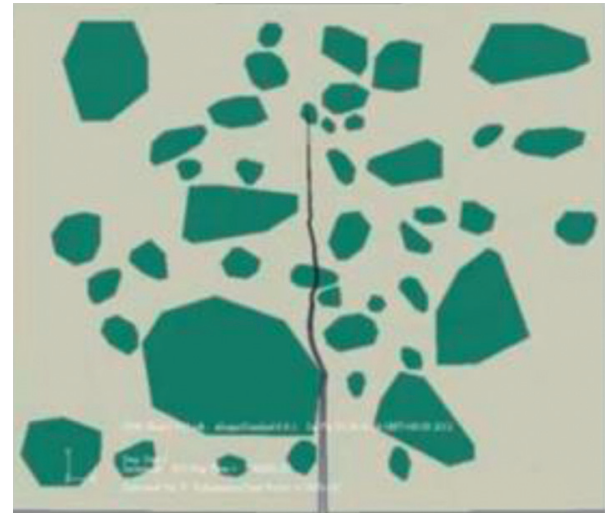

(a)

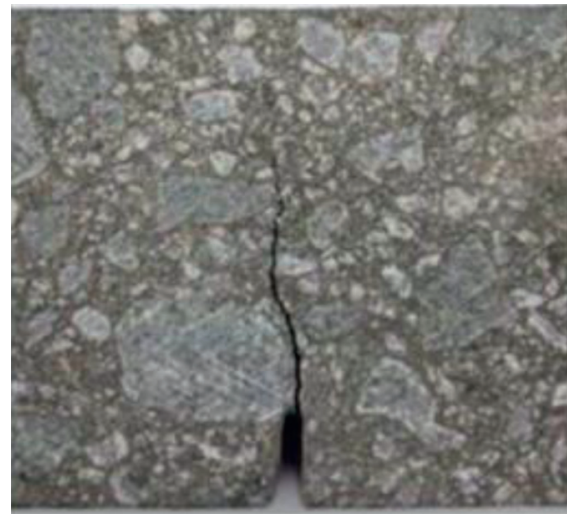

(b)

FiguRe 36: Comparison of cracking path in numerical simulation (a) and bending beam (b) [167]. 
measurements [164]. Temperature was found to have a significant impact on the fracture path morphology, and EAM fracture behavior can be separated into brittle fracture (below $5^{\circ} \mathrm{C}$ ) $[162,163]$ and viscoelastic plastic fracture (above $5^{\circ} \mathrm{C}$ ) [163].

Heavy traffic loading and extreme environmental conditions were found to be mainly responsible for the cracking of EAM surfacing on long-span bridge deck [83]. Tensile strength from the indirect tensile test has also been used to evaluate the cracking resistance of $\operatorname{EAM}[62,103,106,151]$. EAM was reported to have higher indirect tensile strength value than conventional asphalt mixture [62] and even higher than C50 cement concrete [103]. For EAM, granular lightweight aggregates exhibited higher tensile strength than that of rounded lightweight aggregates [106].

It should be recognized that EAM showed strong deformation resistance due to its thermosetting nature, which was exactly the reason why epoxy was introduced into asphalt mixture for pavement engineering. However, EAM showed lower fracture resistance in terms of low fracture energy, while EA and EAM showed better fatigue cracking resistance under cyclic loading. This seemingly contradiction has to do with failure mode of brittle materials, like EAM. It also exhibited significantly improved strength and stiffness, and it has changed asphalt material into a brittle material from the original ductile material.

\section{Summary, Conclusions, and Future Work}

In this work, components of epoxy-asphalt composite, including ER, curing agent, and modifier, were first studied, followed by a review on curing system and curing mechanism. Physicochemical, rheological, and mechanical properties of the epoxy-asphalt composite system were thoroughly studied as well. In this epoxy-asphalt composite system, the two-component phase separated microstructure was manifested not only on microscopic morphology and DSC and TGA curves but also on the rheological and mechanical behavior of EAM. However, ER played a dominant role on the performance of EA, which completely changed the behavior of the asphalt binder from being thermoplastic to be a thermosetting material for EA. In terms of mechanical behavior, EAM exhibited dominant elastic rather than generally observed viscoelastic or viscoelastic-plastic response for asphalt mixture. Therefore, EAM showed strong deformation resistance and brittle failure, especially at low temperatures. Some detailed conclusions are as follows:

(1) Properties of EA can be adjusted by carefully selecting ER, curing agent, asphalt binder, modifier, and each component proportion

(2) Curing method and curing time have a significant effect on the chemical reaction within the epoxyasphalt composite system, and mixed effects of asphalt on epoxy curing reaction were reported

(3) Lower activation energy and higher reaction rate will lead to higher degree of curing, and sulfoxide compounds are effective indicators for evaluation of oxidative curing of epoxy-asphalt composite

(4) Phase separation, dispersion of asphalt in continuous epoxy matrix, occurred in epoxy-asphalt composite after curing reaction and EA will exhibit phase inversion, dispersion of epoxy in asphalt matrix, at high asphalt content

(5) Crosslink density of EA dictates its viscosity and thus the allowable construction time

(6) EA exhibited strong elastic behavior as compared with conventional neat asphalt and SBA

(7) Glass transition temperature of epoxy-asphalt composite was closely related to its crosslink density and thus EA showed lower $T_{g}$ than ER due to asphalt mitigation effect on chemical curing

(8) The two-stage thermal degradation process of EA involves minor volatilization of light components of asphalt and degrading of uncured epoxy, and major decomposition of large asphalt molecules and epoxy network

(9) As compared with ER, better damping property, lower tensile strength, and larger elongation of EA were attributed to improved flexibility from asphalt

(10) EAM exhibited significantly higher compressive strength, much better rutting resistance, superior durability and water resistance, improved noise reduction, slightly compromised permeability, and low temperature cracking resistance as compared conventional asphalt mixture;

(11) Superior fatigue cracking resistance of EAM was probably due to its brittle fracture nature

Due to the high strength but low elongation for EA, and high stiffness but low fracture resistance for EAM, it is recommended to conduct more research on the fracture behavior of EA and EAM in the future to further understand its cracking mechanism. Measures to increase its ductility and thus fracture resistance need to be taken. Meanwhile, more efforts should be made to develop bio-based EA for sustainable development and EA that can adapt to construction conditions of asphalt paving and deformation behavior under loading conditions on pavement layers, especially on bridge decks. Also, correlation between microproperties of EA, e.g., curing characteristics and morphology, and macroproperties of EA and EAM, e.g., tensile strength and fracture behavior, need to be established. Proper application of EA in paving industry has been the focus of pavement engineers without paying much attention to the curing mechanism and how the curing behavior can be adjusted. This needs interdisciplinary cooperation between pavement engineers and chemical engineers to retain the high strength of epoxy without compromising its cracking resistance. Furthermore, numerical experiments/analysis, which can complement traditional experiments, need to be conducted to understand the behavior of EA and EAM without the tremendous efforts normally needed for conventional tests. Lastly, EA as a 
composite material, compatibility characterization, factors affecting compatibility, and effects of compatibility on rheological and mechanical strength need to be well studied to produce EA that can be easily adapted to asphalt paving industry.

\section{Abbreviations}

AASHTO: American Association of State Highway and Transportation Officials

KL-COOH: Kraft lignin-based polycarboxylic acid

AL-3040: Hydrogenated bisphenol A epoxy resin

LSCM: $\quad$ Laser scanning confocal microscope

ARP: $\quad$ Silane coupling agent surface-treated rubber particles

LSP: $\quad$ Liquid state sulfur polymer

ASTM: $\quad$ American society for testing and materials

MAH: $\quad$ Maleic anhydride

ATH: $\quad$ Aluminum trihydroxide

MeTHPA: Methyl-tetrahydrophthalic anhydride

ATT: Attapulgite

MTD: $\quad$ Mean texture depth

$\mathrm{BPN}$ :

NMA:

BrSBS:

NMAS:

CEA:

OGFC:

CTB:

PDL:

DBDPE:

PFA:

DGEBA:

British pendulum number

Nadic methyl anhydride

Brominated styrene-butadiene-styrene

triblock copolymer

Nominal maximum aggregate size

Cold-mixed epoxy asphalt

Open-grade friction course

Cement treated base

Partially depolymerized lignin

DMA:

REAC: $\quad$ Rubber-like thermosetting epoxy asphalt

Decabromodiphenyl ethane

Polymerized fatty acid

Diglycidyl ether of bisphenol A per hundred resin composite

DSC: Differential scanning calorimetry

RPFR: Reactive polymeric flame retardant

DSR: Dynamic shear rheometer

$\mathrm{Sb}_{2} \mathrm{O}_{3}$ : Antimony trioxide

EA: $\quad$ Epoxy asphalt

SBA: $\quad$ SBS-modified asphalt

EAM: $\quad$ Epoxy asphalt mixture

SBR: $\quad$ Styrene-butadiene rubber

EAR: $\quad$ Epoxy asphalt rubber

SBS: $\quad$ Styrene-butadiene-styrene

ECH: $\quad$ Epichlorohydrin

SEM: $\quad$ Scanning electron microscope

ER: $\quad$ Epoxy resin

SMA: $\quad$ Stone matrix asphalt

ESA: $\quad$ Epoxy SBS-modified asphalt

SM-HER: $\quad$ Shape memory hydrogenated epoxy resin

ESO: $\quad$ Epoxidized soybean oil

SPPEA: $\quad$ Small particle porous epoxy asphalt

EVA: $\quad$ Ethylene vinyl acetate copolymer

$T_{\mathrm{g}}$ Glass transition temperature

FEA: $\quad$ Foamed epoxy asphalt
TGA: Thermogravimetric analysis

FM: $\quad$ Fluorescence microscopy

TOA: $\quad$ Tung oil anhydride

FTIR: $\quad$ Fourier transform infrared

TSR: Tensile strength ratio

H102: Second-generation aliphatic hyperbranched polyester with 12 end hydroxyl groups

UTASS: Ultra-thin antiskid surface layer

H102- $\mathrm{C}_{18} \quad \mathrm{H} 102$ with terminated fatty alkyl end groups

$\mathrm{H} 102$ :

V-S method: Volume design method

$\mathrm{H} 102-\mathrm{C}_{2}$ : $\quad \mathrm{H} 102$ with terminated acetyl end groups

WCO-EP: Waste cooking oil-based epoxy resin

HBP: Hyperbranched polyester

WEA: Waterborne epoxy resin emulsified asphalt

HMEA: Hot-mixed epoxy asphalt

WER: Waterborne epoxy resin

IDT: Initial decomposition temperature

WMEA: Warm-mixed epoxy asphalt

JH-230: Polypropylene glycol diglycidyl ether

ZB: $\quad$ Zinc borate.

\section{Data Availability}

No data were used to support this study.

\section{Conflicts of Interest}

The authors declare that they have no conflicts of interest.

\section{Acknowledgments}

This research was supported by the National Natural Science Foundation of China (52078047) and China Postdoctoral Science Foundation Grant (2013M542312 and 2014T70897).

\section{References}

[1] M. H. Irfan, Chemistry and Technology of Thermosetting Polymers in Construction Applications, Springer Netherlands, Dordrecht, Netherlands, 1998.

[2] T. Takeichi and N. Furukawa, "Epoxy resins and phenolformaldehyde resins," in Polymer Science: A Comprehensive Reference, K. Matyjaszewski and M. Möller, Eds., Elsevier, Amsterdam, Netherland, 2012.

[3] F.-L. Jin, X. Li, and S.-J. Park, "Synthesis and application of epoxy resins: a review," Journal of Industrial and Engineering Chemistry, vol. 29, pp. 1-11, 2015.

[4] C. Chen, W. O. Eisenhut, K. Lau, A. Buss, and J. Bors, "Performance characteristics of epoxy asphalt paving material for thin orthotropic steel plate decks," International Journal of Pavement Engineering, vol. 21, no. 3, pp. 397-407, 2020.

[5] Y. Xiao, M. F. C. Van De Ven, A. A. A. Molenaar, Z. Su, and F. Zandvoort, "Characteristics of two-component epoxy modified bitumen," Materials and Structures, vol. 44, no. 3, pp. 611-622, 2011.

[6] Y. Kang, Z. Chen, Z. Jiao, and W. Huang, "Rubber-like thermosetting epoxy asphalt composites exhibiting atypical yielding behaviors," Journal of Applied Polymer Science, vol. 116, no. 3, pp. 1678-1685, 2010. 
[7] H. Yin, Y. Zhang, Y. Sun et al., "Performance of hot mix epoxy asphalt binder and its concrete," Materials and Structures, vol. 48, no. 11, pp. 3825-3835, 2015.

[8] P. Herrington and D. Alabaster, "Epoxy modified opengraded porous asphalt," Road Materials and Pavement Design, vol. 9, no. 3, pp. 481-498, 2008.

[9] I. T. Forum, "Long-life surfacings for roads: field test results," in ITF Research ReportsOECD Publishing, Paris, France, 2017.

[10] S. Pradhan, P. Pandey, S. Mohanty, and S. K. Nayak, "Insight on the chemistry of epoxy and its curing for coating applications: a detailed investigation and future perspectives," Polymer-, vol. 55, no. 8, pp. 862-877, 2016.

[11] R. Thomas, C. Sinturel, S. Thomas, and E. M. Sadek El Akiaby, "Introduction, micro- and nanostructured epoxy/ rubber blends," in Micro- and Nanostructured Epoxy/Rubber Blends, S. Thomas, C. Sinturel, and R. Thomas, Eds., Wiley VCH, Weinheim, Germany, 2014.

[12] Y. Yang, Z. Qian, and X. Song, “A pothole patching material for epoxy asphalt pavement on steel bridges: fatigue test and numerical analysis," Construction and Building Materials, vol. 94, pp. 299-305, 2015.

[13] Y. Zhang, Y. Sun, K. Xu et al., "Brucite modified epoxy mortar binders: flame retardancy, thermal and mechanical characterization," Construction and Building Materials, vol. 93, pp. 1089-1096, 2015.

[14] Y. Liu, J. Zhang, R. Chen, J. Cai, Z. Xi, and H. Xie, "Ethylene vinyl acetate copolymer modified epoxy asphalt binders: phase separation evolution and mechanical properties," Construction and Building Materials, vol. 137, pp. 55-65, 2017.

[15] Y. Liu, J. Zhang, Y. Jiang et al., "Investigation of secondary phase separation and mechanical properties of epoxy SBSmodified asphalts," Construction and Building Materials, vol. 165, pp. 163-172, 2018.

[16] H. Yin, H. Jin, C. Wang et al., "Thermal, damping, and mechanical properties of thermosetting epoxy-modified asphalts," Journal of Thermal Analysis and Calorimetry, vol. 115, no. 2, pp. 1073-1080, 2014.

[17] Y. Kang, M. Song, L. Pu, and T. Liu, "Rheological behaviors of epoxy asphalt binder in comparison of base asphalt binder and SBS modified asphalt binder," Construction and Building Materials, vol. 76, pp. 343-350, 2015.

[18] J. P. Wu, P. R. Herrington, and D. Alabaster, "Long-term durability of epoxy-modified open-graded porous asphalt wearing course," International Journal of Pavement Engineering, vol. 20, no. 8, pp. 920-927, 2019.

[19] M. G. González, J. Cabanelas, and J. Baselga, “Applications of FTIR on epoxy resins - identification, monitoring the curing process, phase separation and water uptake," in Infrared Spectroscopy-Materials Science, Engineering and Technology, T. Theophanides, Ed., IntechOpen, Rijeka, Croatia, 2012.

[20] P. Cong, W. Luo, P. Xu, and Y. Zhang, "Chemical and physical properties of hot mixing epoxy asphalt binders," Construction and Building Materials, vol. 198, pp. 1-9, 2019.

[21] H. Q. Pham and M. J. Marks, "Epoxy resins," Encyclopedia of Polymer Science and Technology, vol. 9, 2004.

[22] B. Madhava Rao, H. Lokesh, S. Kosaraju, K. S. N. Murthy, and M. Jagadish, "Development and characterization of Flame retardant epoxy resin for battery terminal sealing application," American Journal of Engineering Research, vol. 8, no. 1, pp. 260-266, 2019.
[23] W. Zhou, S. Qi, H. Zhao, N. Liu, and M. Zhang, "Research progress of low temperature curing agent for epoxy resin composites," China Adhesives, vol. 16, no. 1, pp. 44-47, 2007.

[24] S. J. Tucker, B. Fu, S. Kar, S. Heinz, and J. S. Wiggins, "Ambient cure POSS-epoxy matrices for marine composites," Composites Part A: Applied Science and Manufacturing, vol. 41, no. 10, pp. 1441-1446, 2010.

[25] H. Kwon, A. S. Lee, J. H. Lee et al., "Characterization of liquid state sulfur polymer/epoxy blend as asphalt pavement materials," Journal of Industrial and Engineering Chemistry, vol. 53, pp. 386-391, 2017.

[26] L. Chen, H. Tian, Q. Liu, and J. Wang, "Curing reaction kinetics of epoxy resin using dicyandiamide modified by aromatic amines," Wuhan University Journal of Natural Sciences, vol. 12, no. 6, pp. 1105-1108, 2007.

[27] X. Yu, F. Dong, G. Ding, S. Liu, and S. Shen, "Rheological and microstructural properties of foamed epoxy asphalt," Construction and Building Materials, vol. 114, pp. 215-222, 2016.

[28] L. Jiang, K. Hu, Z. Liu, Y. Yuan, C. Zhou, and J. Lei, “Aliphatic diamide as novel asphalt-modified epoxy curing agent for enhanced performance," Advances in Polymer Technology, vol. 37, no. 3, pp. 830-836, 2018.

[29] K. Hu, L. Bao, X. Chen, Y. Xiao, and J. Lei, "Synthesis of castor oil-derived decanediamide as a novel flexible asphaltmodified epoxy resin curing agent," Advances in Polymer Technology, vol. 37, no. 4, pp. 1092-1098, 2018.

[30] S. Li, K. Huang, X. Yang, M. Li, and J. Xia, "Design, preparation and characterization of novel toughened epoxy asphalt based on a vegetable oil derivative for bridge deck paving," RSC Advances, vol. 4, no. 84, pp. 44741-44749, 2014.

[31] J. Xin, M. Li, R. Li, M. P. Wolcott, and J. Zhang, "Green epoxy resin system based on lignin and tung oil and its application in epoxy asphalt," ACS Sustainable Chemistry \& Engineering, vol. 4, no. 5, pp. 2754-2761, 2016.

[32] A. A. Fuhaid, Q. Lu, and S. Luo, "Laboratory evaluation of biobased epoxy asphalt binder for asphalt pavement," Journal of Materials in Civil Engineering, vol. 30, no. 7, Article ID 06018007, 2018.

[33] W. Zhou, Y. Xia, F.-C. Tsai, T. Jiang, H. Zhao, and J. Wen, "Effects of compound curing agent on the thermo-mechanical properties and structure of epoxy asphalt," International Journal of Pavement Engineering, vol. 18, no. 10, pp. 928-936, 2017.

[34] Y. Lei and X. Cao, "Preparation of epoxy-resin concrete using microwave curing method and its pavement performance evaluation," Journal of Materials in Civil Engineering, vol. 27, no. 8, Article ID 04014221, 2015.

[35] X. Du, P. Xu, P. Cong, and Z. Zhou, "Compatibilization and toughness modification of linear aliphatic epoxy compound on paving epoxy asphalt," Materials and Structures, vol. 53, no. 2, p. 42, 2020.

[36] Y. Zhang, X. Pan, Y. Sun et al., "Flame retardancy, thermal, and mechanical properties of mixed flame retardant modified epoxy asphalt binders," Construction and Building Materials, vol. 68, pp. 62-67, 2014.

[37] Y. Jiang, X. Han, J. Gong et al., "Laboratory investigation of epoxy asphalt binder modified by brominated SBS," Construction and Building Materials, vol. 228, Article ID 116733, 2019.

[38] G. Ding, X. Yu, J. Si, J. Mei, J. Wang, and B. Chen, "Influence of epoxy soybean oil modified nano-silica on the compatibility of cold-mixed epoxy asphalt," Materials and Structures, vol. 54, no. 1, p. 16, 2021. 
[39] H. Zhang, G. Zhang, F. Han, Z. Zhang, and W. Lv, "A lab study to develop a bridge deck pavement using bisphenol A unsaturated polyester resin modified asphalt mixture," Construction and Building Materials, vol. 159, pp. 83-98, 2018.

[40] G. Odian, Principles of Polymerization, Wiley-Interscience, Hoboken, NJ, USA, 4th edition, 2004.

[41] Z. Ahmad, M. P. Ansell, and D. Smedley, "Effect of nanoand micro-particle additions on moisture absorption in thixotropic room temperature cure epoxy-based adhesives for bonded-in timber connections," International Journal of Adhesion and Adhesives, vol. 30, no. 6, pp. 448-455, 2010.

[42] C. Chen, B. Li, C. Wang, S. Iwasaki, M. Kanari, and D. Lu, $U V$ and Thermal Cure Epoxy Adhesives, Intech Open, London, UK, 2019.

[43] Á. García, E. Schlangen, M. Van de Ven, and Q. Liu, "Electrical conductivity of asphalt mortar containing conductive fibers and fillers," Construction and Building Materials, vol. 23, no. 10, pp. 3175-3181, 2009.

[44] K. Liu, C. Fu, D. Dai et al., "Induction heating performance of asphalt pavements incorporating electrically conductive and magnetically absorbing layers," Construction and Building Materials, vol. 229, Article ID 116805, 2019.

[45] H. Li, J. Yu, S. Wu et al., "Study on the gradient heating and healing behaviors of asphalt concrete induced by induction heating," Construction and Building Materials, vol. 208, pp. 638-645, 2019.

[46] K. Liu, C. Fu, P. Xu, S. Li, and M. Huang, "An ecofriendliness inductive asphalt mixture comprising waste steel shavings and waste ferrites," Journal of Cleaner Production, vol. 283, Article ID 124639, 2021.

[47] P. Apostolidis, X. Liu, M. van de Ven, S. Erkens, and T. Scarpas, "Control the crosslinking of epoxy-asphalt via induction heating," International Journal of Pavement Engineering, vol. 21, no. 8, pp. 956-965, 2020.

[48] Y. Sun, S. Wu, Q. Liu, J. Hu, Y. Yuan, and Q. Ye, "Snow and ice melting properties of self-healing asphalt mixtures with induction heating and microwave heating," Applied Thermal Engineering, vol. 129, pp. 871-883, 2018.

[49] M. T. Bevacqua, T. Isernia, F. G. Praticò, and S. Zumbo, “A method for bottom-up cracks healing via selective and deep microwave heating," Automation in Construction, vol. 121, Article ID 103426, 2021.

[50] L. H. Judith, Comparison of thermal and Microwave Processing of Polyester Resins, University of Manchester, Manchester, England, 1999.

[51] T. Ai, S. Xiang, and Z. Wang, "Effects of microwave curing on the chemical and physical properties of epoxy asphalt," Journal of Materials in Civil Engineering, vol. 28, no. 11, Article ID 06016013, 2016.

[52] B. Golaz, V. Michaud, and J.-A. E. Månson, "Photo-polymerized epoxy primer for adhesion improvement at thermoplastics/metallic wires interfaces," Composites Part A: Applied Science and Manufacturing, vol. 48, pp. 171-180, 2013.

[53] D. Morselli, F. Bondioli, M. Sangermano, and M. Messori, "Photo-cured epoxy networks reinforced with $\mathrm{TiO} 2$ in-situ generated by means of non-hydrolytic sol-gel process," Polymer, vol. 53, no. 2, pp. 283-290, 2012.

[54] Z. Qian, L. Chen, Y. Wang, and J. Shen, "Curing reaction model of epoxy asphalt binder," Journal of Wuhan University of Technology-Materials Science Edition, vol. 27, no. 4, pp. 763-767, 2012.
[55] P. Apostolidis, X. Liu, C. Kasbergen, M. F. C. van de Ven, G. Pipintakos, and A. Scarpas, "Chemo-rheological study of hardening of epoxy modified bituminous binders with the finite element method," Transportation Research Record: Journal of the Transportation Research Board, vol. 2672, no. 28, pp. 190-199, 2018.

[56] J. Si, Y. Li, and X. Yu, "Curing behavior and mechanical properties of an eco-friendly cold-mixed epoxy asphalt," Materials and Structures, vol. 52, no. 4, p. 81, 2019.

[57] X.-y. Zhou, B. Ma, K. Wei, Y.-z. Bo, Z.-p. You, and M. Yu, "Curing process and properties of hydrogenated bisphenol a epoxy resin particles by an interfacial polymerization method for asphalt pavements," Construction and Building Materials, vol. 147, pp. 448-456, 2017.

[58] P. Apostolidis, X. Liu, S. Erkens, and A. Scarpas, "Evaluation of epoxy modification in bitumen," Construction and Building Materials, vol. 208, pp. 361-368, 2019.

[59] X. Zhou, S. Wu, G. Liu, and P. Pan, "Molecular simulations and experimental evaluation on the curing of epoxy bitumen," Materials and Structures, vol. 49, no. 1, pp. 241-247, 2016.

[60] Y. Kang, W. Fei, and C. Zhiming, "Performance optimization and bimodal morphology of advanced epoxy asphalt," in Proceedings of the International Workshop on Energy and Environment in the Development of Sustainable Asphalt Pavements, Xi'an, China, January 2010.

[61] Q. Huang, Z. Qian, L. Chen et al., "Evaluation of epoxy asphalt rubber with silane coupling agent used as tack coat for seasonally frozen orthotropic steel bridge decks," Construction and Building Materials, vol. 241, Article ID 117957, 2020.

[62] P. Apostolidis, X. Liu, S. Erkens, and A. Scarpas, "Use of epoxy asphalt as surfacing and tack coat material for roadway pavements," Construction and Building Materials, vol. 250, Article ID 118936, 2020.

[63] Q. Zhang, Y.-h. Xu, and Z.-g. Wen, "Influence of waterborne epoxy resin content on performance of waterborne epoxy resin compound SBR modified emulsified asphalt for tack coat," Construction and Building Materials, vol. 153, pp. 774-782, 2017.

[64] G. Wang, D. y. Wang, and D. n. Li, "Laboratory study and performance evaluation of a new type of prime coat material used on cement treated base," Construction and Building Materials, vol. 147, pp. 588-597, 2017.

[65] R. Li, A. Bahadori, J. Xin, K. Zhang, B. Muhunthan, and J. Zhang, "Characteristics of bioepoxy based on waste cooking oil and lignin and its effects on asphalt binder," Construction and Building Materials, vol. 251, Article ID 118926, 2020.

[66] M. Çubuk, M. Gürü, and M. K. Çubuk, "Improvement of bitumen performance with epoxy resin," Fuel, vol. 88, no. 7, pp. 1324-1328, 2009.

[67] M. Huang, X. Wen, and L. Wang, "Influence of foaming effect, operation time and health preserving properties of foam epoxy asphalt mixtures," Construction and Building Materials, vol. 151, pp. 931-938, 2017.

[68] J. Si, Z. Jia, J. Wang et al., "Comparative analysis of coldmixed epoxy and epoxy SBS-modified asphalts: curing rheology, thermal, and mechanical properties," Construction and Building Materials, vol. 176, pp. 165-171, 2018.

[69] J. Gong, Y. Liu, Q. Wang et al., "Performance evaluation of warm mix asphalt additive modified epoxy asphalt rubbers," Construction and Building Materials, vol. 204, pp. 288-295, 2019. 
[70] C. Li, X. Han, J. Gong et al., "Impact of waste cooking oil on the viscosity, microstructure and mechanical performance of warm-mix epoxy asphalt binder," Construction and Building Materials, vol. 251, Article ID 118994, 2020.

[71] J. Si, Y. Li, J. Wang, A. R. Niyigena, X. Yu, and R. Jiang, "Improving the compatibility of cold-mixed epoxy asphalt based on the epoxidized soybean oil," Construction and Building Materials, vol. 243, Article ID 118235, 2020.

[72] X. Yu, J. Wang, J. Si, J. Mei, G. Ding, and J. Li, "Research on compatibility mechanism of biobased cold-mixed epoxy asphalt binder," Construction and Building Materials, vol. 250, Article ID 118868, 2020.

[73] Y. Kang, Q. Wu, R. Jin, P. Yu, and J. Cheng, "Rubber-like quasi-thermosetting polyetheramine-cured epoxy asphalt composites capable of being opened to traffic immediately," Scientific Reports, vol. 6, no. 1, Article ID 18882, 2016.

[74] M. Song, R. Liang, J. Deng, and Y. Kang, "Sealed accelerants facilitate epoxy asphalt concretes opening to traffic quickly," Construction and Building Materials, vol. 147, pp. 1-8, 2017.

[75] P. Cong, "Compatibility and mechanical properties of epoxy resin modified asphalt binders," International Journal of Pavement Research and Technology, vol. 4, no. 2, pp. 118-123, 2011.

[76] Y. Kang, Z. Chen, Z. Jiao, and W. Huang, "Rubber-like thermosetting epoxy asphalt composites exhibiting atypical yielding behaviors," Journal of Applied Polymer Science, vol. 116, pp. 1678-1685, 2010.

[77] B. Ma, X. Zhou, K. Wei, Y. Bo, and Z. You, "Analysis of preparation and properties on shape memory hydrogenated epoxy resin used for asphalt mixtures," Applied Sciences, vol. 7, no. 6, p. 523, 2017.

[78] Y. Kang, R. Jin, Q. Wu et al., “Anhydrides-cured bimodal rubber-like epoxy asphalt composites: from thermosetting to quasi-thermosetting," Polymers, vol. 8, no. 4, p. 104, 2016.

[79] J. Yu, P. Cong, and S. Wu, "Laboratory investigation of the properties of asphalt modified with epoxy resin," Journal of Applied Polymer Science, vol. 113, no. 6, pp. 3557-3563, 2009.

[80] Y. Jiang, Y. Liu, J. Gong et al., "Microstructures, thermal and mechanical properties of epoxy asphalt binder modified by SBS containing various styrene-butadiene structures," $M a$ terials and Structures, vol. 51, no. 4, p. 86, 2018.

[81] Y. Liu, Z. Xi, J. Cai, and H. Xie, "Laboratory investigation of the properties of epoxy asphalt rubber (EAR)," Materials and Structures, vol. 50, no. 5, p. 219, 2017.

[82] P. Xu, X. Zhu, P. Cong, X. Du, and R. Zhang, "Modification of alkyl group terminated hyperbranched polyester on paving epoxy asphalt," Construction and Building Materials, vol. 165, pp. 295-302, 2018.

[83] C. Yin, H. Zhang, and Y. Pan, "Cracking mechanism and repair techniques of epoxy asphalt on steel bridge deck pavement," Transportation Research Record: Journal of the Transportation Research Board, vol. 2550, no. 1, pp. 123-130, 2016.

[84] Y. Wang, J. Ye, Y. Liu, X. Qiang, and L. Feng, "Influence of freeze-thaw cycles on properties of asphalt-modified epoxy repair materials," Construction and Building Materials, vol. 41, pp. 580-585, 2013.

[85] Y. Bi, R. Li, S. Han, J. Pei, and J. Zhang, "Development and performance evaluation of cold-patching materials using waterborne epoxy-emulsified asphalt mixtures," Materials, vol. 13, no. 5, p. 1224, 2020.

[86] Z. Zhaoying, H. Yuhui, L. Bing, and C. Guangming, "Studies on particle size of waterborne emulsions derived from epoxy resin," European Polymer Journal, vol. 37, no. 6, pp. 1207-1211, 2001.

[87] C. Hu, J. Ma, H. Jiang, Z. Chen, and J. Zhao, "Evaluation of Nano- $\mathrm{TiO}_{2}$ modified waterborne epoxy resin as fog seal and exhaust degradation material in asphalt pavement," Journal of Testing and Evaluation, vol. 45, no. 1, pp. 260-267, 2017.

[88] M. Liu, S. Han, Z. Wang, W. Ren, and W. Li, "Performance evaluation of new waterborne epoxy resin modified emulsified asphalt micro-surfacing," Construction and Building Materials, vol. 214, pp. 93-100, 2019

[89] M. Liu, S. Han, J. Pan, and W. Ren, "Study on cohesion performance of waterborne epoxy resin emulsified asphalt as interlayer materials," Construction and Building Materials, vol. 177, pp. 72-82, 2018.

[90] R. Li, Z. Leng, Y. Zhang, and X. Ma, "Preparation and characterization of waterborne epoxy modified bitumen emulsion as a potential high-performance cold binder," Journal of Cleaner Production, vol. 235, pp. 1265-1275, 2019.

[91] Z. Zhang, S. Wang, and G. Lu, "Properties of new cold patch asphalt liquid and mixture modified with waterborne epoxy resin," International Journal of Pavement Engineering, vol. 21, pp. 1-11, 2019.

[92] Y. Sun, Y. Liu, Y. Jiang, K. Xu, Z. Xi, and H. Xie, "Thermal and mechanical properties of natural fibrous nanoclay reinforced epoxy asphalt adhesives," International Journal of Adhesion and Adhesives, vol. 85, pp. 308-314, 2018.

[93] Z. Qian and Q. Lu, "Design and laboratory evaluation of small particle porous epoxy asphalt surface mixture for roadway pavements," Construction and Building Materials, vol. 77, pp. 110-116, 2015.

[94] S. Luo, Q. Lu, and Z. Qian, "Performance evaluation of epoxy modified open-graded porous asphalt concrete," Construction and Building Materials, vol. 76, pp. 97-102, 2015.

[95] S. Luo, Z.-d. Qian, and Y.-c. Xue, "Performance evaluation of open-graded epoxy asphalt concrete with two nominal maximum aggregate sizes," Journal of Central South University, vol. 22, no. 11, pp. 4483-4489, 2015.

[96] Y. Zhao, T. Xu, X. Huang, and Z. Li, "Gradation design of the aggregate skeleton in asphalt mixture," Journal of Testing and Evaluation, vol. 40, no. 7, pp. 1071-1076, 2012.

[97] Z.-d. Qian, Y. Liu, C.-b. Liu, and D. Zheng, "Design and skid resistance evaluation of skeleton-dense epoxy asphalt mixture for steel bridge deck pavement," Construction and Building Materials, vol. 114, pp. 851-863, 2016.

[98] Y. Xiao, M. F. C. van de Ven, A. A. A. Molenaar, Z. Su, and K. Chang, "Design approach for epoxy modified bitumen to be used in antiskid surfaces on asphalt pavement," Construction and Building Materials, vol. 41, pp. 516-525, 2013.

[99] M. M. Sprinkel, K. K. McGhee, and E. D. de León Izeppi, "Virginia's experience with high-friction surface treatments," Transportation Research Record: Journal of the Transportation Research Board, vol. 2481, no. 1, pp. 100-106, 2015.

[100] Y. Xiao, M. F. C. van de Ven, A. A. A. Molenaar, and S. P. Wu, "Possibility of using epoxy modified bitumen to replace tar-containing binder for pavement antiskid surfaces," Construction and Building Materials, vol. 48, pp. 59-66, 2013.

[101] Y. Liu, Z. Qian, X. Shi, Y. Zhang, and H. Ren, "Developing cold-mixed epoxy resin-based ultra-thin antiskid surface layer for steel bridge deck pavement," Construction and Building Materials, vol. 291, Article ID 123366, 2021.

[102] S. A. Bagshaw, P. R. Herrington, and J. P. Wu, "Preliminary examination of chipseals prepared with epoxy-modified 
bitumen," Construction and Building Materials, vol. 88, pp. 232-240, 2015.

[103] L. Chen, Z. Qian, and H. Hu, "Epoxy asphalt concrete protective course used on steel railway bridge," Construction and Building Materials, vol. 41, pp. 125-130, 2013.

[104] X. Wang, R. Wu, and L. Zhang, "Development and performance evaluation of epoxy asphalt concrete modified with glass fibre," Road Materials and Pavement Design, vol. 20, no. 3, pp. 715-726, 2019.

[105] Y. Xue and Z. Qian, "Development and performance evaluation of epoxy asphalt concrete modified with mineral fiber," Construction and Building Materials, vol. 102, pp. 378-383, 2016.

[106] Z. Qian, C. Chen, C. Jiang, and A. d. F. Smit, "Development of a lightweight epoxy asphalt mixture for bridge decks," Construction and Building Materials, vol. 48, pp. 516-520, 2013.

[107] Z. Min, L. Zhou, Q. Wang, and Y. Zhang, "Performance evaluation of epoxy-asphalt mixture blended with glass aggregate," Journal of Materials in Civil Engineering, vol. 31, no. 6, Article ID 04019083, 2019.

[108] W. Su, X. Han, J. Gong et al., "Toughening epoxy asphalt binder using core-shell rubber nanoparticles," Construction and Building Materials, vol. 258, Article ID 119716, 2020.

[109] A. Tercjak, "Phase separation and morphology development in thermoplastic-modified thermosets," in Thermosets, Q. Guo, Ed., Elsevier, Amsterdam, Netherland, Second edition, 2018.

[110] J. Zhang, W. Su, Y. Liu et al., "Laboratory investigation on the microstructure and performance of SBS modified epoxy asphalt binder," Construction and Building Materials, vol. 270, Article ID 121378, 2021.

[111] K. Yamanaka and T. Inoue, "Phase separation mechanism of rubber-modified epoxy," Journal of Materials Science, vol. 25, no. 1, pp. 241-245, 1990.

[112] J. Wei and Y. Zhang, "Study on the curing process of epoxy asphalt," Journal of Testing and Evaluation, vol. 40, no. 7, pp. 1-9, 2012.

[113] P. Cong, Y. Tian, N. Liu, and P. Xu, "Investigation of epoxyresin-modified asphalt binder," Journal of Applied Polymer Science, vol. 133, no. 21, 2016.

[114] P. Apostolidis, X. Liu, S. Erkens, and A. Scarpas, "Characterization of epoxy-asphalt binders by differential scanning calorimetry," Construction and Building Materials, vol. 249, Article ID 118800, 2020.

[115] J.-F. Masson, G. M. Polomark, and P. Collins, "Time-dependent microstructure of bitumen and its fractions by modulated differential scanning calorimetry," Energy \& Fuels, vol. 16, no. 2, pp. 470-476, 2002.

[116] R. Thomas, D. Yumei, H. Yuelong et al., "Miscibility, morphology, thermal, and mechanical properties of a DGEBA based epoxy resin toughened with a liquid rubber," Polymer, vol. 49, no. 1, pp. 278-294, 2008.

[117] Y.-L. Liu, C.-S. Wu, Y.-S. Chiu, and W.-H. Ho, "Preparation, thermal properties, and flame retardance of epoxy-silica hybrid resins," Journal of Polymer Science Part A: Polymer Chemistry, vol. 41, no. 15, pp. 2354-2367, 2003.

[118] H.-Y. Zhao, Y. Cao, S. P. Sit, Q. Lineberry, and W.-P. Pan, "Thermal characteristics of bitumen pyrolysis," Journal of Thermal Analysis and Calorimetry, vol. 107, no. 2, pp. 541547, 2012.

[119] G. Jing-Song, F. Wei-Biao, and Z. Bei-Jing, "A study on the pyrolysis of asphalt,” Fuel, vol. 82, no. 1, pp. 49-52, 2003.

[120] S. Seidelt, M. Müller-Hagedorn, and H. Bockhorn, "Description of tire pyrolysis by thermal degradation behaviour of main components," Journal of Analytical and Applied Pyrolysis, vol. 75, no. 1, pp. 11-18, 2006.

[121] S. Zavareh and G. Vahdat, "Toughening of brittle epoxy using bitumen as a new modifier," Journal of Reinforced Plastics and Composites, vol. 31, no. 4, pp. 247-258, 2012.

[122] Y. Sun, Y. Zhang, K. Xu et al., "Thermal, mechanical properties, and low-temperature performance of fibrous nanoclay-reinforced epoxy asphalt composites and their concretes," Journal of Applied Polymer Science, vol. 132, no. 12, 2015.

[123] J. Gong, Y. Liu, Y. Jiang et al., "Performance of epoxy asphalt binder containing warm-mix asphalt additive," International Journal of Pavement Engineering, vol. 22, no. 2, pp. 223-232, 2021.

[124] J. Yu, P. Cong, S. Wu, and S. Cheng, "Curing behavior of epoxy asphalt," Journal of Wuhan University of TechnologyMaterials Science Edition, vol. 24, no. 3, pp. 462-465, 2009.

[125] P. Apostolidis, X. Liu, S. Erkens, and T. Scarpas, "Oxidative aging of epoxy asphalt," International Journal of Pavement Engineering, pp. 1-11, 2020.

[126] Q. Huang, Z. Qian, Y. Yang, and D. Zheng, "Investigation of warm mix epoxy asphalt compaction with gyratory compactor and charge coupled photoelectric imaging," Construction and Building Materials, vol. 271, Article ID 121506, 2021.

[127] W. Huang, W. Guo, and Y. Wei, "Prediction of paving performance for epoxy asphalt mixture by its time- and temperature-dependent properties," Journal of Materials in Civil Engineering, vol. 32, no. 3, Article ID 04020017, 2020.

[128] Y. Jiang, R. Zhao, Z. Xi et al., "Improving toughness of epoxy asphalt binder with reactive epoxidized SBS," Materials and Structures, vol. 54, no. 4, p. 145, 2021.

[129] Y. Sun, J. Gong, Y. Liu et al., "Viscous, damping, and mechanical properties of epoxy asphalt adhesives containing different penetration-grade asphalts," Journal of Applied Polymer Science, vol. 136, no. 5, Article ID 47027, 2019.

[130] D. O. Larsen, J. L. Alessandrini, A. Bosch, and M. S. Cortizo, "Micro-structural and rheological characteristics of SBSasphalt blends during their manufacturing," Construction and Building Materials, vol. 23, no. 8, pp. 2769-2774, 2009.

[131] S. Biro, T. Gandhi, and S. Amirkhanian, "Determination of zero shear viscosity of warm asphalt binders," Construction and Building Materials, vol. 23, no. 5, pp. 2080-2086, 2009.

[132] C. Peiliang, Y. Jianying, and C. Shuanfa, "Effects of epoxy resin contents on the rheological properties of epoxy-asphalt blends," Journal of Applied Polymer Science, vol. 118, no. 6, pp. 3678-3684, 2010.

[133] Z. Min, Q. Wang, Y. Xie, J. Xie, and B. Zhang, "Influence of polyethylene glycol (PEG) chain on the performance of epoxy asphalt binder and mixture," Construction and Building Materials, vol. 272, Article ID 121614, 2021.

[134] Y. Edwards, Y. Tasdemir, and U. Isacsson, "Rheological effects of commercial waxes and polyphosphoric acid in bitumen 160/220-low temperature performance," Fuel, vol. 85, no. 7, pp. 989-997, 2006.

[135] S. D. Capitão, L. G. Picado-Santos, and F. Martinho, "Pavement engineering materials: review on the use of warm-mix asphalt," Construction and Building Materials, vol. 36, pp. 1016-1024, 2012.

[136] L. Chen, Z. Qian, and L. Zhang, "Evaluation of epoxy asphalt concrete damping parameters using impact resonance test," Journal of Testing and Evaluation, vol. 40, no. 5, pp. 853-859, 2012.

[137] E. Santagata, O. Baglieri, D. Dalmazzo, and L. Tsantilis, "Evaluation of the anti-rutting potential of 
polymer-modified binders by means of creep-recovery shear tests," Materials and Structures, vol. 46, no. 10, pp. 1673-1682, 2013.

[138] F. Olard and H. Di Benedetto, "General 2S2P1D model and relation between the linear viscoelastic behaviours of bituminous binders and mixes," Road Materials and Pavement Design, vol. 4, no. 2, pp. 185-224, 2003.

[139] Q. Wu, C. Wang, R. Liang, Y. Liu, J. Cheng, and Y. Kang, "Fractional linear viscoelastic constitutive relations of anhydride-cured thermosetting rubber-like epoxy asphalt binders," Construction and Building Materials, vol. 170, pp. 582-590, 2018.

[140] P. Apostolidis, X. Liu, M. Van De Ven, S. Erkens, and T. Scarpas, "Kinetic viscoelasticity of crosslinking epoxy asphalt," Transportation Research Record: Journal of the Transportation Research Board, vol. 2673, no. 3, pp. 551-560, 2019.

[141] R. Liang, R. Jin, D. Zhou, W. Sun, and Y. Kang, "Nonlinear rheological behaviors of epoxy asphalt binder compared to base asphalt binder and SBS modified asphalt binder at above ambient temperatures," Construction and Building Materials, vol. 250, Article ID 118755, 2020.

[142] T. Niranjana Prabhu and T. Demappa, "Thermal degradation kinetics, mechanical, and flame retardant properties of epoxy-HDPE fabric-clay composite laminates," Journal of Applied Polymer Science, vol. 131, no. 18, 2014.

[143] G. Polacco, J. Stastna, D. Biondi, and L. Zanzotto, "Relation between polymer architecture and nonlinear viscoelastic behavior of modified asphalts," Current Opinion in Colloid \& Interface Science, vol. 11, no. 4, pp. 230-245, 2006.

[144] J. E. Mark, Polymer Data Handbook, Oxford University Press, Oxford, England, 2009.

[145] Y. Chen, S. Dong, H. Wang, R. Gao, and Z. You, "Using surface free energy to evaluate the fracture performance of asphalt binders," Construction and Building Materials, vol. 240, Article ID 118004, 2020.

[146] B. Yao, F. Li, X. Wang, and G. Cheng, "Evaluation of the shear characteristics of steel-asphalt interface by a direct shear test method," International Journal of Adhesion and Adhesives, vol. 68, pp. 70-79, 2016.

[147] J. Chen, C. Yao, H. Wang, W. Huang, X. Ma, and J. Qian, "Interface shear performance between porous polyurethane mixture and asphalt sublayer," Applied Sciences, vol. 8, no. 4, p. 623, 2018.

[148] P. Cong, S. Chen, and J. Yu, "Investigation of the properties of epoxy resin-modified asphalt mixtures for application to orthotropic bridge decks," Journal of Applied Polymer Science, vol. 121, no. 4, pp. 2310-2316, 2011.

[149] W. Huang, W. Guo, and Y. Wei, "Thermal effect on rheological properties of epoxy asphalt mixture and stress prediction for bridge deck paving," Journal of Materials in Civil Engineering, vol. 31, no. 10, Article ID 04019222, 2019.

[150] B. Yao, G. Cheng, X. Wang, C. Cheng, and S. Liu, "Linear viscoelastic behaviour of thermosetting epoxy asphalt concrete-experiments and modeling," Construction and Building Materials, vol. 48, pp. 540-547, 2013.

[151] E. Bocci, A. Graziani, and F. Canestrari, "Mechanical 3D characterization of epoxy asphalt concrete for pavement layers of orthotropic steel decks," Construction and Building Materials, vol. 79, pp. 145-152, 2015.

[152] Z. Zhang, Z. D. Chen, L. H. Guo, X. F. Niu, P. T. Xue, and S. J. Zhang, "The mechanical behavior of epoxy asphalt mixture under cyclic loading," IOP Conference Series:
Materials Science and Engineering, vol. 504, Article ID 012017, 2019.

[153] J. Xu, B. Ma, W. Mao, and X. Wang, "Strength characteristics and prediction of epoxy resin pavement mixture," Construction and Building Materials, vol. 283, Article ID 122682, 2021.

[154] K. Zhong, M. Sun, and X. Tang, "Laboratory evaluation on functional characteristics of open-graded epoxy asphalt mixture," in Proceedings of the IOP Conference Series: Earth and Environmental Science, Tokyo, Japan, September 2018.

[155] D. Zheng, Z.-d. Qian, Y. Liu, and C.-b. Liu, "Prediction and sensitivity analysis of long-term skid resistance of epoxy asphalt mixture based on GA-BP neural network," Construction and Building Materials, vol. 158, pp. 614-623, 2018.

[156] Z. Min, Y. Xia, X. Li, and Z. Tao, "Performances evaluation of epoxy asphalt mixture containing snow-melting agent," Construction and Building Materials, vol. 155, pp. 762-769, 2017.

[157] S. Luo, Z. Qian, X. Yang, and Q. Lu, "Laboratory evaluation of double-layered pavement structures for long-span steel bridge decks," Journal of Materials in Civil Engineering, vol. 30, no. 6, Article ID 04018111, 2018.

[158] M. Zhang, Z. Qian, and Q. Huang, "Test and evaluation for effects of freeze-thaw cycles on fracture performance of epoxy asphalt concrete composite structure," Journal of Testing and Evaluation, vol. 47, no. 1, pp. 556-572, 2018.

[159] Z.-D. Qian, J. Y. Wang, L. L. Chen, and L. B. Wang, “Threedimensional discrete element modeling of crack development in epoxy asphalt concrete," Journal of Testing and Evaluation, vol. 43, no. 2, pp. 1-13, 2015.

[160] H. Bahmani, H. K. Sanij, and F. Peiravian, "Estimating moisture resistance of asphalt mixture containing epoxy resin using surface free energy method and modified Lottman test," International Journal of Pavement Engineering, pp. 1-13, 2021.

[161] S. Luo, Z. Qian, X. Yang, and Q. Lu, "Fatigue behavior of epoxy asphalt concrete and its moisture susceptibility from flexural stiffness and phase angle," Construction and Building Materials, vol. 145, pp. 506-517, 2017.

[162] Y. Zhao, L. Jiang, and L. Zhou, "Improvement of bending fatigue test for asphalt surfacing on orthotropic steel bridge deck," Advances in Civil Engineering Materials, vol. 5, no. 1, pp. 325-336, 2016.

[163] Z.-D. Qian and J. Hu, "Fracture properties of epoxy asphalt mixture based on extended finite element method," Journal of Central South University, vol. 19, no. 11, pp. 3335-3341, 2012.

[164] J. Hu, Z. Qian, and L. Chen, "Fracture behavior of epoxy asphalt pavement on steel bridges based on optical fiber sensing technology and numerical simulation," Journal of Wuhan University of Technology-Materials Science Edition, vol. 29, no. 4, pp. 858-862, 2014.

[165] J. Hu, Z. Qian, Y. Xue, and Y. Yang, "Investigation on fracture performance of lightweight epoxy asphalt concrete based on microstructure characteristics," Journal of Materials in Civil Engineering, vol. 28, no. 9, Article ID 04016084, 2016.

[166] M. R. Islam and R. A. Tarefder, "Study of asphalt aging through beam fatigue test," Transportation Research Record: Journal of the Transportation Research Board, vol. 2505, no. 1, pp. 115-120, 2015.

[167] L. Chen, Z. Qian, and Q. Lu, "Crack initiation and propagation in epoxy asphalt concrete in the three-point bending test," Road Materials and Pavement Design, vol. 15, no. 3, pp. 507-520, 2014. 